PLEASE NOTE:-

IMAGES 1-4 HAVE BEEN REMOVED FROM THIS THESIS FOR COPYRIGHT REASONS. A COMPLETE VERSION IS AVAILABLE IN PRINT FROM THE UNIVERSITY OF BALLARAT LIBRARY. 


\title{
Incidence and Aetiological Factors in the Development of Medial Tibial Stress Syndrome.
}

\author{
DIMITRI DIACOGIORGIS B.POD
}

This thesis is submitted in total fulfillment

of the requirements of the degree of

Master of Applied Science

School of Human Movement and Sports Sciences

University of Ballarat

PO Box 663

University Drive Mount Helen

Ballarat, Victoria, 3353.

Submitted in February 2005 


\section{TABLE OF CONTENTS}

\section{CHAPTER ONE - INTRODUCTION}

1.1 Significance of the study

1.2 Purpose of the study

1.3 Research questions

1.4 Limitations ....

1.5 Thesis structure

CHAPTER TWO - LITERATURE REVIEW

2.1 Diagnosis and Site Specific Anatomy of MTSS

2.1.1 Anterior Compartment.

2.1.2 Posterior Compartment

2.2 Incidence Rates of MTSS

2.3 Risk Factors

2.3.1 Intrinsic Risk Factors

2.3.2 Extrinsic Risk Factors

2.4 Instrument Reliability

2.5 Summary

CHAPTER THREE - METHOD

3.1 Ethics

3.2 Subjects

3.3 Selection Criteria

3.4 Testers

3.5 Testing Procedures

3.5.1 Hip: Flexion/Extension

3.5.2 Hip: Abduction/Adduction

3.5.3 Hip: Medial (Internal) rotation/ Lateral (External) rotation

3.5.4 Knee: Flexion/Extension...

3.5.5 Ankle: Doris / Plantar flexion...

3.5.6 Resting Calcaneal Stance Position (RCSP)

3.5.7 First Metatarsophalangeal Joint (MPJ): Dorsi flexion

3.6 Data Collection

3.6.1 Baseline Data Collection.

3.6.2 Physical Activity Survey....

3.6.3 Retest Data Collection....

3.6.4 Reliability data collection

3.7 Data Analysis

3.7.1 Reliability.

3.7.2 Joint range of motion testing.

3.7.3 Physical activity...

3.7.4 Predictors

\section{CHAPTER FOUR - RESULTS AND DISCUSSION}

4.1 Introduction

4.2 Injury Incidence 
4.3 Test-Retest Reliability

4.4 The occurrence of MTSS and its relationship to variation in lower limb joint ranges of motion

4.5 The side of occurrence of MTSS and its relationship to variation in lower limb joint range of motion

4.6 Gender Comparison ....

4.7 The occurrence of MTSS and its relationship to duration and intensity of physical activity

4.7.1 The relationship between duration of physical activity, injury, and injury side of MTSS.

4.7.2 The relationship between the intensity of physical activity and the onset of MTSS

4.8 Physical activity levels and variables in joint range of motion as predictors of MTSS onset ....

CHAPTER FIVE - SUMMARY AND CONCLUSIONS

5.1 Introduction

5.2 Procedure

5.3 Conclusions

5.4 Recommendations for Further Study

REFERENCES

APPENDICES 


\section{LIST OF FIGURES}

Figure 1. Anterior View of the Lower Leg (Snell, 1995, p.555)

Figure 2. The Postero-Medial View of the Ankle (Snell, 1995, p.560)

Figure 3. Soleus and its Scintigraphic Pattern in the Symptoms of MTSS (Michael \& Holder, 1985, p.91)

Figure 4. Location of the Site of Tenderness of MTSS

(Mubarak et al.,1982, p.202)

Figure 5. Hip Flexion and Extension measurement (Adapted from Norkin \& White, 1995, p.123 (a) \& p.125 (b)).

Figure 6. Hip Abduction and Adduction measurement (Adapted from Norkin \& White, 1995, p.129 (a) \& p.131 (b)).

Figure 7. Hip Internal and External Rotation measurement (Adapted from Norkin \& White, 1995, p. 133 (a) \& p.135 (b)).

Figure 8. Knee Flexion Prone (Adapted from Norkin \& White, 1995, p.145 (a, b)).

Figure 9. Ankle Dorsi flexion and Plantar flexion measurement (Adapted from Norkin \& White, 1995, p.155 (a) \& p.157 (b)).

Figure 10. Resting Calcaneal Stance Position (RCSP) measurement.

Figure 11. First Metatarsophalangeal Joint (MPJ) measurement.

Figure 12. Descriptive Flowchart of the Data Collection Process.

Figure 13. SPSS plot of the interaction between time and gender for left hip external rotation.

Figure 14. SPSS plot of the interaction between time and injury for mean weekly time spent walking

Figure 15. SPSS plot for the interaction between time and injury site in relation to mean weekly time spent walking 


\section{LIST OF TABLES}

Table 1: Mean (X and Standard Deviation (sd) of Subject Age, Height, Weight and BMI

Table 2: Mean and standard deviation (sd) of height, weight and BMI for injured $(\mathrm{N}=14)$ and non-injured $(\mathrm{N}=14)$ subjects.

Table 3: $\quad$ Baseline and retest mean and standard deviations $(\mathrm{N}=8)$ and ICC/ 95\% confidence values to determine level of intra-rater reliability of lower limb joint range of motion.

Table 4: Change in means and standard deviations(sd) for injured $(\mathrm{N}=14)$ and non-injured $(\mathrm{N}=14)$ groups. Significance values for changes in the baseline range of motion testing values at the retest due to time, injury and the interaction of time and injury.

Table 5: $\quad$ Change in means for right sided $(\mathrm{N}=2)$, left sided $(\mathrm{N}=3)$ and bilateral groups $(\mathrm{N}=9)$. Significance values for changes in the baseline range of motion testing values at retest with respect to time, side of injury and the interaction between time and side of injury.

Table 6: Change in means for male $(\mathrm{N}=6)$ and female groups $(\mathrm{N}=22)$ range of motion variables. Repeated measures ANOVA significance values for the range of motion variables due to time, gender and the interaction between time and gender.

Table 7: Repeated measures ANOVA of the influence of left hip external rotation, left and right hip internal rotation, and right ankle plantar flexion on the incidence of MTSS from baseline (bl) to retest (rt) in the female subjects $(\mathrm{N}=22)$

Table 8: Mean weekly time in minutes (mins) spent completing physical activity at baseline (bl) and retest (rt) for injured $(\mathrm{N}=12)$ and non-injured groups $(\mathrm{N}=9)$. Repeated measures ANOVA significance values for physical activity in relation to time, injury and the interaction between time and injury

Table 9: Mean weekly time spent in minutes (mins) completing physical activity at baseline (bl) and retest ( $\mathrm{rt})$ for bilateral $(\mathrm{N}=9)$, left $(\mathrm{N}=2)$, right sided $(\mathrm{N}=1)$ MTSS groups and non-injured $(\mathrm{N}=9)$ group. Repeated Measures 
ANOVA significance for time, injury side and the interaction between time and side of injury

Table 10: Mean weekly time spent completing in minutes (mins) walking (W), vigorous (V), and moderate (M) physical activity in the six months before and during the study for non-injured $(\mathrm{N}=9)$ and injured $(\mathrm{N}=12)$. Repeated measures ANOVA significance values for physical activity intensity in relation to time, injury and the interaction between time and injury.

Table 11: Mean weekly time spent completing in minutes (mins) walking (W), vigorous $(\mathrm{V})$, and moderate $(\mathrm{M})$ physical activity in the six months before and during the study for bilateral $(\mathrm{N}=9)$, right sided $(\mathrm{N}=1)$, left sided $(\mathrm{N}=2)$ injured and non-injured (9). Repeated measures ANOVA significance values for physical activity intensity in relation to time, injury and the interaction between time and injury.

Table 12: Change in mean degrees of knee extension for the non-injured $(\mathrm{N}=14)$ and injured $(\mathrm{N}=14)$ MTSS groups. Significance value for this change and odds ratio for knee extension as a predictor of MTSS 



\section{ABSTRACT}

The aim of this 13 week prospective study was to investigate whether differences in hip, knee, ankle, subtalar, or first metatarsophalangeal joint (MPJ) range of motion and physical activity levels increase a person's likelihood of developing medial tibial stress syndrome (MTSS). Joint range of motion was measured in a cohort of 39 female and 17 male university students, aged 17 to 32 years. A survey was used to document the subjects' weekly intensity and duration of physical activity. Fifty-six subjects presented for baseline testing whilst only 28 returned for retest after 13 weeks.

The incidence of MTSS in this study was $50 \%$ in those who returned for retest. Of the 14 subjects who developed MTSS, symptoms were bilateral in nine subjects, left-sided in three subjects, and right-sided in two subjects.

All range of motion variables tested, apart from right first MPJ Dorsi flexion $(p=0.002)$, were not seen to significantly change over time from baseline to retest.

No range of motion variable was found to significantly influence the onset of MTSS in the 28 subjects retested.

Of the 28 subjects followed from baseline through to retest, 22 were female and six were male. The change in the range of motion measures from baseline to retest in the male and female groups was shown to be significantly different for right hip internal rotation $(p=0.001)$, right ankle plantar flexion $(p=0.001)$, left hip internal rotation $(\mathrm{p}=0.000)$ with an interaction between time and gender for left hip external rotation $(\mathrm{p}=0.000)$. However, right and left hip internal rotation, right ankle plantar flexion and left hip external rotation did not to influence the onset of MTSS in either gender.

Physical activity was not seen to be significant in the onset of MTSS, nor did it influence the location of injury. However, in relation to the effect of intensity of activity on injury, decreases in average weekly time spent walking was significantly 
higher in the injured group, influencing the onset of MTSS $(p=0.029)$ and the side of injury in those who developed MTSS $(p=0.011)$. In the latter results, the change in average weekly time spent walking in the bilateral injured group was significantly different from the other three groups $(p<0.05)$. The bilateral group showed the greatest decrease in average weekly time spent walking. As the numbers in each group were relatively small, the results should be treated with caution.

Through the use of logistic stepwise regression, increased right knee hyperextension $(\mathrm{p}=0.028)$ was shown to be 1.5 times more likely to lead to the onset of MTSS. 


\section{CHAPTER ONE - INTRODUCTION}

Millions of Australians enjoy recreational and competitive activity every year. Literature from the late 1980's and early 1990's referred to the increase in awareness of personal physical fitness and its importance in the maintenance of general health (Taunton, McKenzie \& Clement, 1988; Batt, 1995). The literature surrounding the pursuit of cardiovascular fitness leaves no doubt as to the physical and psychological benefits (Neely, 1998; Taimela, Kujala \& Osterman, 1990). The downside to participation in physical activity is that it can lead to injury.

The cost of injury includes financial and psychological components. However, researchers cannot ignore the monetary burden placed on society due to a high prevalence of lower limb injury caused by physical activities. "The cost of an injury can be high: loss of earnings with sick leave, cost of medical treatment and therapy, not withstanding the penalty of loss of function per se" (Neely, 1998, p.253).

Both adults and children alike may experience sports injury of the lower limbs due to overuse and trauma (Krivickas, 1997). The research in this thesis responds to the ever-increasing incidence of overuse injuries such as shin splints. Shin splints refers to a large number of overuse syndromes of the lower leg believed to be too general and confusing in classification terms (Batt, 1995). Variation in reported incidence rates, imprecise terminology, poor diagnostic techniques and limited understanding of shin splints often serve to complicate its management and therapeutic outcomes.

More recently, the emergence of more specific diagnoses of shin splints such as of Medial Tibial Stress Syndrome (MTSS), chronic compartment syndrome and stress fractures, have been classified in terms of pathophysiology and site of symptoms for the purposes of guiding management. These have replaced the problematic, confusing and generic term of shin splints (Beck, 1998; Detmer, 1986; Touliopoulos \& Hershman, 1999). The research developed for this thesis explores MTSS, which is a condition 
prevalent among individuals participating in competition or recreational physical activity (Bennett.et al., 2001).

There are no reported studies in the literature which examine the relationship between the range of motion of the major joints of the lower extremity and the incidence of MTSS. To date, a relationship between a biomechanical anomaly in the kinetic chain of the lower extremity and MTSS has not been established in the literature. This thesis focuses upon MTSS and whether its incidence is altered by variations in range of motion at the hip, knee, ankle, and first metatarsophalangeal joints and Resting Calcaneal Stance Position (RCSP).

There is evidence in the literature that physical activity levels and sudden increases in activity have been postulated to contribute, if not cause the onset of overuse injuries and in particular MTSS (Jones Cowan et al., 1993; Reynolds, White, Knapik, Witt \& Amoroso, 1999; Touliopoulos et al., 1999). If the results of this study indicate that the level of physical activity, for example sudden increases, predisposes an individual to MTSS then this may be of benefit in educating the public about the appropriate training intensities and durations.

\subsection{Significance of the study}

MTSS is a common cause of exercise related leg pain and overuse injury of the lower limbs in active populations (Kortebein, Kaufman, Basford \& Start, 2000). The most recent definition of MTSS in the literature, by Yates and White (2004) is that is an overuse condition which affects the lower two thirds of the postero-medial shaft of the tibial region. The pathophysiology and therefore the definition of MTSS still remains a contentious issue amongst researchers. This thesis does not provide an updated definition of MTSS.

Through the identification of significant intrinsic and extrinsic risk factors, researchers in recent studies have improved clinicians' knowledge of MTSS. This thesis 
investigates the effect of variations in flexibility (range of motion at joints) as a potential risk factor for the development of MTSS. This research is the first to simultaneously investigate range of motion at the hip, knee, ankle, and first metatarsophalangeal joint (MPJ) and RCSP in relation to MTSS within a single study.

The majority of previous research concerning MTSS incidence and etiology is retrospective (Johnell, Rausing, Wedeberg, \& Westlin, 1982; Sommer \& Vallentyne, 1995). The design of retrospective studies makes it difficult to elicit a relationship between incidence and aetiology over time. The methodology of this thesis was a prospective design. Very few studies have used a prospective design to investigate intrinsic risk predictors for MTSS (Bennett et al., 2001, Yates \& White, 2004). The elicitation of potential intrinsic risk factors in the development of MTSS has wide reaching benefits, for example, clinicians will be able to assess their patients for identified risk factors for MTSS and thus be guided in its preventative management.

The research in this thesis delimits itself to a particular group of subjects, and is not cross-sectional across ages, level of fitness, type and level of activity groups. Such delimitations, in conjunction with the findings presented in this thesis, are intended by the author to contribute to the literature surrounding MTSS and spawn new research ideas which will ultimately lead to more holistic management of MTSS.

\subsection{Purpose of the study}

The purpose of the study is to prospectively determine whether:

1. Variations in joint range of motion in the lower limb increase the incidence of MTSS.

2. The amount and intensity of physical activity influences the onset of MTSS.

3. Joint ranges of motion and the amount and intensity of physical activity enable the prediction of those predisposed to developing MTSS. 


\subsection{Research questions}

The research questions for this study are whether:

1. Differences in hip, knee, ankle, resting calacaneal stance position (RCSP), and first metatarsophalangeal joint (MPJ) range of motion increase the incidence of MTSS?

2. Differences in physical activity levels increase the incidence of MTSS?

3. Differences in hip, knee, ankle, RCSP, and first MPJ range of motion and physical activity can be used as predictors for the development of MTSS?

\subsection{Limitations}

The limitations which exist in this study include:

- Subjects volunteered to partake in the study. There was no way of influencing the level of attendance at each of the testing sessions.

- The type of footwear the subjects wore during the testing period was not controlled for.

- The type of terrain trained upon was not controlled for.

- Bone mineral density and its effect on the incidence of MTSS was not investigated.

\subsection{Thesis structure}

In the next section, the literature review, the background and generation of the classification of MTSS and its various reported incidence rates are explored. Intrinsic and extrinsic risk factors implicated in the literature surrounding the pathophysiology of MTSS are also discussed. 
Recruitment of subjects, inclusion criteria of subjects, testing procedures and statistical analyses utilized are reported in the method section. The findings of the data collection phase of the study and a further description and exploration of the statistical findings are presented in a combined results and discussion section.

The final section includes recommendations for future research directions and the conclusions drawn from the study. 


\section{CHAPTER TWO - LITERATURE REVIEW}

This chapter explores the literature in relation to overuse injury, but more specifically into MTSS. A small number of studies specifically related to the aetiology and associated incidence of MTSS exist in the literature. Section 2.1 of this chapter discusses the link between the anatomy of the lower leg and the site of symptoms of MTSS.

Section 2.2 explores the reported incidence rates of MTSS. A comparison is drawn between the incidence rates of MTSS and stress fractures of the tibia due to a reported similarity in the onset of these conditions in the literature. Risk factors for the incidence of MTSS are discussed in section 2.3. Section 2.3.1 describes how flexibility and malalignment, foot biomechanics, gender, bone susceptibility, fitness and age can impact upon the incidence of MTSS. Similarly, section 2.3.2 describes how extrinsic factors such as training intensity and duration, footwear and terrain can impact upon the incidence of MTSS.

In section 2.4 a rationale for the use of standard goniometric measures for the elicitation of static range of motion testing, through the results of previous studies is provided. The final section 2.5 provides a summation of chapter two.

\subsection{Diagnosis and Site Specific Anatomy of MTSS}

Medial Tibial Stress Syndrome commonly occurs at the postero-medial lower two thirds of the tibia. The anatomy of this area is complex which may make it difficult to differentiate MTSS from other overuse syndromes such as compartment syndrome, or tibial stress fractures. Kortebein et al. (2000) stated that MTSS is just a name for the commonly coined term of shin splints.

Puranen (1974), was perhaps the first to coin the phrase 'medial tibial syndrome' as an explanation for exercise ischaemia in the medial fascial compartment of the leg. This definition more suitably fits with that of compartment syndrome. Classification of 
the various kinds of shin splints overwhelmingly state that MTSS presents as an acute periostitis (Kortebein et al., 2000).

Some studies have reported that MTSS is a cause or symptom, rather than a type of shin splints. In one such early study, Mubarak, Gould, Lee, Schmidt and Hargens (1982) investigated intra-muscular pressures within the posterior compartment of the leg in twelve symptomatic clients presenting with pain localized to an area in the leg. A recent review (Touliopoulis et al., 1999) has identified this study by Mubarak et al. as perhaps the first to describe MTSS as being more commonly caused by periostitis rather than raised intra-compartment pressure in the leg.

Diagnostic studies (Eriksen, Melsen, \& Mosekilde, 1984; Batt, Ugalde, Anderson \& Shelton, 1998; Fredericson, Bergman, Hoffman \& Dillingham, 1995) have been able to identify and provide a visual perspective of the periostitis commonly found in overuse syndromes such as shin splints. Periostitis, referred to as an inflammation of the periosteum or outer layer of bone, evidently could be considered as the cause or symptom of the condition MTSS. Johnell et al. (1982), in a study of 62 patients complaining of medial tibia pain over five years, demonstrated through bone biopsies of the tibia that increased osteoblast and vascular activity resulted in inflammation of the crural fascia. This may have been a direct result of trauma or insult of the soft tissues in close proximity to the tibia. Detmer (1986) added strength to the idea that MTSS is a type rather than a cause of shin splints, classifying the various causes of MTSS:

1. Type I - stress fracture/ bone stress reaction;

2. Type II - periostitis; and

3. Type III - chronic posterior compartment syndrome.

According to Touliopoulis et al. (1999) these three causes can co-exist in the pathophysiology of MTSS. 
The definition of MTSS is neither complete nor accurate without specifying the anatomic location of the tenderness. DeLacerda (1980), defined shin splints as pain localized along and posterior to the medial crest of the tibia bone. Through the citation of the American Medical Association Subcommittee on Classification of Sports Injuries, Touliopolous et al. (1999) stated that the definition of shin splints only includes musculoskeletal inflammation, and not stress fractures nor ischaemic disorders such as compartment syndrome. An understanding of the anatomy of the lower leg is important for the differential diagnosis between shin splints and other closely associated conditions such as stress fractures and compartment syndrome.

In the lower leg there are three compartments, the anterior, posterior and lateral. However, the lateral compartment is not relevant to the diagnosis of shin splints or

MTSS. The tibia and fibula, fascial septa and the interosseous membrane largely form the barriers for these compartments (Snell, 1995).

\subsubsection{Anterior Compartment}

The front of the leg comprises cutaneous nerves such as lateral cutaneous nerve of the calf, the superficial peroneal nerve (both of which are branches of the common peroneal nerve) and the saphenous nerve (a branch of the femoral nerve). Numerous small veins are present around the medial aspect of the leg which drain into the great saphenous vein. Similarly, numerous lymph vessels run parallel to the great saphenous vein upward and medially, to end in the superficial inguinal lymph nodes. The contents of the anterior fascial compartment of the leg has a blood supply provided by the anterior tibial artery and nerve supply from the deep peroneal nerve. Muscles of the anterior fascial compartment include tibialis anterior, extensor digitorum longus, peroneus tertius and extensor hallucis longus which all act to invert and dorsiflex the foot to varying degrees (Figure 1). These muscles have been implicated in the pathogenesis of anterior shin splints and compartment syndrome (Detmer, 1986)

\section{IMAGE REMOVED}


Figure 1. Anterior View of the Lower Leg (Snell, 1995, p.555)

\subsubsection{Posterior Compartment}

The posterior leg, like the front, comprises of superficial cutaneous nerves; the posterior cutaneous nerve of the thigh (which supplies the skin over the back of the knee and upper back of the leg), the lateral cutaneous nerve of the calf (which supplies the posterolateral surface of the leg), the sural nerve (a branch of the tibial nerve supplying the lower posterolateral skin of the leg) and the saphenous nerve (which supplies the posteromedial skin of the leg). The small saphenous vein arises from the dorsal venous arch of the foot and drains into the deeper popliteal vein. Similarly, the lymph vessels end in the superficial inguinal nodes or the popliteal nodes (Snell, 1995).

The posterior fascial compartments of the lower leg are supplied with blood by the posterior tibial artery, and innervated by the tibial nerve. The superficial muscles of the posterior fascial compartment of the leg include gastrocnemius, plantaris and soleus which serve to plantarflex the foot at the ankle joint. The deep muscles of the posterior fascial compartment of the leg include popliteus, flexor hallucis longus, flexor digitorum longus and tibialis posterior which also plantarflex the foot at the ankle joint. Of note is tibialis posterior and the deep flexors; which have been implicated in part as the mechanism of periosteal inflammation (Figure 2). Saxena, O'Brien and Bunce (1990) identified co-constituents such as tibialis posterior and extrinsic long flexor tendons in the pathogenesis and onset of MTSS.

\section{IMAGE REMOVED}

\section{Figure 2. The Postero-Medial View of the Ankle (Snell, 1995, p.560)}

Beck and Osternig (1994) focused upon the soleus muscle, due to its close proximity to the medial shaft of tibia. Through the dissection of fifty legs from cadavers, these authors found that only the soleus, flexor digitorum longus, and deep crural fascia, and not tibialis posterior arose in the vicinity of the area corresponding to where the symptoms of MTSS are commonly diagnosed. This was in direct contradiction with Saxena et al. (1990) who concluded that tibialis posterior did almost always arise in the 
distal third border of the tibia. However, the results of Beck and Osternig (1994) do confirm the findings of Holder and Michael (1984), and Detmer (1986). Holder and Michael (1984) demonstrated increased scintigraphic patterns associated with the area in which the soleus muscle is located (Figure 3). In 1985, Michael and Holder further described the periostitis caused by the soleus muscle as the soleus syndrome. The periostitis caused by the soleus is important in the pathophysiology, and ultimately the diagnosis of MTSS (Figure 3).

\section{IMAGE REMOVED}

\section{Figure 3. Soleus and its Scintigraphic Pattern in the Symptoms of MTSS} (Michael \& Holder, 1985, p.91).

Michael and Holder (1985) dismissed tibialis posterior as a direct cause of MTSS because through their anatomical study, they were able to demonstrate that the origin of tibialis posterior is a considerable distance away from the postero-medial border of the tibia and that the area of pain usually associated with MTSS was lower than the location of the soleus muscle belly. However, they maintain that it may be a contributing factor. The most relevant definition of medial tibial stress syndrome is that by Mubarak et al.(1982), who stated that it presents "as a symptom complex seen in athletes who complain of exercise induced pain along the posteriormedial border of the tibia" (p.209), as demonstrated in Figure 4.

\section{IMAGE REMOVED}

Figure 4. Location of the Site of Tenderness of MTSS (Mubarak et al.,1982, p.202)

\subsection{Incidence Rates of MTSS}

It is well recognised that in the pursuit of greater fitness, there are likely to be many lower limb injuries occurring, hence the significance of MTSS. Studies have 
reported various incidence rates of sports injuries in the lower extremity (Messier \& Pitalla, 1988; Jordaan \& Schwellnus, 1994; Rudzki, 1997; Bennett et al., 2001). However, there are limited reports into incidence rates of MTSS (Montgomery, Nelson, Norton \& Deuster, 1989; Sommer \& Vallentyne, 1995; Bennett et al., 2001; Yates \& White, 2004). When considering overuse injuries most studies discuss the incidence of tibial stress fractures (Beck et al., 2000; Korpelainen, Orava, Karpakka, Siira \& Hulkko, 2001) or trauma-related injury of the lower leg (Hoffman, Chapnik, Shamis, Gavon \& Davidson, 1999; Rudzki, 1997).

Few early studies investigate the link between MTSS and associated stress fractures of the tibia through reports of incidence rates. One study by Montgomery et al. (1989), investigated the types of orthopaedic injuries military recruits developed during basic training. Of the 400 army trainees, 133 (33.4\%) had experienced some shin pain. Eleven $(8.3 \%)$ of the trainees went on to develop a tibial stress fracture. The authors put this down to a previous history of stress fractures.

Relatively high incidence rates for tibial stress fractures and/or trauma-related injury of the lower leg are not uncommon. Jordaan and Schwellnus (1994) observed in a large sample of 1261 military recruits over a nine week basic training program that in an overall incidence of injury of $31.9 \%$, of which tibial bone stress reactions were the most prevalent injury 71\%. Macleod, Houston and Saunders (1999) found an incidence of $8.8 \%$ for shin splints and $68 \%$ for lower limb stress fractures out of 273 referrals from a basic army training group of 4222 recruits. The two studies outlined contrast greatly in reported incidence rates due to differences in the definitions of injury.

Milgrom et al. (1985) reported an unusually high incidence of stress fractures in $31 \%$ of 295 military recruit. In a survey of 1505 runners, Brunet, Cook, Brinker and Dickinson (1990) found that $44.7 \%$ of males and $42 \%$ of females reported tibia and fibula stress fractures. Such findings could hold particular relevance due to the close association between stress fractures of the shaft of tibia which is commonly caused by chronic or long-standing MTSS (Kortebein et al. 2000). What is unclear from the study by Brunet et al. (1990), is the location of the stress fractures on the tibia and fibula, increasing the 
difficulty in establishing an association with MTSS.

Fallon (1996) documented the injuries of 32 runners involved in an ultra marathon race between Sydney and Melbourne. It was found that MTSS was one of the highest reported incidences of specific lower limb injuries at $8 \%$. Whilst medical staff were employed to diagnose the injuries, the criteria used to diagnose MTSS was not specified by the author.

Sommer and Vallentyne (1995) used a retrospective study design to demonstrate that $28 \%$ of 25 folk dancers studied developed MTSS. This study, in comparison to that by Fallon (1996), clearly outlines the criteria used to diagnose MTSS. Such criteria outlined for the diagnosis of MTSS in the study by Sommer and Vallentyne (1995) included:

- pain at the distal half of the medial tibial border,

- no infection, fractures or other inflammatory processes,

- Recent change in activity frequency, duration and intensity (p 801).

Interestingly, there have not been investigations undertaken to explore whether clearly defined criteria for the diagnosis of overuse injuries such as MTSS, increases the reliability of reported incidence rates. Whilst such a gap in the literature is beyond the scope of this study, similar clearly defined criteria for the diagnosis of MTSS will be utilized.

\section{$2.3 \quad$ Risk Factors}

Training error, muscle inflexibility and structural malalignment have all been implicated in the development of overuse syndromes such as MTSS (Jones, Bovee, Harris \& Cowan, 1993; Bennett et al., 2001; Twellar, Verstappen, Husan \& van Mechelen, 1997).

In the pursuit of evidence based knowledge, the research methodologies of previous studies must be examined closely. The cause of overuse injuries such as MTSS remains an issue of wide debate. "Running injuries may be caused by either extrinsic...; 
or intrinsic factors" (Brunet et al., 1990, p.307). Though reasonable to expect, the combination of intrinsic and extrinsic risk factors serve to complicate the isolation of one common cause.

Many studies that have substantiated reliable and valid findings in relation to the cause of overuse injury do not specifically refer to MTSS. In a study by Jones, Cowan et al. (1993), 303 army trainees were followed over their 12 week basic training program to determine incidence, type, and risk factors for training related injury through the use of anthropometric data (height, weight, body mass index (BMI)) and physical fitness tests (2 mile run, sit ups, push ups). Jones, Cowan et al. (1993) concluded that age, smoking, low physical fitness, previous injury, flexibility and type of training were all risk factors in the 112 (37\%) trainees treated for sprains, strains, stress fractures and tendonitis. A breakdown of the diagnoses and site of injury was not documented. Of greatest relevance to this particular review is if intrinsic risk factors increase the incidence of overuse injury and more specifically MTSS.

\subsubsection{Intrinsic Risk Factors}

Previous researchers have used prospective study designs to identify biomechanical risk factors for stress fractures (Bennell et al., 1996; Finestone, Shlamkovitch, Eldad, \& Wosk, 1991), and micro-fractures along the shaft of the tibia; a characteristic of the end-stage of MTSS (Johnell et al., 1982, Kortebein et al., 2000; Bennell et al., 1996). Intrinsic risk factors such as flexibility and malalignment, foot biomechanics (Jones, Cowan et al., 1993), gender susceptibility, bone density, and Body Mass Index (BMI) (Jones, Bovee et al., 1993) are thought to be involved in the pathogenesis of overuse injuries such as stress fractures and will be discussed in relation to MTSS

\section{Flexibility and Malalignment}

Flexibility is a key indicator in the pathogenesis of injury (Jones et al., 1993). Biomechanical limitations and associated inflexibility at joints can predispose to injury. (Cowan et al., 1996). Recently, studies have attempted to investigate subjects with 
moderate activity levels more reflective of the wider community (Bennett et al., 2001;.Twellar, Verstappen, Husan \& van Mechelen, 1997). A study by Jones et al. (1993), identified high and low levels of flexibility linked to injuries such as ankle sprains. This study found that subjects at both extremes of flexibility were two times more likely to experience injury than those who had close to normal levels of flexibility.

Limitations and associated compensations at various joints in the lower limb kinetic chain have been investigated to identify their role in the pathogenesis of MTSS Bennett et al., 2001; Cowan et al., 1996). Abnormal joint range of motion or decreased muscle flexibility can be identified by comparison with an established normal, for range of motion (American Academy of Orthopedic Surgeons, 1965).

Studies that investigate range of motion as a predictor of injury, seldom investigate whether each leg can be considered as functionally independent from each other (Roass \& Andersson,1982). However, one study by Roaas and Andersson (1982), in a randomized sample from the general population reports on normal range of motion in healthy male subjects 30 to 40 years of age using 210 hips (105 subjects), 180 knees (90 subjects), and 192 (96 subjects) ankle joints. Through the measurements of arcs of passive motion at these joints Roass \& Andersson (1982) found that there was no statistical difference between legs with normal range of motion at the hip, knee and ankle. Whilst all their subjects were healthy, Roass and Anderson (1982) stated that clinically, a healthy lower limb may be used for comparison with an affected side in the presence of disease or a lesion. One such study may not be enough to confirm or deny such conclusions.

Anatomic malalignment is often attributed to biomechanical limitations during gait or physical activity. Gunderson et al.(1989), through the investigation of 12 kinematic variables in 30 healthy subjects whilst walking, concluded that there were significant differences between limbs, across subjects for stance time and maximum knee extension. The results of the study by Gunderson et al. (1989), strengthens the idea that the biomechanics of each lower limb is dependent upon the contralateral limb. 
Biomechanical studies have demonstrated a relationship between the hip, knee and ankle joints with simultaneous action of the agonist and antagonistic musculature of these joints. The extent to which this co-activation occurs is dependent on type and velocity of movement. Co-activation of musculature at a given lower limb joint can be compromised due to decreased flexibility. Injury to lower limb joints, could lead to compensation and injury in close proximity to that joint. For example, a lack of ankle joint Dorsi flexion, can lead to increased knee flexion, or excessive subtalar joint pronation.

Such compensations can cause overuse of muscles and consequently conditions such as MTSS.

Limited muscle flexibility and reduced joint range of motion, have been shown to be a significant predictor in the development of overuse injuries (Cowan et al., 1996). Giladi et al. (1987) stated "studies of this relationship between intrinsic anatomic characteristics of trainees and the incidence of stress fractures are limited"(p.133). In the study by Giladi et al. (1987), 295 new male army recruits were studied over a 14 week training period. Subjects with external hip rotation greater than 65 degrees were considered at risk of developing stress fractures of the shaft of tibia. This particular parameter was reported because it was the only factor, as part of a wider physical and orthopaedic examination, which showed a significant correlation with injury. This association between hip external rotation and tibial stress fractures was later confirmed by Milgrom et al. (1994). The authors of both studies were uncertain as to why hip external rotation was associated with the development of tibial stress fractures.

Other studies have implicated abnormal hip motion in the pathogenesis of overuse injury (Krivickas, 1997; Pavol \& Grabiner, 2000). In a prospective study following 392 Israeli military recruits, Finestone et al. (1991) found that shorter tibial length, greater than 65 degrees external rotation of the hip and right leg dominance were significantly correlated with increased incidence of tibial stress fractures.

Flexibility, leg length inequality and malalignment of the knees were not seen to 
be related to shin splints and other injuries such as sprains, dislocations, and fractures in the study by Twellar et al. (1997). The subjects were followed over a period of four years, and the sample population was 136 physical education students. The authors concluded that their findings were not significant.

An earlier study by Roach and Miles (1991) demonstrated that until a mean age of 74, all hip range of motion except hip extension does not reduce, significantly. Therefore, for people under 74 who have reduced hip range of motion, it is more likely due to a lack of flexibility (i.e. hamstring) rather than due to ageing.

Hartig and Henderson (1999), using a sample of 148 military infantry trainees, concluded that increasing hamstring flexibility decreased the incidence of overuse injuries, such as tibial stress fractures, anterior compartment syndrome of the lower leg and shin splints.

"The load on a joint is a function of the alignment of the bones relative to that joint" (Chao, Neluheni, Hsu \& Paley, 1994, p.379). In the case of leg length asymmetry, differing pressure loading and torsion of bones has been implicated in the development of femoral, tibial and metatarsal stress fractures in the longer leg and the development of fibular stress fractures in the shorter leg (Friberg, 1982). Cowan et al. (1996) prospectively looked at the effect of lower limb morphology in male infantry recruits, the number of subjects not disclosed. Limb length difference, genu varum/ valgum, genu recurvatum and increased Q-angle were all seen to be of significance in the pathogenesis of overuse injury such as tibial stress fractures and knee injuries. The relative risk of developing an overuse injury was higher in those who exhibited greater genu valgum of the knees, and a Q-angle of greater than 15 degrees. In their study, foot morphology is postulated as being problematic, however this was not investigated.

\section{$\underline{\text { Foot Biomechanics }}$}

Control of foot biomechanics is hypothesised in the literature to reduce symptoms of MTSS (Michael \& Holder, 1985; Milgrom et al., 1985). However, demonstration of 
the relationship between foot pathomechanics and the pathophysiology of MTSS is limited in the literature (Sommer \& Vallentyne, 1995; Bennett et al, 2001; Yates \& White 2004). Cowan, Jones and Robinson (1993) investigated foot morphology and its effect on exercise-related injury. Their findings were consistent with that of Giladi et al. (1987). Both the studies by Giladi et al. (1987) and Cowan et al. (1993) were quantitative, used healthy male infantry recruits, and prospectively tracked the recruits over a 12 week basic training program finding that the low arched foot did not increase the risk of developing tibial stress fractures.

An earlier study by Messier and Pitalla (1988), examined whether a relationship existed between selected biomechanical, anthropometric and training variables and lower limb injury in 19 control subjects, 17 subjects with shin splints, 15 subjects with plantar fasciitis and 13 subjects with Iliotibial band friction syndrome. The subjects' ankle joint Dorsi flexion and plantar flexion range of motion, hamstring and lower leg flexibility (though not specified as to which muscle groups), Q angle and leg length were measured. Messier and Pitalla (1988) implicated a lack of ankle Dorsi flexion in the shin splint groups. Excessive total rear foot contact phase pronation and maximum velocity of pronation was higher in the injury groups as compared to the control group, thus a likely predictor of overuse injury such as shin splints, illiotibial band syndrome and plantar fasciitis.

Gehlsen and Seger (1980) reported greater angular displacement between the calcaneus and the midline of the lower leg in those with shin splints. However, the authors do not state whether such angular displacement was medial or lateral. The velocity of movement was further demonstrated to affect the extent of this displacement. Plantar flexor muscle strength was higher in those with shin splints. The explanation provided is that the strong calf muscles cause varus malalignment of the tibia with exertion of pressure upon it.

The function of the subtalar joint and its importance to the lower limb and especially foot stability is well established (Close, Inman, Poor and Todd, 1967; Root, Orien \& Weed, 1977). The subtalar joint functions in three planes to produce the movements of pronation and supination. Pronation contributes to the ability to adapt to 
different terrain, whilst supination serves to promote the propulsive phase of gait by making the foot a rigid lever (Michaud, 1995).

An early study by Delacereda (1980) described a positive relationship between navicular tuberosity position and the incidence of shin splints. The authors stressed the idea that navicular position is not related to weak or fallen arches, rather of subtalar position. When the foot is in an abducted position, the subtalar joint plantar flexes and everts. In this position it appears that structures like the navicular tuberosity appear to collapse, however, the subtalar joint is merely pronated.

In a case study interview of a twenty year old male runner, Cibulka, Sinacore and Mueller (1994) pondered the possibility of a relationship between forefoot contact running and posteromedial tenderness of the tibia. In this case, a lack of subtalar joint pronation at contact phase was implicated given its functional importance in sensory attenuation of ground reaction forces. This case report demonstrated that when the subject with shin splints adopted a more functional heel to toe running pattern, his posterior medial tibial pain ceased. Decreased subtalar joint pronation can lead to injury due to a lack of antagonistic muscle balance at the ankle joint. A lack of balance for these muscles could lead to the pathogenesis of overuse injury and MTSS.

In a retrospective study, Sommer and Vallentyne (1995) in a sample of 25 folk dancers found that subjects with rear foot or forefoot varus were more likely to develop MTSS. The researchers believe compensatory subtalar joint eversion, and forced pronation of the midtarsal joint to be the causative aetiology. Rearfoot movement and velocity of contact phase pronation was seen to be higher in these injury groups, one of which included shin splints. The authors identified the need for further studies to evaluate the ankle Dorsi flexion and foot pronation ranges due to the low sample size in their study. Hyper-pronation places an additional strain on the antagonistic musculature (i.e. the medial half of soleus) and may precipitate MTSS.

Kaufman et al. (1999) confirmed the generalisability of Sommer et al. (1995) and 
Cowan et al (1993) findings by stating that "risk factors that predispose people to lower extremity overuse injuries include dynamic pes planus, pes cavus, restricted ankle Dorsi flexion, and increased hind foot inversion" (p.585). Yates and White (2004), investigated 124 naval recruits and prospectively followed these subjects during their basic training. With the use of the foot posture index (Redmond, 2001), a more pronated foot type $(p=0.002)$ was demonstrated to increase the incidence of MTSS.

Bennett et al. (2001), used a predicitive correlational model to measure tibial varum, resting calcaneal position and gastrocnemius length in 125 high school cross country runners. The navicular drop test was also performed, which is a clinical means of measuring the amount of pronation occurring at the subtalar joint. In the 15 (13 women, 2 men) subjects who developed MTSS over the eight week duration of the study, the mean of their navicular drop test was 6.8 millimetres as compared to $3.6 \mathrm{~mm}$ in the non-injured group. Navicular drop was only measured once subjects developed MTSS. It is uncertain whether the high levels of navicular drop developed over the course of the eight weeks of the study, or existed prior to the study. However, through the use of logistic regression statistical analysis, navicular drop had a significance of 0.01 , and along with gender variables was able to predict those who developed MTSS with 76\% accuracy.

This study provides some evidence of a link between navicular drop, or pronation and the development of MTSS in runners.

First metatarsophalangeal joint (MPJ) range of motion has been reported to be important in the establishment of the windlass mechanism in the foot (Payne \& Dananberg, 1997). The windlass mechanism is made up primarily of the calcaneus, plantar aponeurosis and first MPJ. Its function is to aid the transfer of body weight during heel to toe gait. This ultimately allows the body's centre of gravity to pivot over the foot during the propulsive phase of gait. Structural deformities such as hallux-abducto valgus, hallux limitus or hallux rigidus can lead to a pathological decrease in MPJ Dorsi flexion. Passive Dorsi flexion less than 65 degrees and active Dorsi flexion less than 35 degrees can result in a decrease in ankle Dorsi flexion, increased knee flexion and a lumbar 
kyphosis to compensate for such a limitation. Such compensations can lead to overuse of the medial musculature of the lower leg and hence predispose to MTSS (Root, Orien \& Weed, 1977).

\section{Gender, Bone Susceptibility, Fitness, and Age}

Gender and bone susceptibility factors have also been investigated primarily in relation to stress fractures with some researchers finding that females have a higher risk of this form of overuse exercise-related injury (Jones, Bovee et al., 1993; Macleod et al. 1999). "Individuals with low Bone Mineral Density (BMD) are susceptible to fractures by virtue of a reduced bone mass upon which loads can be distributed“ (Beck, 1998, p.273). Definitive links have been found between amenorrhea in women and the incidence of overuse injury and more specifically stress fracture of the shaft of tibia (Beck, 1998; Magnusson et al., 2001).

Whilst bone is a strong and rigid tissue, in normal weight bearing circumstances, loading of the long bones of the lower limb causes curving and hence strain to occur either by torsion, compression, shear or tension (Chao et al., 1994). The tibia is widely recognised as the most prevalent site for stress fractures (Milgrom, 1989; Beck, 1998). "If the width of the tibia is increased in size by $5 \mathrm{~mm}$ from $22 \mathrm{~mm}$ to $27 \mathrm{~mm}$, the bone's strength in compression increases by $51 \%$ and in bending and torsion by $126 \%$ " (Milgrom, 1989, p19). Therefore, the wider the tibia the greater it is in resisting stress fracture from bending, compression and tensile forces. Milgrom et al. (1989) stated that depending on the type and intensity of training, repetitive compression, tension, torsion and bending of the tibia will vary, and thus the type of tibial stress injury.

Milgrom et al. (1985) found that $31 \%$ of 295 Israeli military recruits sustained a stress fracture in the lower limb. Eighty percent of the stress fractures were in the tibia. The tibia is a common site for friction-related stress fractures, an end stage of MTSS.

More recently investigators have confirmed the findings of Milgrom et al. (1985). Korpelainen et al. (2001) found that lower limb bone density is a significant predictor of tibial stress fractures. Magnusson et al. (2001) found a significant difference in bone 
mineral density of those with MTSS. Bone mineral density was $15 \%$ less in people with MTSS than in non-athletic controls and 23\% less than athletic controls. Whilst bone mineral density was not investigated in this thesis, it could be responsible for the onset of tibial stress fractures and MTSS.

Magnusson et al. (2001) investigated eighteen male subjects with MTSS who participated in competitive level weight bearing sports. Thirteen athletes had MTSS bilaterally and five had symptoms unilaterally. The 18 subjects with MTSS were compared with 16 age and sex-matched volunteer hospital staff who were completing at least a mean of two hours exercise a week, and also a further 18 age and sex-matched competitive athletes without MTSS but a similar training regime. Those who had unilateral symptoms of MTSS, had significantly lower bone mineral density on the unaffected side relative to the same region in both groups of control subjects. This demonstrates that the symptoms of MTSS are not isolated to one side, rather it affects each person differently.

Symptomatic individuals were found by Magnusson et al. (2001) to have no significant difference in bone mineral density between affected and unaffected leg. The authors were uncertain whether the lower bone mineral density in the affected area was attributable to MTSS, however they concluded that decreased bone mineral density may predispose the individual to MTSS. Future studies investigating the scintigraphic pattern of those who have symptomatic MTSS may need to look at a prospective design which includes taking baseline measurements of regional bone mineral density prior to the commencement of a training program or sporting season so that these may be compared at time of injury. Bone mineral Density was not investigated in this study.

Investigators have implicated physical fitness as a possible risk factor in overuse injury. Jones, Bovee et al. (1993) found that people with low fitness levels, as tested by aerobic tests in 391 army trainees, was a risk factor for overuse injury. However, a more recent study by Hoffman et al. (1999) found no statistical correlation between poor aerobic fitness and stress fracturing in their prospective study into 136 male military recruits. Instead, the researchers' explanation for overuse injury was decreased strength 
associated with a lack of resistance training and thus decreased bone mineral density.

Hoffman et al. (1999) investigated the relationship between leg strength and lower limb injury. The authors measured leg strength using a one repetition maximum leg press in 136 military recruits and concluded that the lower the leg strength, the higher the chance of lower limb overuse injury. More recently, low physical fitness and thigh muscle size are suggested to be significant factors in the development of lower limb overuse injury (Beck et al., 2000).

Age has been implicated as a factor in the development of overuse injuries like MTSS. Bone derives its strength "from mass, density, three dimensional arrangement and the quality of the component material" (Heaney, as cited in Milgrom et al., 1994, p.20). The factors that contribute to a lack of bone mineral density have been explored previously. Age can have a direct effect on the 'architecture' of the bone structure (Milgrom et al., 1994).

Bone density is a poor predictor of stress fracture or overuse injury in the elderly, because it is bone porosity not bone density which is directly related to bone fragility (Milgrom et al., 1994). Milgrom et al. investigated youth as a factor using a sample of 783 military personnel. As age increased, the incidence of stress fractures decreased. However, the age of subjects studied ranged from 17 to 26 . Being a military study, the range of age of the subjects is not typical of the general population, therefore the results of Milgrom et al. must be treated with caution. Age has also been implicated as having an effect of range on motion of joints (Boone \& Azen, 1979). The study of 109 healthy males by Boone and Azen (1979) was among one of the first to attempt to establish what the effect of age is on normal range of motion of joints using a sample size of 109 young healthy male subjects. In this research The American Academy of Orthopedic Surgeons' "Joint motion: Method of Measuring and Recording" (1965) is used as a reference for what would be considered an acceptable range of motion at specific joints with the lower extremity. 


\subsubsection{Extrinsic Risk Factors}

Extrinsic variables such as footwear, hard and uneven terrain, and the type and volume of activity have been related to the pathogenesis of MTSS or stress fracture (Taimela, Kujala, \& Ostermen, 1990). Similarly, extrinsic variables may act in conjunction with, or independent of, intrinsic variables such as anatomical malalignment and associated decreased flexibility in joints of the lower limb (Messier \& Pitalla, 1988; Jordaan \& Schwellnus, 1994).

\section{$\underline{\text { Measuring Fitness }}$}

According to Bauman, Owen and Leslie (2000), the measurement of the level of physical activity, whilst complex, is essential in the promotion of community sports or recreational pastimes. The majority of measurements of physical activity centre around the use of questionnaires or interviews (telephone/web based or face-to-face). Whatever the style, investigations into conditions such as MTSS must be able to demonstrate an association between level of activity and injury, if it exists. Considerations of costeffectiveness with respect to the sample size, representativeness, rate of response and confidentiality are important in the type of survey utilized (Frey, 1983).

The Australian Institute for Health and Welfare (AIHW) sets Australian national standards for measurement of physical activity. A questionnaire applicable to the Australian population was developed by Bauman and colleagues (2000), and validated by Bull (2000). This instrument assesses the individual's intensity of activity performed during one week. It includes recreational types of activity such as walking, swimming, golf, and household chores which cause an individual to puff and pant, and vigorous activity such as competitive sports. Examples of the instrument's usage can be seen in the National Physical Activity Surveys of 1997 (ASC, 1998), 1999 (Armstrong, Bauman \& Davies, 2000) and 2000 (Bauman, Wright \& Brown, 2000). All three surveys measure adult men and women of ages 18-75 with sample sizes of 6803, 3841 and 3590 respectively. In each successive survey, there was no demonstrated increase in sufficient levels of activity from previous surveys. A sufficient level of activity is defined by the 
Department of Health and Ageing (DHA, 1999) as 30 minutes or more of moderate level of activity daily, or vigorous activity three to four times per week. The proportion of the Australian population which met sufficient levels of activity was $62.2 \%$ in 1997 , and $56.6 \%$ in the 1999 and 2000 surveys.

The surveys depict a sedentary lifestyle in a large proportion of the Australian population over the last seven years. In consideration of this, anecdotal evidence from Neely (1998) and Touliopoulis et al. (1999) suggests that those previously inactive individuals suddenly commencing a high level of activity, are more likely to sustain an overuse injury such as MTSS.

\section{$\underline{\text { Training Levels }}$}

"An abrupt increase in the level of physical activity during the early weeks of a conditioning program represents the classical conditions that typify injury" (Montgomery et al., 1989, p.237). Often a change in training will increase the amount of bone stress and hence tibial pathology, especially if it is a sudden rather than a gradual transition. A contributing factor often implicated is low level of fitness prior to the change in activity level (Jones, Cowan et al. 1993; Beck, 1998). Many of the studies which investigated injury levels in military recruits involved testing prior to the initiation of a basic training program and then a retest of the same parameters immediately at its conclusion. It is highly likely that many of the subjects in these studies are experiencing a significant change in their respective training levels and are predisposing themselves to injury.

Orava, Puranen and Ala-Ketola (1978), studied 68 medium-long distance runners, 12 skiers, 10 sprinters and 9 orienteers who were tracked over an eight year period to determine the relationship between intensity and duration of training and the appearance of stress fractures. One hundred and forty two stress fractures in total were diagnosed in this sample population, 76 of these occurred in the tibia, most of which were present in the distal third of the leg. The authors found that a change in activity from low to high intensity, as opposed to constant high intensity training, predisposed athletes to injuries. 
Messier and Pitalla (1988), through their comparison of athletes with plantar fasciitis, shin splints, or illiotibial band syndrome and a control group comprising athletes with no injury, found that those with no injury had been training at a moderate intensity for the most years . Conversely those with shin splints had been running the least amount of years compared with the other groups but at a higher intensity.

In a study by Jordaan and Schwellnus (1994), a large sample of 1261 military recruits was observed over a nine week basic training program which involved predominately marching in weeks one to five and nine, and a greater emphasis on field training in weeks six to eight. Less injuries were observed during weeks six to eight. It also is interesting to note that in weeks one to five and nine, the highest number of injuries and lost training hours were observed. That is, "marching ... is associated with a high risk of injury, and that field training was associated with a low risk of injury" (Jordaan \& Schwellnus, 1994, p.425). Ross (1993) reported that overuse injuries of the lower extremities are common in the military and have been associated with the rigors of marching, drilling and running. Studies such as that by Ross (1993) have implicated overuse injury in $10-20 \%$ of male Army recruits. Over a period of eight weeks, Ross (1993) observed six army training companies in their basic military exercises. Of the 1357 male Army recruits, 236 (17\%) suffered overuse injury, though these were predominately stress fractures, the location was not specified. The companies were divided into intervention and non-intervention companies, with the intervention company enjoying a one week rest from running early in the basic training. The authors, were aiming to elicit evidence that rest from activity can be used as a protective measure against overuse injury. However no such evidence was found. This was attributed to a difference in physical training between companies and physiological factors other than rest.

\section{$\underline{\text { Footwear and Terrain }}$}

Beck (1998) and Neely (1998) have suggested that inappropriate footwear relative 
to the type and duration of activity, may increase the risk of injury. Beck (1998) discussed the findings of past research and concluded that appropriate footwear will decrease overuse injury such as MTSS. This is thought to be due to a reduction of tibial deformation during midstance as the foot is neutral progressing from pronation to the supination phase of gait (Beck, 1998).

Many of the studies into overuse injuries involve military recruits, all of whom wear military boots during their military duties. These military boots have been implicated as a risk factor for stress fractures, due to their lack of built-in shock absorbancy (Milgrom et al., 1985). With recent innovations in orthotic interventions, many of the harsh terrain and inappropriate footwear risk factors have been decreased. However, the extent to which abnormal motion and associated compensations within the lower limb and foot occur is dependent on the type of terrain.

Terrain type has been implicated in the pathogenesis of overuse injury (Milgrom et al., 1988). Tax (1985) stated that if people walked, jogged or ran on grass without footwear, the likelihood of lower limb and foot biomechanical anomalies would be greatly diminished. Irregular surfaces like sand and sloping pavement have been identified as non-preferred running surfaces (Beck, 1998). Similarly, soft surfaces (such as mud and sand) have been seen to cause triceps surae strain, periosteal traction and abnormal tibial bending (Beck, 1998).

In a study of 12 subjects, Richie, DeVries and Endo (1993) investigated the effect of three surfaces (hardwood, carpet and concrete) on the medial musculature of the leg. This study found that uncompromising surfaces increase the incidence of medial tibial stress syndrome through associated increases in eccentric muscle activity. The harder the surface the greater the ground reaction force opposing foot motion, thus the greater the compensation and potential for injury.

\subsection{Instrument Reliability}

This section explores the rationale for the use of the goniometer in lower limb 
range of motion studies.A limited number of studies have been completed to establish the reliability of lower limb static range of motion measures relevant to the aetiology of MTSS. The goniometer is the most widely used tool to measure range of motion studies due to its cost effectiveness and relative precision (Baggett \& Young, 1993; Eliasziw, Young, Woodbury \& Fryday-Field, 1994, Giladi et al., 1987; Kaufman et al., 1999; Sommer et al., 1995).

Various forms of the goniometer have been investigated in the past, and used in the measurement of lower extremity range of motion. A study by Rome and Cowleson (1996) evaluated the reliability of three different goniometers (universal goniometer, fluid goniometer and electrogoniometer) in relation to ankle joint Dorsi flexion. Although this study had a low sample size of eight subjects, intra-tester reliability was demonstrated for all except the universal goniometer, whilst inter-tester reliability was not evident in any of the three instruments. The authors identified a lack of standard protocols for the use of these instruments in the measurement of ankle joint range of motion, though do suggest that if the subject is supine sitting with the knee flexed 90 degrees, then the tension of gastrocnemius may be reduced and the amount of ankle joint range of motion optimized.

The two-arm goniometer is documented in the literature as the most frequently used instrument in relation to range of motion testing and overuse injury such as MTSS. In an early study of 109 subjects, Boone and Azen (1979) investigated the normal range of motion of joints. The testing procedures adhered to the techniques specified in the manual of the American Academy of Orthopaedic Surgeons (1965) for the measurement of active motion at the hips, knees, ankles and feet. A two-arm goniometer was used to conduct the measurements. Intra-observer variance between occasions of measurement was low for both left and right sides, indicating an adequate level of reliability in the testing procedure.

Through the evolution of range of motion testing, many different instruments have been developed. A study by Ekstrand, Wiktorsson, Oberg and Gillquist (1982) 
involved 22 subjects and used recommended testing procedures as outlined by the American Academy of Orthopaedic Surgeons (1965) to test hip abduction, knee flexion and ankle Dorsi flexion with the leg flexed or extended. This study demonstrated statistically significant intra-tester reliability using the two-arm goniometer with minimal variation in the mean on the left and right lower limbs.

Few studies exist which solely evaluate the reliability of instruments, individually or in comparison to other instruments, in the measurement of lower limb range of motion. Bierma-Zeinstra et al. (1998) compared the reliability of the inclinometer and a two-arm goniometer for hip range of motion. All hip range of motion measures were completed as recommended by the American Academy of Orthopedic Surgeons (1965).

With a rather low sample size of nine, inter-observer variability for the inclinometer was higher than or equal to the goniometer for most positions except passive hip rotations. Bierma-Zeinstra et al. (1998) acknowledged that horizontal measures (that is, the patient lying supine for hip rotation abduction/adduction measures) are not possible with the inclinometer as it is driven by gravity. A further disadvantage of the inclinometer was during the retest section of their study due to the constant need for recalibration between tests of the inclinometer against a known surface. This was a time consuming means of measurement. The two-arm goniometer is accepted as the more widely used and reliable instrument.

Precision alignment of the goniometer can be difficult when trying to passively move a joint. Many studies investigating interrater and intrarater reliability determine that results of range of motion testing by the same tester are more consistent than those between therapists (Hopkins, 2000). The reliability of goniometric measurements between testers has been shown to be low in ankle and subtalar joint measures (Elveru, Rothstein \& Lamb, 1988). In a study with 42 patients, Elveru et al. (1988) investigated intertester and intratester reliability of passive ankle and subtalar joint range of motion. Reliability was shown to be compromised. However, if the same tester completed both occasions of testing within a small amount of time (that is, a few minutes), then intraobserver reliability was "fair" In a study of 138 subjects, Cook, Gorman and Morris 
(1988), looked at three techniques for the measurement of the Neutral Calcaneal Stance Position (NCSP). This study demonstrated equal interrater reliability for all three techniques, however the authors stated that clinical error was determined to be outside a 2 degree difference between testers. Resting Calcaneal Stance Position (RCSP) has been demonstrated to have greater inter and intratester reliability for measurement (Freeman, 1990). Further RCSP has been shown to be the position showing the greatest reliability for evaluation of tibial varum. Menz (1995) in a review of the literature on goniometric evaluation of the hind foot (i.e. NCSP and RCSP) stated that "the only remaining option is to concentrate on improving the reliability of techniques currently employed" ( $p$ 63). However, Menz and Keenan (1997) investigated RCSP in ten healthy subjects in their reliability study. Menz and Keenan (1997) compared gravity angle finder and a digital goniometer (manufactured by the author) to measure RCSP and NCSP. They found that intra- and inter-tester reliability was poor.

Today, standard goniometers are regarded as the most cost effective and efficient tool for static range of motion testing. Clapper and Wolf (1988) looked at the reliability of the Orthoranger pendulum and compared this to a standard goniometer. In this study of 20 subjects (10 men, 10 women), hip flexion, extension, abduction, adduction, and internal/external rotation, knee flexion and extension, and ankle plantar flexion and Dorsi flexion were assessed. The standard goniometer in all measurements except hip external rotation was found to be consistently more reliable (accurate to within 5 degrees) than the Orthoranger pendulum.

"The measuring techniques and the instruments usually are crude, and their imprecision is compounded when the measurements of one tester are studied together" (Boone \& Azen, 1979, p 158). Such a statement is still valid as investigators still use goniometers whilst keeping limitations of this tool in mind. In relation to this part and in relation to this thesis on MTSS, two major points arise from the literature range of motion testing and subsequent instrument reliability:

- The use of the two-arm goniometer in range of motion testing from early studies such as those of Boone and Azen (1979) or Ekstrand et al. (1982) 
compared to more recent studies such as Bierma-Zeinstra et al. (1998) warrants its usage in this thesis due to the level of intratester reliability demonstrated.

- The studies by Rome and Cowleson (1996) and Bierma Zeinstra (1998) indicate that if one tester in a test-retest structured range of motion procedure completes the same measurements on all occasions of testing, variance within results of the same parameter will be minimized compared to using multiple testers. That is, intra-observer reliability in most cases is higher than intertester reliability (ie one tester is preferable).

\subsection{Summary}

This literature review has explored previous findings in the area of overuse injury and MTSS. The information that can be obtained using a prospective study design for the investigation of MTSS and its associated risk factors provides the rationale for the objectives of this thesis. The primary objective is to determine whether range of motion of hip, knee, ankle, first MPJ and the RCSP is significantly associated with the incidence of MTSS. The findings of previous studies have been explored.

Intrinsic factors for MTSS such as age, gender, bone mineral density, level of physical activity and fitness levels have been explored. There have been some links made between these and overuse injury, though in most cases not specifically to MTSS. This thesis also aims to explore whether level of physical activity, gender, age, height, weight, and BMI are related to the incidence of MTSS. Extrinsic factors such as terrain trained upon, footwear utilized and changes in type of physical activity are also recognized as a factor in the pathogenesis of overuse injury. However these extrinsic factors are extraneous variables not controlled for in this study.

Whether range of motion, physical activity levels, age, gender, height, weight and BMI are predictors for the incidence of MTSS remains uncertain in the literature, and will be investigated in this study. This thesis will prospectively evaluate whether range of motion of the hip, knee, ankle and first MPJ and RCSP and level of physical activity are 
significant predictors of MTSS.

Studies cited in this literature review investigate inter-rater and intra-rater reliability in relation to lower limb joint range of motion testing. The majority of these studies utilize The Academy of Orthopedic Surgeons (1965) as a reference for normal lower limb joint range of motion. The standard two-arm goniometer seems the widest used instrument for static joint range of motion testing. Due to its cost effectiveness, and studies such as Elveru et al. (1988) demonstrating reliability with the use of the goniometer, this study utilizes it in range of motion testing documented in Chapter 3. 


\section{CHAPTER THREE - METHOD}

\subsection{Ethics}

The methodology outlined in this section was approved by the University of Ballarat Human Research Ethics Committee.

\subsection{Subjects}

The subjects were first year students from the School of Human Movement and Sport Sciences at the University of Ballarat who volunteered for the study. A total of 56 subjects volunteered comprising 17 males and 39 females. Table 1 outlines the means and standard deviations of subjects' ages, height, weight, and Body Mass Index (BMI).

Table 1:

Mean (X and Standard Deviation (sd) of Subject Age, Height, Weight and BMI.

\begin{tabular}{|c|c|c|c|c|c|c|c|c|}
\hline & \multicolumn{2}{|c|}{ Age } & \multicolumn{2}{|c|}{ Height (m) } & \multicolumn{2}{|c|}{ Weight (kg) } & \multicolumn{2}{|c|}{$B M I$} \\
\hline & $\mathrm{X}$ & $\mathrm{sd}$ & $\mathrm{X}$ & $\mathrm{Sd}$ & $\mathrm{X}$ & $\mathrm{sd}$ & $\mathrm{X}$ & $\mathrm{sd}$ \\
\hline $\begin{array}{l}\text { Total } \\
\text { group } \\
(n=56)\end{array}$ & 18.96 & 2.57 & 1.70 & 0.10 & 70.41 & 13.17 & 24.35 & 3.11 \\
\hline $\begin{array}{l}\text { Males } \\
(n=17)\end{array}$ & 20.41 & 3.59 & 1.79 & 0.07 & 82.53 & 12.44 & 25.67 & 3.77 \\
\hline $\begin{array}{l}\text { Females } \\
(n=39)\end{array}$ & 18.33 & 1.68 & 1.65 & 0.08 & 65.13 & 9.58 & 23.77 & 2.62 \\
\hline
\end{tabular}

\subsection{Selection Criteria}

Subjects were required to:

- have given written informed consent to participate in the study; - be students in the School of Human Movement and Sport Sciences who were enrolled in the Fundamentals of Fitness unit in semester one at the University of Ballarat. This is so the subjects could be followed over the course of this unit which consisted of a physical training component. 
Subjects were withdrawn from the study in the event of any of the following:

- Withdrawal of consent;

- Development of systemic conditions unforeseen to render the subject unable to complete the requirements of the Fundamentals of Fitness unit.

\subsection{Testers}

There were five testers and three assistants during the course of the data collection:

- One tester marked the required anatomical features on all subjects prior to them being tested on each occasion.

- A clinical exercise physiologist within the School of Human Movement and Sport Sciences completed part of the hip range of motion testing. This tester had two assistants, to help position each subject's lower limb appropriately for testing. This tester completed all the hip measurements for subjects 1 to 30 , and 54 to 56 . One of the assistants completed all the hip measurements for subjects 31 to 53 . All the subjects were tested by the same tester on each occasion.

- An additional lecturer from the School of Human Movement and Sport Sciences at the University of Ballarat completed all the knee and ankle range of motion testing.

This tester had one assistant, to help position each subject's lower limbs appropriately for testing. All subjects were tested by the same tester on each occasion.

- A podiatrist completed all the Resting Calcaneal Stance Position (RCSP) and first metatarsophalangeal joint (MPJ) range of motion measurements on all testing occasions. All bisections were re-marked for each testing session. 


\subsection{Testing Procedures}

This section details the testing procedures undertaken by the testers during the data collection period. All measurements were taken twice during the baseline, repeat and reliability measure stages of the data collection. All measurement scores were recorded to the nearest degree. If there was a difference of more than five degrees between two separate measures, another test was completed, and then the average was used. All tests measured passive joint range of motion.

\subsubsection{Hip: Flexion/Extension}

\section{Landmarks}

The anatomical landmarks were the greater trochanter, lateral midline of the pelvis, lateral midline of the femur and lateral epicondyle of the femur.

\section{Testing Position: Hip flexion}

For hip flexion, the subject testing position was supine with the hip in zero degrees of adduction, abduction and rotation, whilst the pelvis was stabilized. The knee was extended initially, then was allowed to flex as the hip flexed (Figures 5 a).

\section{Testing Position: Hip Extension}

For hip extension, the subject testing position was prone with the hip in zero degrees of adduction, abduction and rotation whilst the pelvis was stabilized. The hip was then extended (Figures $5 \mathrm{~b}$ ).

\section{$\underline{\text { Goniometer Alignment }}$}

The fulcrum of the goniometer was placed over the lateral hip with the greater trochanter used as a reference. The proximal arm was aligned over the lateral midline of pelvis, and the distal arm over the lateral midline of femur. 


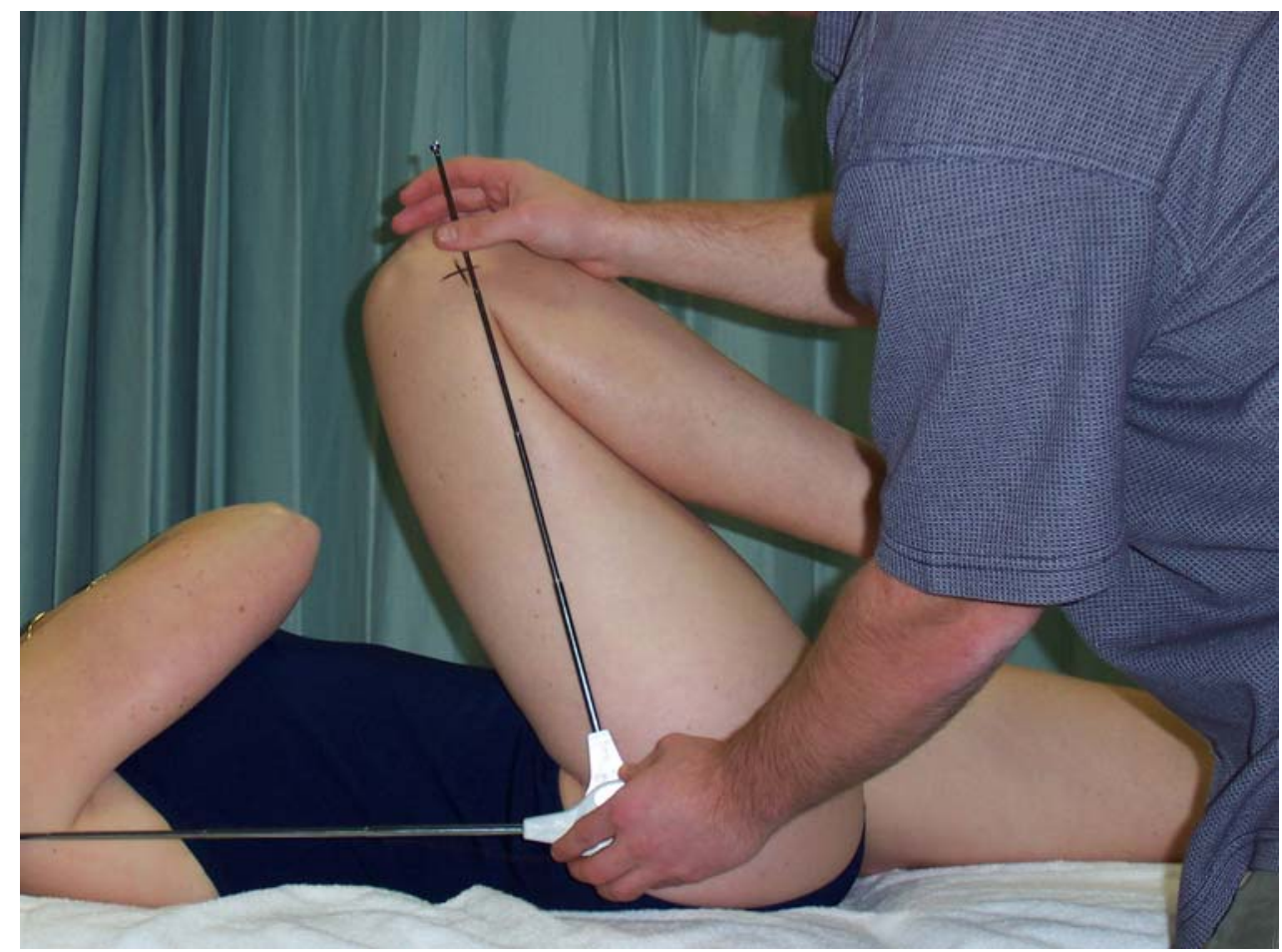

(a) FLEXION



(b) EXTENSION

Figure 5. Hip Flexion and Extension measurement (Adapted from Norkin \& White, 1995, p.123 (a) \& p.125 (b)). 


\subsubsection{Hip: Abduction/Adduction}

$\underline{\text { Landmarks }}$

The landmarks were the anterior superior iliac spine (ASIS), anterior midline of the femur and patella.

\section{$\underline{\text { Testing Position }}$}

For both hip abduction and adduction, the subject testing position was supine. With the knee extended, the hip was stabilized and in zero degrees of flexion, extension and rotation. The hip was abducted. However, in testing hip adduction the contralateral hip was slightly abducted to allow full hip adduction.

\section{Goniometer Alignment}

The fulcrum of the goniometer was placed over the ASIS on the testing side. The proximal arm was aligned between both ASIS and the distal arm with the anterior midline of femur using the patella as a reference (Figures $6 \mathrm{a}$ and $\mathrm{b}$ ) 


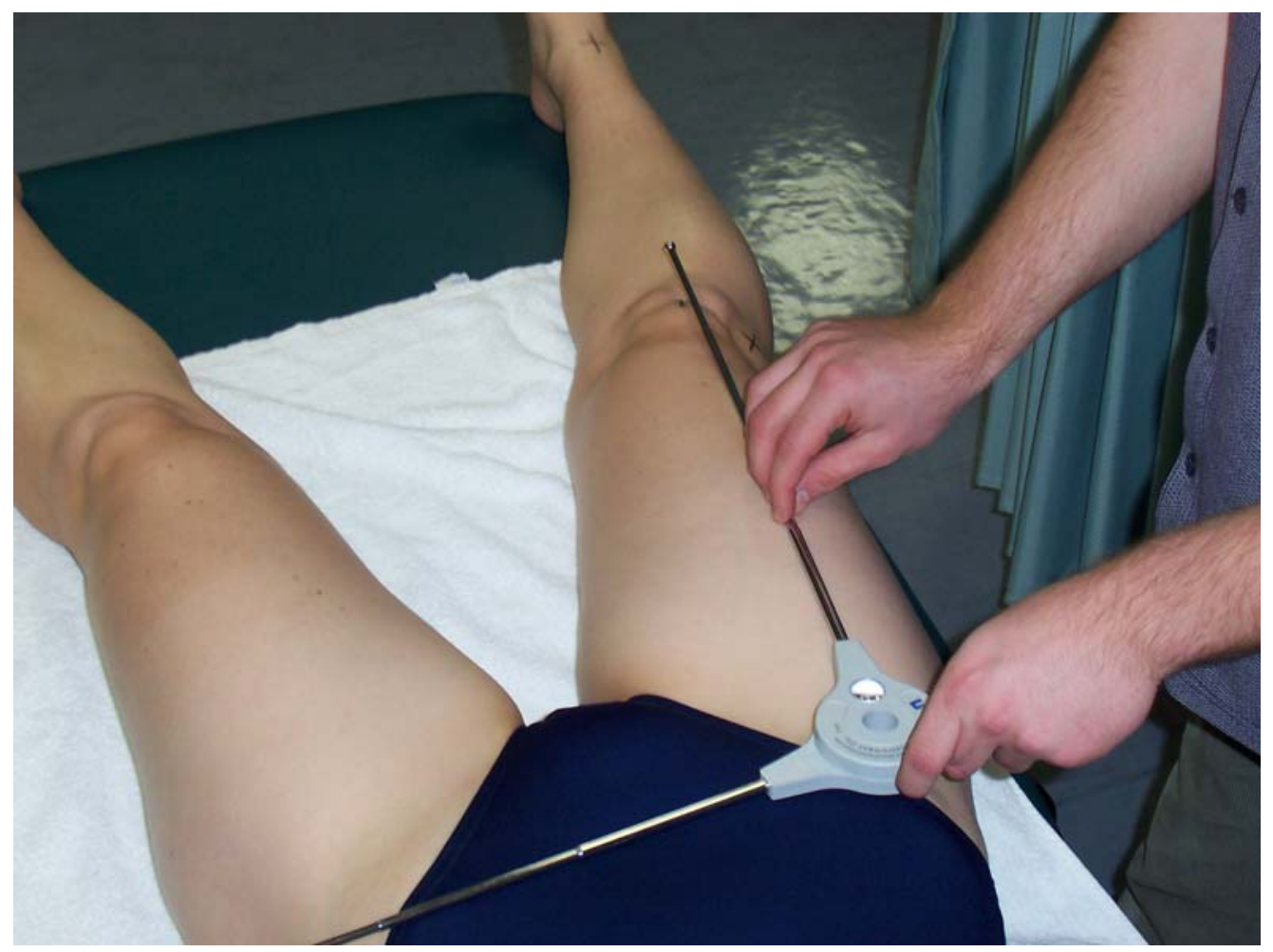

(a) ABDUCTION

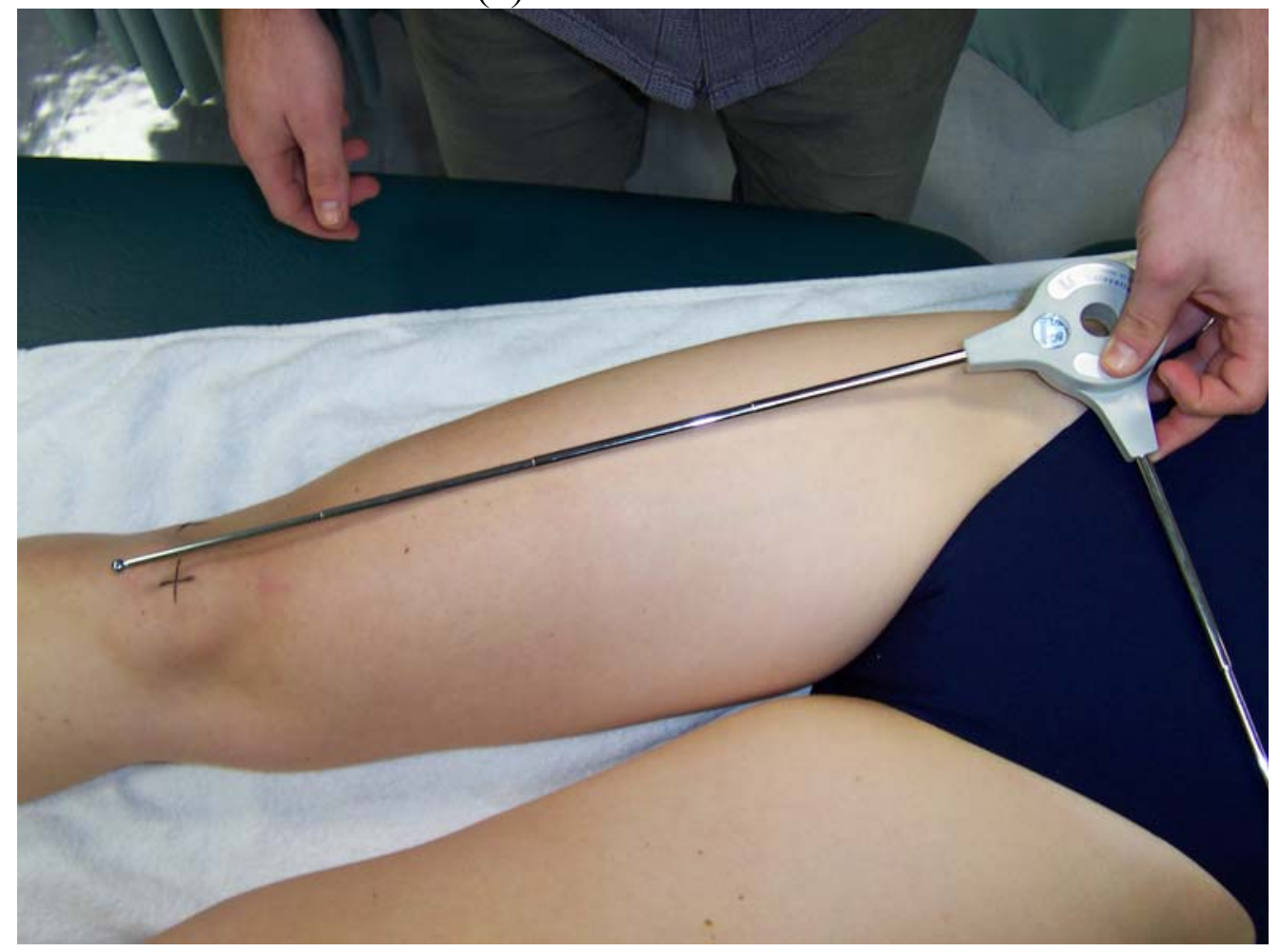

(b) ADDUCTION

Figure 6. Hip Abduction and Adduction measurement (Adapted from Norkin \& White, 1995, p.129 (a) \& p.131 (b)). 


\subsubsection{Hip: Medial (Internal) rotation/ Lateral (External) rotation}

$\underline{\text { Landmarks }}$

The landmarks were the anterior midpoint of the patella, anterior midline of the lower leg, crest of tibia, and both the medial and lateral malleoli.

\section{Testing Position}

For both medial (internal) rotation and lateral (external) rotation, the subject testing position was seated on a firm surface with knees flexed 90 degrees (Figures 7 a and $b$ ). The distal end of the femur was stabilized by placing a towel roll under it. The hip was maintained in zero degrees of abduction and adduction and 90 degrees of flexion. For medial rotation, testing the hip was passively internally rotated. However, the contralateral knee was sometimes flexed to allow full external hip rotation range of motion on the testing side.

\section{$\underline{\text { Goniometer Alignment }}$}

The fulcrum of the goniometer was placed over the anterior midline of the patella. The proximal arm was aligned parallel to the supporting surface; the distal arm with the anterior midline of the lower leg, using the crest of tibia and midpoint between the malleoli as a reference (Figures $7 \mathrm{a}$ and $\mathrm{b}$ ). 


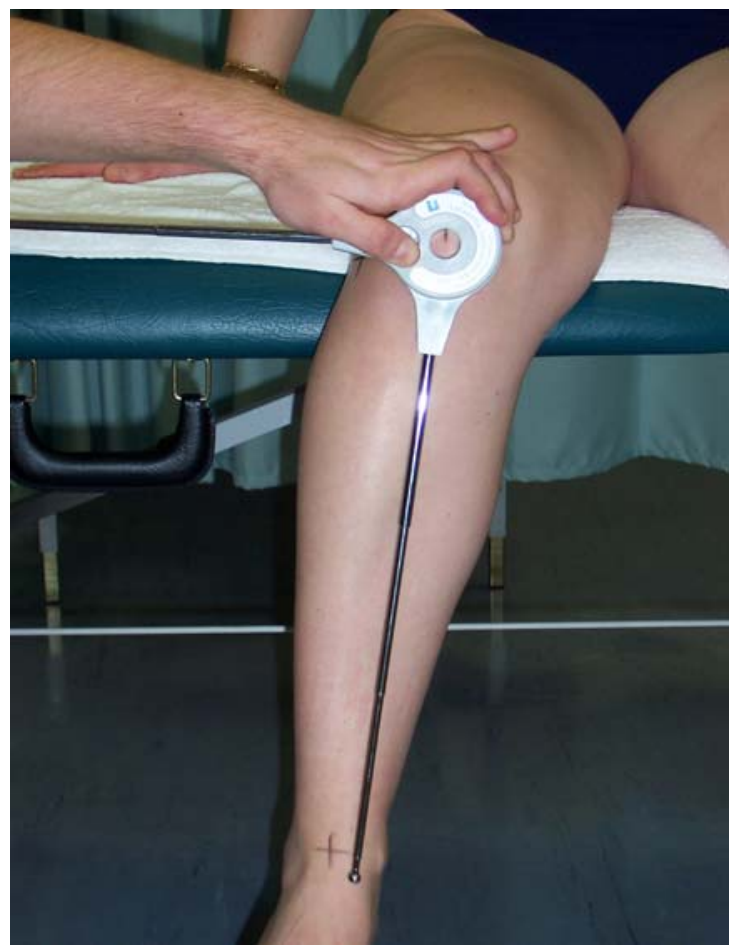

(a) HIP INTERNAL ROTATION

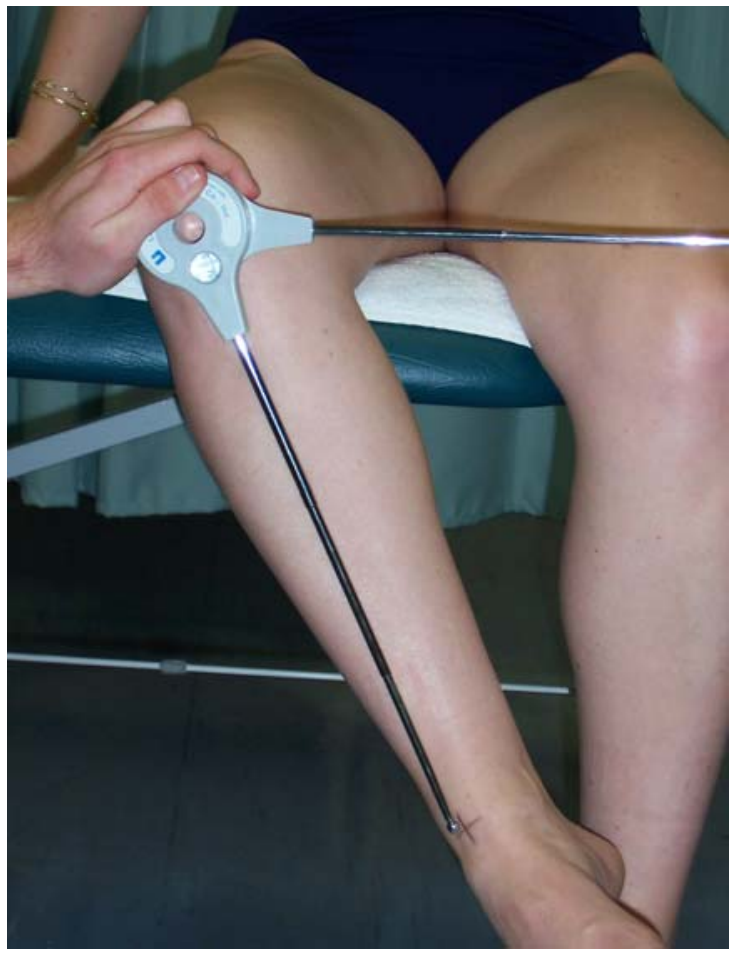

(b) HIP EXTERNAL ROTATION

Figure 7. Hip Internal and External Rotation measurement (Adapted from Norkin \& White, 1995, p. 133 (a) \& p.135 (b)). 


\subsubsection{Knee: Flexion/Extension}

$\underline{\text { Landmarks }}$

The landmarks were the lateral epicondyle of femur, lateral midline of femur, greater trochanter, lateral midline of fibula, lateral malleolus and fibular head.

\section{Testing Position: Knee Flexion}

For knee flexion, the subject testing position was prone with the knee in extension. The hip was placed at zero degrees extension/ abduction/ adduction but was flexed as the knee was flexed. The femur was stabilized (Figures 8 a).

\section{Testing Position: Knee Extension}

For knee extension the subject testing position was supine with the hip in zero degrees abduction/adduction, flexion/extension and rotation. The foot was over the edge of the supporting surface. The ankle on the side being tested was lifted off the supporting surface.

\section{$\underline{\text { Goniometer Alignment }}$}

The fulcrum of the goniometer was placed over the lateral epicondyle of femur. The proximal arm was aligned with the lateral midline of femur using the greater trochanter as a reference. The distal arm was aligned with the lateral midline of fibula using the lateral malleolus and head of fibula as references (Figures $8 \mathrm{a}$ and $\mathrm{b}$ ). 


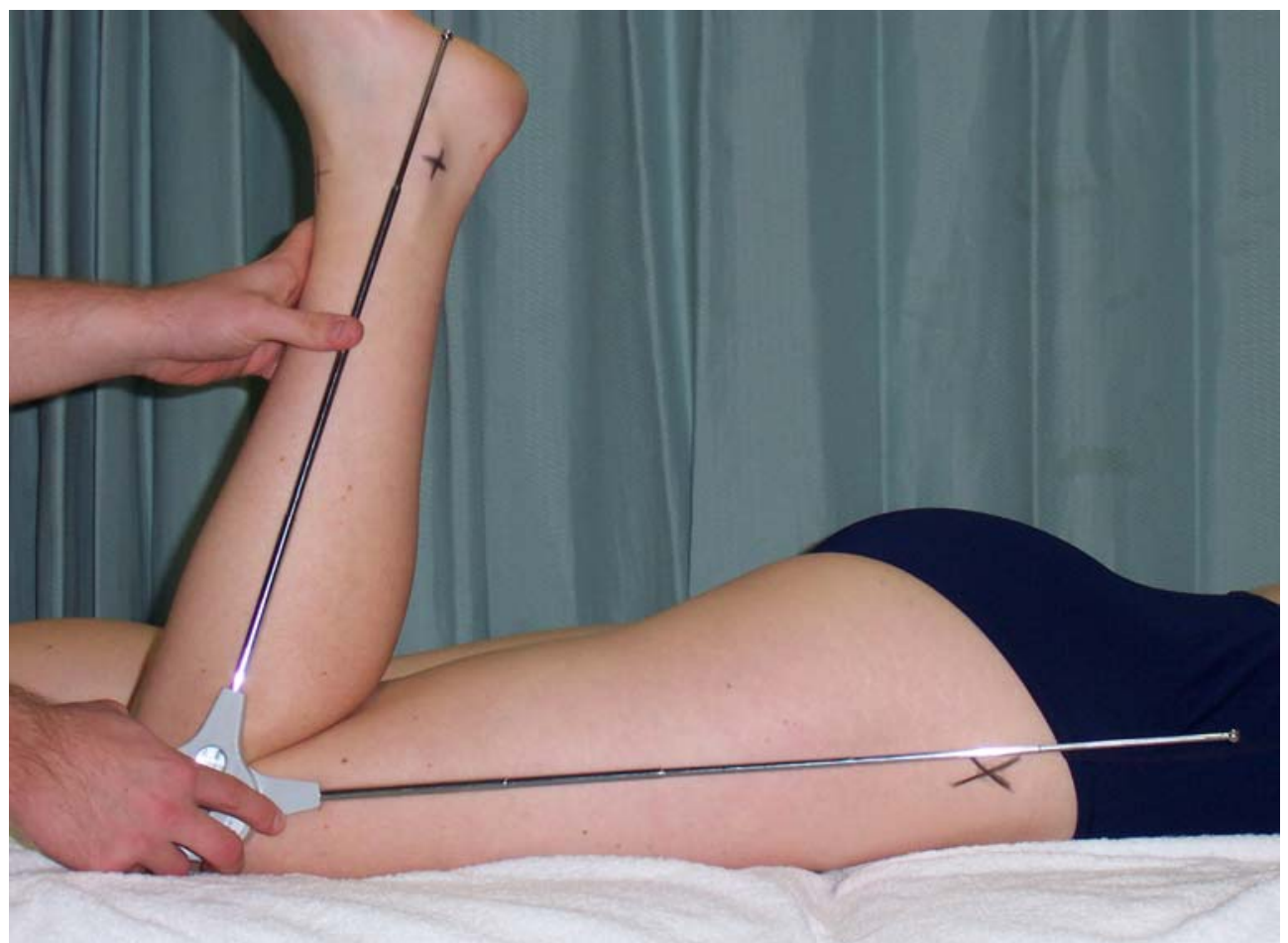

(a) KNEE FLEXION (PRONE)

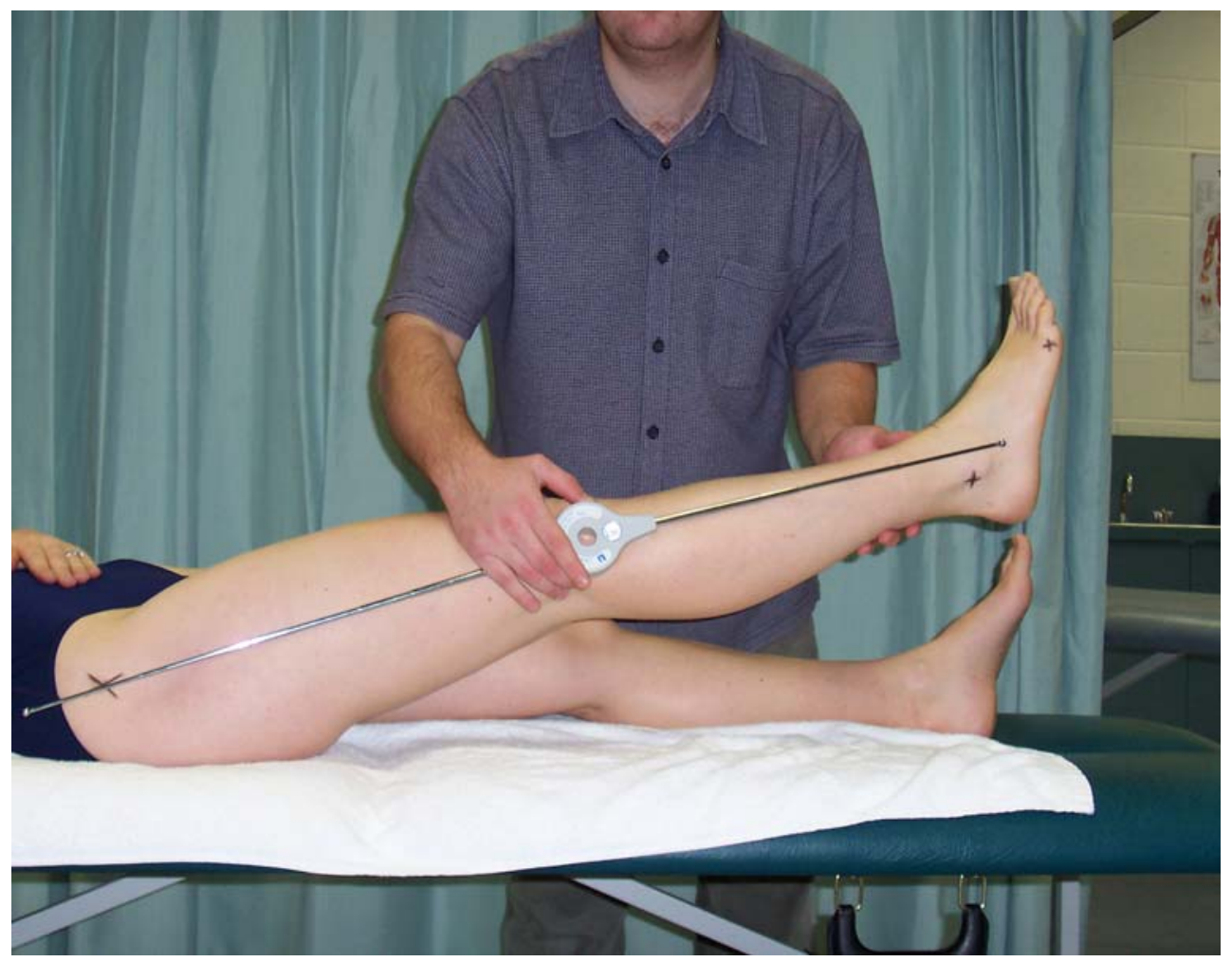

(b) KNEE EXTENSION (SUPINE)

Figure 8. Knee Flexion Prone (Adapted from Norkin \& White, 1995, p.145 (a, b)). 


\subsubsection{Ankle: Doris / Plantar flexion}

\section{$\underline{\text { Landmarks }}$}

The landmarked features were the lateral malleolus, lateral midline of fibula, and fifth metatarsal.

\section{Testing Position}

For both ankle Dorsi flexion and plantar flexion, the subject's testing position was sitting, with the knee flexed to 90 degrees. The foot was maintained in zero degrees of inversion and eversion whilst the tibia and fibula were stabilized (Figure $9 \mathrm{a}$ and $\mathrm{b}$ ).

\section{Goniometer Alignment}

The fulcrum of the goniometer was placed over the lateral aspect of the lateral malleolus. The proximal arm was aligned with the lateral midline of fibula with the head of fibula used as a reference. The distal arm was aligned parallel to the lateral aspect of the fifth metatarsal. 


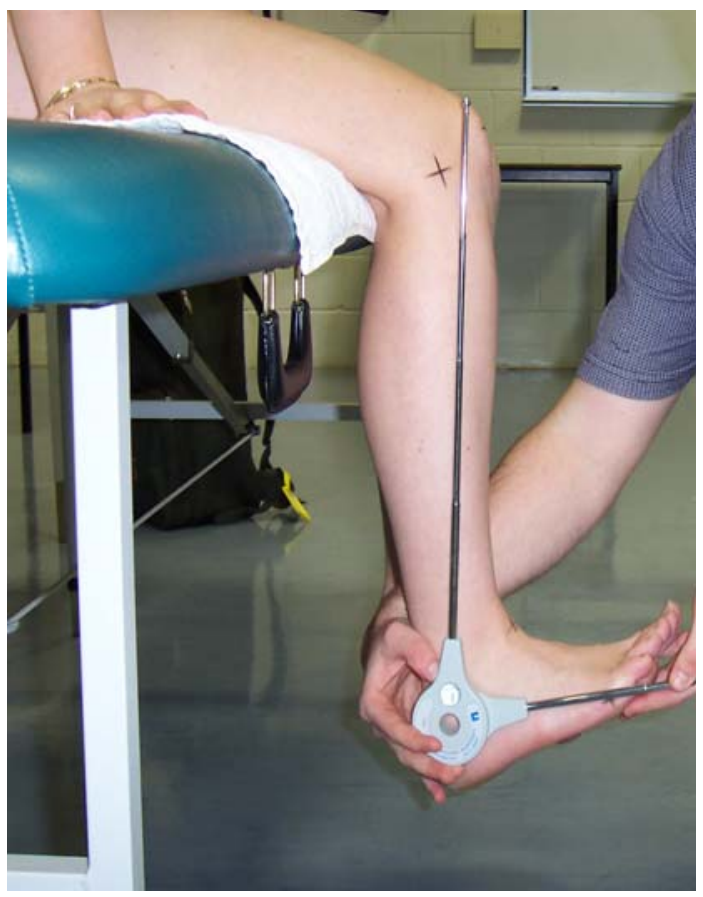

(a) ANKLE DORSI FLEXION

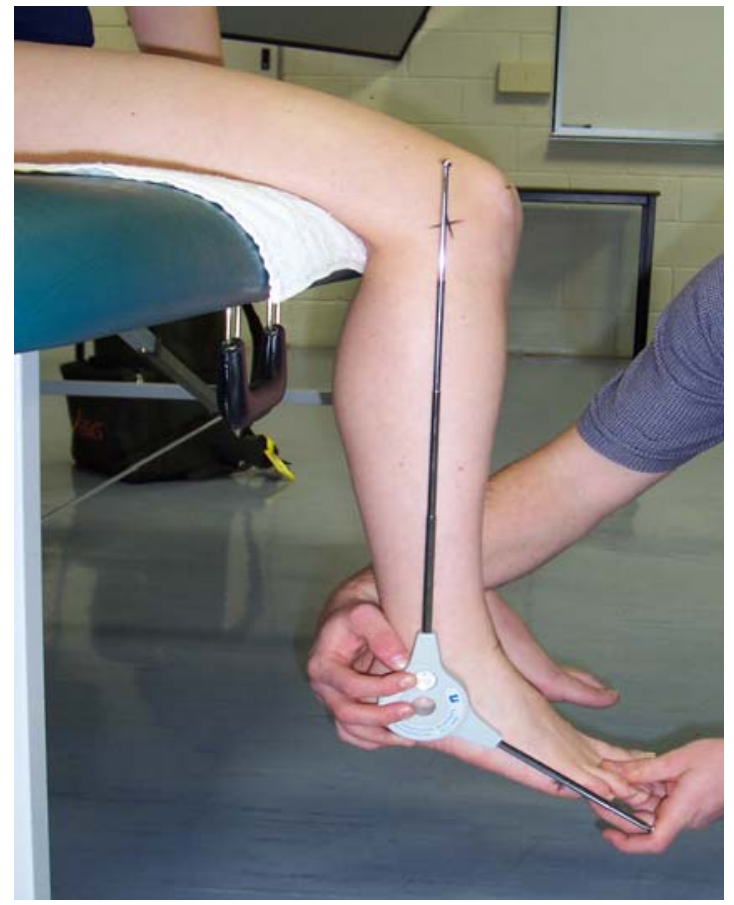

(b) ANKLE PLANTAR FLEXION

Figure 9. Ankle Dorsi flexion and Plantar flexion measurement (Adapted from Norkin \& White, 1995, p.155 (a) \& p.157 (b)). 


\subsubsection{Resting Calcaneal Stance Position (RCSP)}

$\underline{\text { Landmarks }}$

The landmarks of importance were the talar heads. The bisection of the calcaneus was used as a landmark.

\section{$\underline{\text { Testing Position }}$}

The subject testing position involved standing on a stool (Figure 10).

\section{Goniometer Alignment (Gravity)}

A gravity goniometer was aligned with the posterior bisection of the calcaneus.

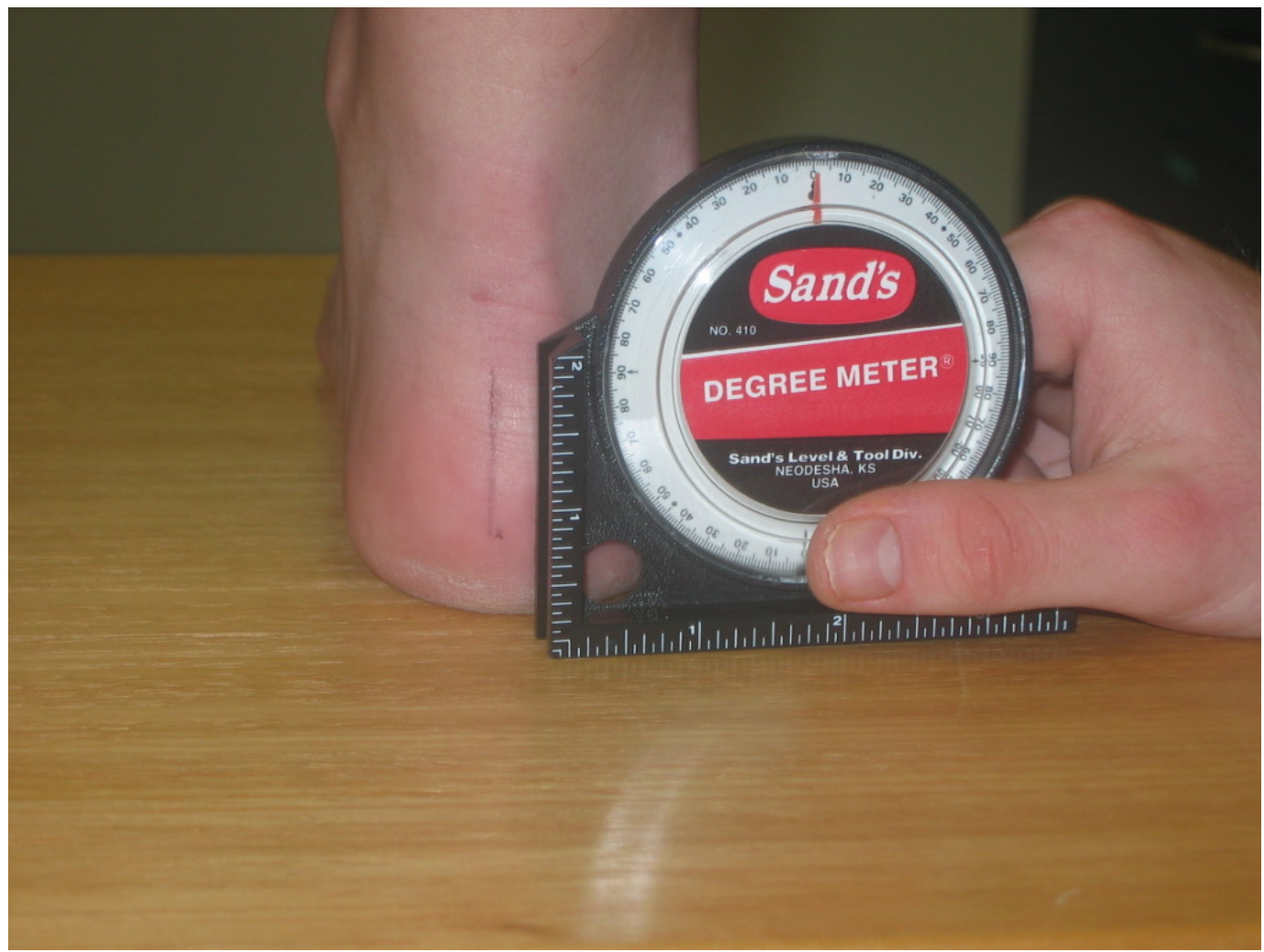

Figure 10. Resting Calcaneal Stance Position (RCSP) measurement. 


\subsubsection{First Metatarsophalangeal Joint (MPJ): Dorsi flexion}

\section{$\underline{\text { Landmarks }}$}

The landmark was the first MPJ, the bisection of the shaft of the first metatarsal, and the bisection of the proximal phalanx of the hallux.

\section{Testing Position}

The subject testing position was supine with the lower two thirds of leg over the edge of the supporting surface (Figure 11).

\section{$\underline{\text { Tractograph Alignment }}$}

One arm was lined up with the medial bisection of the shaft of the first metatarsal and the other with the medial bisection of the proximal phalanx (Figure 11).

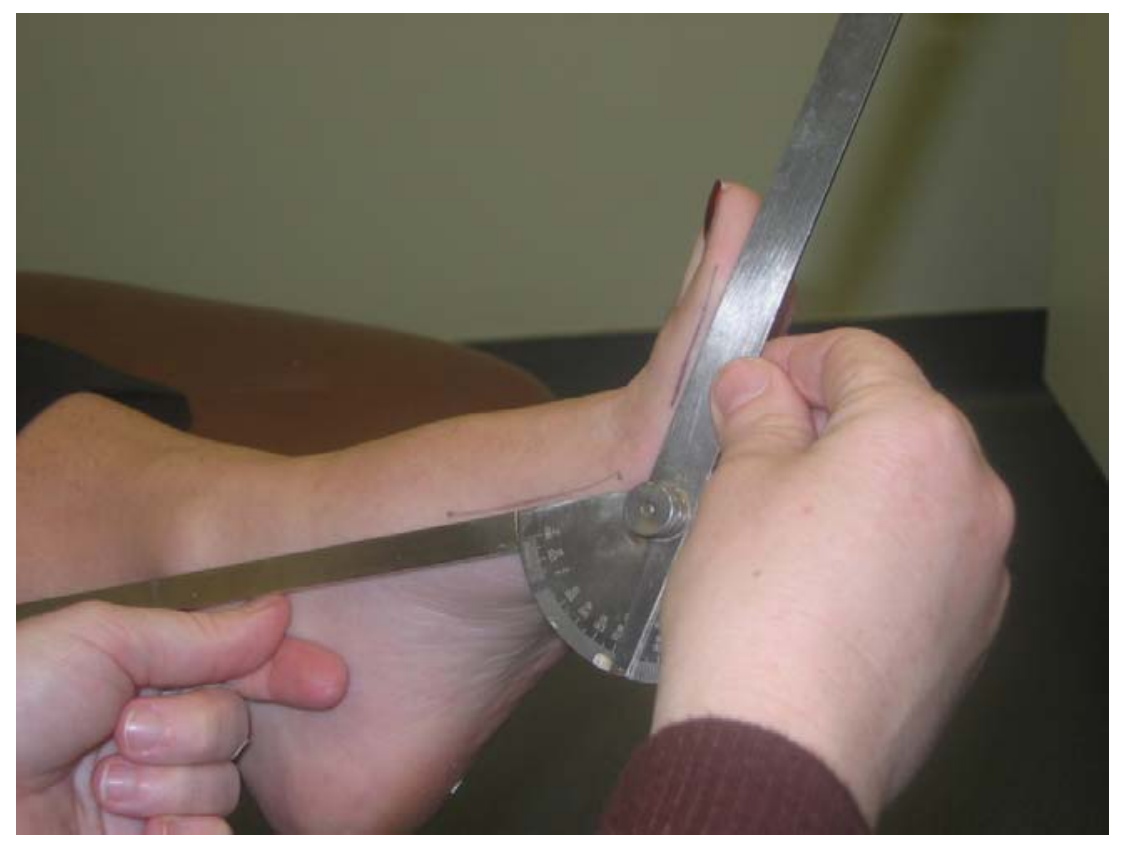

Figure 11. First Metatarsophalangeal Joint (MPJ) measurement. 


\subsection{Data Collection}

The data collection consisted of three separate testing sessions. Fifty-six subjects attended a baseline testing session prior to the commencement of their semester one classes. At the end of 13 weeks, 28 of the 56 subjects returned for retesting. Eight of the 28 subjects $(29 \%)$ returned for reliability testing (Figure 12$)$.

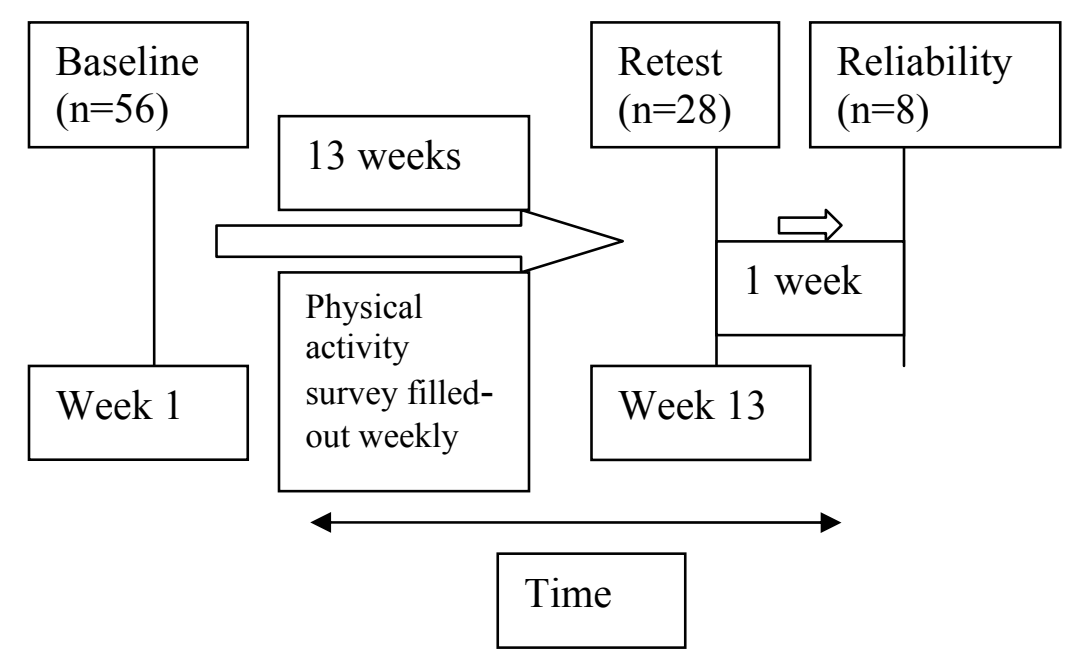

Figure 12. Descriptive Flowchart of the Data Collection Process.

\subsubsection{Baseline Data Collection}

After explanation of the test protocols, informed consent was completed by the 56 subjects. All test protocols complied with the University of Ballarat ethical guidelines for human experimentation. The baseline measurements were completed over a course of three afternoons on consecutive days in the same environment. At the commencement of the study, each subject completed an injury history form (Appendix 1). The baseline measures were taken on both legs of each of the 56 subjects. First metatarsophalangeal joint (MPJ) Dorsi flexion, Resting Calcaneal Stance Position (RCSP) and all planes of motion at the hip, knee and ankle were recorded on data collection sheets (Appendix 2) and then transferred into an Excel database. Age, gender, height, and weight data were also collected. Body Mass Index (BMI) was calculated after the initial data collection. 


\subsubsection{Physical Activity Survey}

At the conclusion of baseline measurement testing, each subject commenced the first semester of their course. The course included a substantial physical exercise component in a unit entitled 'Fundamentals of Fitness'. It is acknowledged by the researchers that some subjects were involved in external training programs in addition to the University directed training program. For this reason, each subject was invited to complete a survey of their physical activity levels for each of the thirteen (13) weeks between baseline testing and retesting.

The survey was designed to collect information regarding each subject's level of activity. The data were collected as the level of physical activity was hypothesized to be an extrinsic factor in the pathophysiology of MTSS in the related literature. The survey comprised of questions related to the duration and number of times household chores, gardening, moderate and vigorous physical activities were undertaken:

(a) in the six months leading up to the commencement of the study. This survey form is shown in Appendix 3(a). These surveys were collected at the baseline testing, and,

(b) each week of the study.

This survey form is shown in Appendix 3(b) (as adapted from Bauman et al. 2000). The surveys were collected weekly. At the conclusion of each week, the subjects were asked to indicate if they had experienced shin and/or calf pain.

\subsubsection{Retest Data Collection}

After the 13 week training period, all 56 subjects were asked to complete a survey. This question is shown in Appendix 4. The question was used to indicate whether the subjects were currently experiencing any shin and/ or calf pain, or had experienced shin and/or calf pain during the semester. 
This information was critical as some students had indicated they had experienced shin and/or calf pain during the semester, but did not state this on their weekly physical activity surveys, or they stated that they did not currently have shin and/or calf pain at the time they filled out the question shown in Appendix 4.

At the completion of the thirteen week training period, 28 of the original 56 subjects voluntarily returned for a repeat of all of the measurements, previously taken at baseline. This was despite constant reminders and phone calls to all 56 original subjects. Fourteen subjects had indicated that they had experienced shin and or lower calf pain during the thirteen week training period. These 14 subjects were placed in the injured group, and a further 14 were classified as the non-injured group.

All testers completed the same tests on the same subjects from the baseline data collection stage. The podiatrist upon completion of the RCSP and first MPJ range of motion testing, palpated the medial lower two-thirds of the leg in order to elicit any pain consistent with the diagnosis of MTSS. Some subjects who had indicated they had experienced shin and/or calf pain during the course of the semester did not have the diagnosis of MTSS. Conversely, some of those who indicated that they did not have shin and/or calf pain during the course of the semester were diagnosed as having MTSS.

At the completion of the second testing session 14 subjects had a diagnosis of MTSS.

\subsubsection{Reliability data collection}

At the end of the second testing session, 14 of the 28 subjects were asked to return for reliability testing. One week later, only eight subjects voluntarily returned for reliability testing which followed the same testing procedures as previously described. This was to test intra tester reliability. 


\subsection{Data Analysis}

All statistics were performed with the Statistical Package for the Social Sciences Version 11.0 (SPSS Inc., Chicago, Illinois).

\subsubsection{Reliability}

In order to determine the reproducibility of the joint range of motion measurements completed by the testers who were blinded, the data from the retest was compared with that of the reliability testing completed one week later using an Excel data sheet with formulae for calculating means, standard deviations, and Interclass Correlation Coefficients.

\subsubsection{Joint range of motion testing}

Risk factor predictors from the joint range of motion tests completed at baseline were compared between those who incurred an injury and those who did not using a logistic regression in order to elicit any significant predictors of injury with the reference significance level being at $\alpha=0.05$.

Data from the male and female subjects were analyzed together. Repeated measure analysis of variance (ANOVA) was used to compare the joint range of motion measurements taken at baseline compared with those measured after the thirteen week period. This was to determine whether lower limb joint range of motion changes with time and if a change is significantly associated with the onset of injury. Due to the low number of subjects as compared to the number of variables a Bonferroni correction was calculated $(\alpha=0.002)$ as the significance level for all range of motion statistical analyses.

Using a repeated measures ANOVA, male and female data were compared for each of the range of motion variables. 


\subsubsection{Physical activity}

Data from the weekly surveys (Appendix 3 (a) \& (b)) that the subjects completed weekly, between baseline and retest, were entered into an Excel database. In the weekly surveys (Appendix 3 (b)), time spent walking and completing vigorous, moderate and household activities were assigned five minutes (if the subject ticked the box pertaining to ' 0 to 10 ' mins), 15 minutes (' 10 to 20 ' mins), 25 minutes (' 20 to 30 ' mins), 35 minutes (' 30 to 40 ' mins), 45 minutes (' 40 to 50 ' mins), 55 minutes ('50 to 60 ' mins) and 65 minutes (' $60+$ ' mins). The total time spent over the 13 weeks between baseline and retest for walking and completing vigorous, moderate and household activities were collated.

For this section of the data analysis the significance level was set at $\alpha=0.05$.

The average weekly time spent completing physical activity was derived from the total over the 13 weeks, and this was compared to the reported average weekly level of physical activity of the subjects prior to the commencement of this study with the use of repeated measures ANOVA. This was to determine if the level of physical activity affects the onset of MTSS in the subjects studied. A second repeated measures ANOVA was completed to determine if physical activity levels affected the site of MTSS (for example left sided, right sided, or bilateral). Only subjects who completed their physical activity survey were included in the statistical analyses.

\subsubsection{Predictors}

Variables including age, height, weight, BMI, range of motion of the hip, knee, ankle, and first MPJ, RCSP, intensity and duration of physical activity were analysed for the elucidation of possible predictors for the onset of MTSS, using a logistic stepwise regression. 


\section{CHAPTER FOUR - RESULTS AND DISCUSSION}

\subsection{Introduction}

This study address whether the occurrence of MTSS is related to range of motion differences in hip, knee, ankle, subtalar and first metatarsophalangeal joints (MPJ). The effect of physical activity levels on the incidence of MTSS was also investigated.

\subsection{Injury Incidence}

In this study, 14 of the 28 subjects returning (50\%) had developed MTSS, nine were bilateral, three were left sided, and two were right sided. The baseline height, weight and body mass Index (BMI) for the injured and non-injured groups are presented in Table 2.

Table 2:

Mean and standard deviation (sd) of height, weight and BMI for injured $(\mathrm{N}=14)$ and noninjured $(\mathrm{N}=14)$ subjects.

\begin{tabular}{|c|cccccc|}
\hline Variable & \multicolumn{2}{|c}{ Height $(\mathrm{m})$} & \multicolumn{2}{c|}{ Weight $(\mathrm{kg})$} & \multicolumn{2}{c|}{ BMI } \\
& Mean & sd & Mean & sd & Mean & sd \\
\hline Injured & 1.63 & 0.09 & 65.50 & 10.46 & 23.30 & 3.30 \\
Non-Injured & 1.65 & 0.12 & 73.25 & 13.98 & 25.47 & 2.31 \\
\hline
\end{tabular}

The level of reported incidence rates of overuse injury and more specifically MTSS varies in the literature. Sommer and Vallentyne (1995), in their study of 25 folk dancers, demonstrated a $25 \%$ incidence of MTSS. The present study is similar to the study by Sommer and Vallentyne in that they utilized a similar number of subjects, but demonstrated a very different incidence rate of MTSS. An explanation for the discrepancy may lie in the nature of the variables investigated, the nature of the activity the subjects engaged in, the level of conformity of activities across the subject sample, and that only $50 \%$ of the original sample returned for the retest at the end of the 13 week period. 
A study by Montgomery et al. (1989) reported a 34.9\% incidence of medial tibia pain in a sample of 505 army trainees. This level of incidence is quite similar to that reported by Yates and White (2004) in their study of 141 naval recruits whereby 34\% developed MTSS. The present study may have a slightly higher incidence because the subjects were from a civilian population engaging in other physical activities in addition to those completed as part of their university requirements. The incidence rate in the present study may have been different if all 56 subjects tested at baseline had presented at the retest. The studies by Montgomery et al. (1989) and Yates and White (2004) were completed using military and naval populations whereby the subjects completed the same level and intensity of physical activity as part of their basic training.

\subsection{Test-Retest Reliability}

Intra-class coefficients (ICC), were used to establish the test-retest intra-rater reliability of individual testers for the goniometric measures of range of motion at the hip, knee, ankle, subtalar and first metatarsophalangeal joints (MPJ). Eight of the subjects participated in this section of the study. The method for reliability measurement is described on pages 52 to 61 of this thesis.

According to Hopkins (2000), the rationale for the use of ICC instead of the Pearson's $r$, is that when there are less than ten subjects in a reliability study of two trials, the within-subject variation when combined with the between-subject standard deviation differs only marginally between the two correlation calculations. In fact, Hopkins (2000) stated that the Pearson's $r$ often overestimates the true correlation for small sample sizes. Table 3 shows ICC values for each range of motion variable and the 95\% confidence intervals around each value. 
Table 3:

Baseline and retest mean and standard deviations $(\mathrm{N}=8)$ and $\mathrm{ICC} / 95 \%$ confidence values to determine level of intra-rater reliability of lower limb joint range of motion.

\begin{tabular}{|c|c|c|c|c|c|c|}
\hline \multirow[t]{2}{*}{ Variable } & \multicolumn{2}{|c|}{ Baseline } & \multicolumn{2}{|c|}{ Retest } & \multirow{2}{*}{$\begin{array}{c}\text { Mean } \\
\text { Diff }\end{array}$} & \multirow[t]{2}{*}{ ICC } \\
\hline & Mean & SD & Mean & SD & & \\
\hline R/Hip Flex & 135.9 & 10.31 & 132.54 & 9.26 & 2.00 & -0.11 \\
\hline R/Hip Ext & 46.55 & 8.43 & 42.63 & 5.45 & 2.31 & 0.59 \\
\hline R/Hip Abd & 27.86 & 6.55 & 29.25 & 4.93 & 7.50 & 0.45 \\
\hline R/Hip Add & 15.29 & 4.06 & 14.21 & 4.33 & 0.13 & 0.79 \\
\hline R/Hip Int Rot & 53.09 & 9.88 & 50.00 & 9.52 & 1.00 & 0.80 \\
\hline R/Hip Ext Rot & 53.02 & 9.38 & 50.89 & 6.26 & 1.00 & 0.38 \\
\hline $\mathrm{R} /$ Knee Ext & 1.160 & 4.08 & 1.54 & 1.92 & 0.25 & 0.77 \\
\hline $\mathrm{R} /$ Knee Flex & 153.50 & 5.83 & 152.00 & 5.03 & 2.50 & 0.75 \\
\hline R/Ankle DF & 12.2 & 4.63 & 14.71 & 12.15 & 1.13 & 0.42 \\
\hline R/Ankle PF & 61.91 & 7.94 & 59.07 & 11.06 & 0.38 & 0.83 \\
\hline $\mathrm{R} / \mathrm{RCSP}$ & -2.64 & 3.27 & -2.11 & 2.64 & 0.50 & -0.38 \\
\hline R/First MPJ DF & 60.75 & 11.23 & 67.68 & 10.01 & 7.00 & 0.84 \\
\hline L/Hip Flex & 136.32 & 10.96 & 134.27 & 11.44 & 4.00 & 0.61 \\
\hline L/Hip Ext & 43.40 & 8.10 & 44.07 & 6.54 & 3.50 & 0.62 \\
\hline L/Hip Abd & 28.56 & 6.75 & 29.61 & 5.92 & 1.25 & 0.15 \\
\hline L/Hip Add & 15.73 & 4.13 & 13.79 & 4.11 & 0.00 & 0.45 \\
\hline L/Hip Int Rot & 55.48 & 10.05 & 48.89 & 7.50 & 7.00 & 0.90 \\
\hline L/Hip Ext Rot & 50.91 & 10.69 & 50.32 & 6.09 & 5.13 & 0.88 \\
\hline L/Knee Ext & 1.73 & 3.39 & 1.82 & 2.37 & 0.75 & 0.38 \\
\hline L/Knee Flex & 151.32 & 7.43 & 147.50 & 18.11 & 1.88 & 0.89 \\
\hline L/Ankle DF & 14.48 & 5.45 & 15.96 & 9.86 & 2.00 & 0.80 \\
\hline L/Ankle PF & 60.59 & 8.43 & 56.89 & 12.35 & 1.38 & 0.94 \\
\hline L/RCSP & -2.16 & 3.00 & -2.54 & 2.67 & 0.13 & -0.52 \\
\hline L/First MPJ DF & 60.54 & 11.87 & 64.36 & 15.66 & 8.63 & 0.84 \\
\hline
\end{tabular}

(Note: $\mathrm{R}=$ Right, $\mathrm{L}=$ Left, Flex $=$ Flexion, Ext $=$ Extension, Add $=$ Adduction, $\mathrm{Abd}=$ Abduction, Int Rot $=$ Internal Rotation, Ext Rot $=$ External Rotation, DF $=$ Dorsi flexion, $\mathrm{PF}=$ Plantar flexion, $\mathrm{RCSP}=$ Resting Clacaneal Stance Position, MPJ = Metatarsophalangeal Joint)

The small numbers of subjects in the reliability part of the study lends to a decreased reliability of some of the measurements. Perhaps if there were more subjects in this section of the study reliability of the variables may have improved. However, from the clinical perspective, it can be seen that the actual change in mean degrees of each range of motion variable ranges between 0.00 and 8.63 degrees. The changes in degree can be seen to be relatively proportional to the angular measurement for a given variable. Further, these relatively small changes in the mean may be due in part to the accuracy of the instruments. 
According to Eliasziw, et al. (1994), the critical value of the ICC is 0.6, above which any ICC value can be accepted. The ICCs for the variables R/Hip Flex, R/Hip Ext, R/Hip Abd, R/Hip Ext Rot, R/Ankle DF, R/RCSP, L/Hip Flex, L/Hip Ext, L/Hip Abd, L/Hip Add, L/Knee Extension, and L/RCSP are below the critical value of 0.6 indicating a low intra-rater reliability. The low intra-rater reliability in these 12 range of motion variables indicates inconsistencies between the two occasions of measurement taken for reliability testing. The low intra-rater reliability for static goniometric measurements of these range of motion variables indicates that there is a high level of error. Such high levels of measurement error masks any systematic effects of these range of motion variables and they should be treated with caution.

The ICC values for R/Hip Add, R/Hip Int Rot, R/Knee Ext, R/Knee Flex, R/Ankle PF, R/First MPJ DF, L/Hip Int Rot, L/Hip Ext Rot, L/Knee Flex, L/Ankle DF, L/Ankle PF, R/ First MPJ DF were above the critical value of 0.6 indicating a moderate to high level of intra-rater reliability. The moderate to high level of inter-rater reliability in these 12 range of motion variables indicates consistencies at the two occasions of measurements taken for reliability testing. The moderate to high intra-rater reliability for static goniometric measurements of these range of motion variables indicates that they can be accepted without caution when utilizing them as independent variables in the present study.

\subsection{The occurrence of MTSS and its relationship to variation in lower limb joint ranges of motion}

Decreased range of motion has been postulated in the literature (Giladi et al., 1987; Montgomery et al., 1989; Bennell et al., 1996) as a contributing factor in the pathogenesis of several overuse syndromes of the lower limb. This particular study aimed to investigate whether this was true in relation to the incidence of MTSS.

A repeated measures analysis of variance was used to determine whether there was a significant relationship between changes in the variables tested at baseline and at the end of a 13 week exercise period (for the 28 subjects who returned) and injury. The 
significance values for each range of motion variable with respect to time, and injury as the main effects and the interaction between time and injury are detailed in Table 4. Means and standard deviations for the injured and non-injured groups for all range of motion variables are detailed in Appendix 5.

Table 4:

Change in means and standard deviations(sd) for injured $(\mathrm{N}=14)$ and non-injured $(\mathrm{N}=14)$ groups. Significance values for changes in the baseline range of motion testing values at the retest due to time, injury and the interaction of time and injury.

\begin{tabular}{|c|c|c|c|c|c|c|c|c|}
\hline \multirow[t]{2}{*}{ Variable } & \multicolumn{2}{|c|}{ Injured } & \multicolumn{2}{|c|}{ Non-Injured } & \multirow{2}{*}{$\begin{array}{l}\text { Time } \\
\text { (p) }\end{array}$} & \multirow{2}{*}{$\begin{array}{l}\text { Injury } \\
\text { (p) }\end{array}$} & \multirow{2}{*}{$\begin{array}{l}\text { Time } x \\
\text { Injury } \\
\text { (p) }\end{array}$} & \multirow{2}{*}{$\begin{array}{l}\text { Reliable } \\
\text { (ख) }\end{array}$} \\
\hline & $\begin{array}{l}\text { Change } \\
\text { in Mean }\end{array}$ & $\begin{array}{c}\text { Change } \\
\text { in sd }\end{array}$ & $\begin{array}{l}\text { Change } \\
\text { in Mean }\end{array}$ & $\begin{array}{c}\text { Change } \\
\text { in sd }\end{array}$ & & & & \\
\hline R/Hip Flex & -2.36 & 0.12 & -4.57 & -1.84 & 0.02 & 0.023 & 0.466 & \\
\hline R/Hip Ext & -3.60 & -2.88 & -2.72 & -4.83 & 0.15 & 0.523 & 0.837 & \\
\hline R/Hip Abd & 0.57 & -2.58 & 1.35 & -0.87 & 0.456 & 0.011 & 0.76 & \\
\hline R/Hip Add & 0.35 & -0.70 & -1.00 & 1.54 & 0.438 & 0.125 & 0.712 & 凶 \\
\hline R/Hip Int Rot & -5.72 & 1.19 & -2.70 & -2.23 & 0.047 & 0.027 & 0.421 & 凶 \\
\hline R/Hip Ext Rot & -6.09 & -0.29 & 0.50 & -5.95 & 0.121 & 0.013 & 0.072 & \\
\hline $\mathrm{R} /$ Knee Ext & -1.29 & -1.80 & 0.93 & -1.06 & 0.708 & 0.011 & 0.069 & 凶 \\
\hline R/Knee Flex & -2.43 & -0.61 & -0.85 & 0.01 & 0.012 & 0.574 & 0.209 & 凶 \\
\hline R/Ankle DF & 5.64 & 12.11 & 0.57 & 0.30 & 0.136 & 0.422 & 0.207 & \\
\hline R/Ankle PF & -3.49 & -1.39 & -2.93 & 6.41 & 0.061 & 0.070 & 0.863 & 凶 \\
\hline R/RCSP & 0.07 & -1.69 & 0.36 & -0.26 & 0.842 & 0.185 & 0.766 & \\
\hline R/First MPJ DF & 8.86 & 2.76 & 2.86 & 0.43 & 0.002 & 0.802 & 0.09 & 凶 \\
\hline L/Hip Flex & -4.25 & 2.41 & -0.07 & -0.65 & 0.375 & 0.226 & 0.391 & \\
\hline L/Hip Ext & 0.07 & -0.78 & -1.17 & -1.36 & 0.809 & 0.186 & 0.785 & \\
\hline L/Hip Abd & -0.72 & -1.69 & 1.56 & 0.64 & 0.791 & 0.782 & 0.481 & \\
\hline L/Hip Add & -2.07 & 0.94 & -1.00 & -0.02 & 0.18 & 0.697 & 0.685 & \\
\hline L/Hip Int Rot & -10.29 & -1.47 & -3.86 & -3.58 & 0.003 & 0.024 & 0.163 & 凶 \\
\hline L/Hip Ext Rot & -2.56 & -1.39 & 1.79 & -7.96 & 0.855 & 0.020 & 0.316 & 区 \\
\hline L/Knee Ext & -0.56 & -0.63 & 0.22 & -1.83 & 0.77 & 0.186 & 0.521 & \\
\hline L/Knee Flex & -4.35 & 12.83 & 0.21 & 1.89 & 0.576 & 0.839 & 0.537 & 凶 \\
\hline L/Ankle DF & -0.64 & 1.45 & 3.49 & 7.41 & 0.43 & 0.953 & 0.256 & 凶 \\
\hline L/Ankle PF & -8.00 & 8.24 & -1.42 & -1.64 & 0.054 & 0.296 & 0.171 & 凶 \\
\hline $\mathrm{L} / \mathrm{RCSP}$ & 0.72 & -1.76 & -0.29 & -0.57 & 0.449 & 0.214 & 0.744 & \\
\hline L/First MPJ DF & 8.14 & -2.57 & -1.07 & 7.14 & 0.264 & 0.266 & 0.148 & 区 \\
\hline
\end{tabular}

(Note: $\mathrm{R}=$ Right, $\mathrm{L}=$ Left, Flex $=$ Flexion, Ext $=$ Extension, Add = Adduction, Abd = Abduction, Int Rot $=$ Internal Rotation, Ext Rot $=$ External Rotation, DF $=$ Dorsi flexion, $\mathrm{PF}=$ Plantar flexion, RCSP $=$ Resting Clacaneal Stance Position, MPJ = Metatarsophalangeal Joint) 
Hopkins (2000) discussed the possibility of an inflation of the type 1 error rate, which occurs when there is a high number of variables compared to the number of subjects being studied. When this happens there is the possibility that the effects being studied exhibit a greater level of significance than they really have.

A Bonferroni adjustment is proposed in the literature (Hopkins, 2000) as the simplest method of obtaining an altered significance level $\alpha$ in accordance with the number of independent tests being studied. In this case there are 24 independent variables. The Bonferroni adjustment is calculated as follows:

$$
0.05 / 24=0.002(24=\text { number of variables })
$$

When interpreting the results of the repeated measures ANOVA in this case, all results will be compared to the altered $\alpha$ value $\mathrm{p}=0.002$.

From Table 4, it can be seen that right first MPJ Dorsi flexion is the only variable which reached significance over time from baseline to retest. According to the reliability testing using the ICC, right first MPJ Dorsi flexion was a reliable measure. In both the injured and non-injured groups the mean right first MPJ Dorsi flexion increased (injured = 8.86; non-injured=2.86). However this change over time in mean right first MPJ Dorsi flexion was not significantly different between the non-injured and injured groups and hence not related to the onset of MTSS. The fact that such a significant change was not related to the incidence of MTSS confirms the findings of Payne and Dananberg (1997), that decreased (rather than increased) first MPJ motion below 65 degrees can predispose a person to compensation in more proximal joints and lead to injury such as. plantar fasciitis. Furthermore, all the range of motion variables tested in this study were not significantly different between the injured .and non-injured groups.

These findings are attributable only to the 28 subjects who partook in the baseline and the retest. In consideration of this, this study suggests that in this group of 28 subjects, none of the parameters tested influenced the onset of symptoms generally across 
the sample. Furthermore, there seems to be no significant difference between the injured and non-injured groups in the 24 range of motion parameters measured. This suggests that other factors such as physical activity, footwear or training terrain may have influenced the onset of MTSS in those who developed the injury.

Findings from past studies (Montgomery et al., 1989; Bennell et al., 1996) have found links between variations in lower limb joint range of motion and the incidence of overuse syndromes of the lower limb, such as stress fractures of the tibia and plantar fasciitis, not always specific to MTSS. The literature relevant to this study, has identified some of the joint range of motion variables as significantly correlated with overuse injury.

Giladi et al. (1987) demonstrated that external hip rotation greater than 65 degrees increased the likelihood of the development of stress fractures along the shaft of the tibia. The subjects who exhibited higher than 65 degrees hip external range of motion were found to be at a higher risk of tibial stress fractures, than those who exhibited under 65 degrees. Furthermore, Milgrom et al. (1994) later confirmed the findings of Giladi et al., stating that for every 1 degree increase in hip external rotation above 65 degrees, the risk of tibial stress fractures increased 2\%. In studies by Montgomery et al. (1989) and Bennell et al. (1996), external hip rotation was not significantly related to the incidence of overuse injury. In the present study, the mean hip rotation in both legs for both the injured and non-injured groups was shown to be approximately 50 degrees. Therefore, based on the criteria of Milgrom et al. (1994), the subjects in the present study did not exhibit a significant relationship between hip external rotation and the incidence of MTSS.

Knee range of motion did not significantly relate to the incidence of MTSS in this study. In the study by Montgomery et al. (1989), knee extension and flexion were investigated in relation to the incidence of tibial stress fractures. No relationship was found between knee range of motion and tibial stress fracture which is similar to the results of this study. 
Giladi et al. (1987), Montgomery et al. (1989) and Bennell et al. (1996) have all investigated ankle joint range of motion in relation to the incidence of tibial stress fractures. All three studies failed to find a relationship between ankle joint range of motion and the incidence of stress fractures. Similarly, this study also showed in this group of 28 subjects that ankle joint range of motion did not influence the onset of MTSS $($ Left $\mathrm{p}=0.256$; Right $\mathrm{p}=0.207)$.

Excessive rear foot pronation is postulated as being significant in the onset of MTSS (Sommer \& Vallentyne, 1995). In the research outlined in this thesis, rear foot posture was determined using the resting calcaneal stance position (RCSP). Freeman (1990) demonstrated the use of the RCSP to be more reliable than that of the neutral calcaneal stance position (NCSP). Abnormal subtalar joint pronation has been implicated in the development and incidence of MTSS in static and dynamic studies (Messier \& Pitalla, 1988; Sommer \& Vallentyne, 1995; Viitasalo \& Kvist, 1983). The present study results do not support the hypotheses that RCSP is related to the onset of MTSS.

The study by Sommer and Vallentyne (1995) prospectively investigated rear foot posture and its effect on the incidence on MTSS. A more recent study by Yates and White (2004) also investigated rear foot posture though they used the foot posture index outlined in the literature review. Comparatively, the study by Yates and White (2004) investigated 141 naval recruits, a larger sample size than in the study by Sommer and Vallentyne (1995) which included 25 folk dancers. Although the present study did not find a relationship between RCSP and the incidence of MTSS, the studies by Sommer and Vallentyne (1995) and Yates and White (2004) did find a relationship between a pronated foot posture and the incidence of MTSS. The contradiction between the present studies and the two former may be due to differing measurement techniques, and that the RCSP goniometric measurements in this study were not reliable and must be treated with caution.

A lack of first MPJ Dorsi flexion range of motion in this study was not seen to increase the incidence of MTSS in the sample of 28 subjects. Payne and Dananberg (1997), suggested that first MPJ Dorsi flexion range of motion was important in the 
facilitation of the windlass mechanism. A failure of the windlass mechanism due to limited first MPJ Dorsi flexion could result in more compensations proximally such as a decrease in ankle Dorsi flexion and increased knee flexion. Whilst, in the present study the measurement of first MPJ Dorsi flexion was reliable, a lack of first MPJ Dorsi flexion did not increase the onset of MTSS.

\subsection{The side of occurrence of MTSS and its relationship to variation in lower limb joint range of motion}

Of the 14 subjects who developed MTSS in the present study, a repeated measures ANOVA was used to determine whether changes in lower limb range of motion variables were significantly related to the side of injury. Changes in the mean from baseline to retest in the left-sided, right-sided and bilateral MTSS groups and the significance values with respect to time, injury side as the main effect and the interaction between time and injury side are shown in Table 5. Means and standard deviations for all range of motion measures for the injury side groups and non-injury group at baseline and retest are shown in Appendix $6 a$ and $b$. 
Table 5:

Change in means for right sided $(\mathrm{N}=2)$, left sided $(\mathrm{N}=3)$ and bilateral groups $(\mathrm{N}=9)$. Significance values for changes in the baseline range of motion testing values at retest with respect to time, side of injury and the interaction between time and side of injury.

\begin{tabular}{|c|c|c|c|c|c|c|c|}
\hline \multirow[t]{2}{*}{ Variable } & \multicolumn{3}{|c|}{ Change in Mean } & \multirow{2}{*}{$\begin{array}{l}\text { Time } \\
\text { (p) }\end{array}$} & \multirow{2}{*}{$\begin{array}{l}\text { Injury } \\
\text { Side } \\
\text { (p) }\end{array}$} & \multirow{2}{*}{$\begin{array}{l}\text { Time } x \\
\text { Injury } \\
\text { side (p) }\end{array}$} & \multirow{2}{*}{$\begin{array}{c}\text { Reliable } \\
\text { (ख) }\end{array}$} \\
\hline & Right & Left & Bil & & & & \\
\hline R/Hip Flex & -2.00 & -2.17 & -2.50 & 0.188 & 0.152 & 0.915 & \\
\hline R/Hip Ext & -12.50 & -1.00 & -2.50 & 0.120 & 0.913 & 0.692 & \\
\hline R/Hip Abd & -1.50 & -0.34 & 1.34 & 0.904 & 0.054 & 0.934 & \\
\hline R/Hip Add & -2.00 & -0.66 & 0.11 & 0.462 & 0.218 & 0.923 & 区 \\
\hline R/Hip Int Rot & -6.00 & -8.67 & -1.66 & 0.055 & 0.175 & 0.816 & 区 \\
\hline R/Hip Ext Rot & -7.00 & -8.67 & -5.33 & 0.051 & 0.072 & 0.336 & \\
\hline R/Knee Ext & -1.50 & 0.67 & -1.44 & 0.387 & 0.098 & 0.344 & 区 \\
\hline R/Knee Flex & -2.50 & -3.00 & -2.22 & 0.018 & 0.953 & 0.651 & 区 \\
\hline R/Ankle DF & -1.00 & 3.00 & 9.55 & 0.347 & 0.197 & 0.392 & \\
\hline R/Ankle PF & -2.00 & 0.67 & -5.22 & 0.297 & 0.166 & 0.778 & 凶 \\
\hline $\mathrm{R} / \mathrm{RCSP}$ & -1.00 & 2.00 & -0.33 & 0.937 & 0.430 & 0.777 & \\
\hline R/First MPJ DF & 7.50 & 9.34 & 9.00 & 0.006 & 0.953 & 0.422 & 区 \\
\hline L/Hip Flex & -18.50 & -8.67 & -5.28 & 0.192 & 0.531 & 0.072 & \\
\hline L/Hip Ext & -8.50 & 5.67 & 0.11 & 0.751 & 0.541 & 0.636 & \\
\hline L/Hip Abd & -2.50 & -1.33 & -0.11 & 0.791 & 0.880 & 0.892 & \\
\hline L/Hip Add & -2.00 & -6.33 & 0.67 & 0.105 & 0.278 & 0.520 & \\
\hline L/Hip Int Rot & -10.00 & -11.67 & -9.33 & 0.006 & 0.174 & 0.592 & 区 \\
\hline L/Hip Ext Rot & -8.50 & -8.34 & 0.67 & 0.217 & 0.038 & 0.391 & 凶 \\
\hline L/Knee Ext & -1.00 & 1.00 & -1.00 & 0.814 & 0.497 & 0.734 & \\
\hline L/Knee Flex & 1.50 & -2.00 & -6.44 & 0.741 & 0.632 & 0.878 & 区 \\
\hline L/Ankle DF & 4.00 & -0.33 & -1.78 & 0.587 & 0.994 & 0.609 & 凶 \\
\hline L/Ankle PF & -3.00 & -1.33 & -11.33 & 0.184 & 0.042 & 0.306 & 区 \\
\hline $\mathrm{L} / \mathrm{RCSP}$ & -3.50 & -1.34 & 0.77 & 0.357 & 0.351 & 0.484 & \\
\hline L/First MPJ DF & 11.00 & 12.00 & 6.23 & 0.112 & 0.643 & 0.505 & 区 \\
\hline
\end{tabular}

(Note: $\mathrm{R}=$ Right, $\mathrm{L}=$ Left, Flex $=$ Flexion, Ext $=$ Extension, Add $=$ Adduction, $\mathrm{Abd}=$ Abduction, Int Rot $=$ Internal Rotation, Ext Rot $=$ External Rotation, DF $=$ Dorsi flexion, $\mathrm{PF}=$ Plantar flexion, $\mathrm{RCSP}=$ Resting Clacaneal Stance Position, MPJ = Metatarsophalangeal Joint)

From Table 5, the change in the range of motion measures from baseline to retest were not significant over time. Furthermore, these changes did not significantly affect whether the injury was right sided, left sided or bilateral. In the 24 range of motion variables studied, with consideration of the bonferroni adjustment calculated as 0.002 , there were no significant differences between the means of the left sided, right sided and 
bilateral MTSS groups. This suggests that other factors such as physical activity, footwear and training terrain may have influenced the onset of MTSS in those who eveloped the injury. However, due to the small numbers in each group, such results must be treated with caution as they may not be reflective of similar trends within the general population.

\subsection{Gender Comparison}

From the 28 subjects who returned for retesting, 22 were female and six were male. Of the 14 subjects who sustained MTSS, 13 were female and one was male. A repeated measures ANOVA was used to determine if there were any significant differences in the changes in the mean from baseline to retest between males and females $(\mathrm{N}=28)$. The changes in the means for all males and females who returned for restest and the significance values for each range of motion variable with respect to time, gender as the main effect and the interaction between time and gender are shown in Table 6 . Means and standard deviations for the male and female groups for all range of motion measures at baseline and retest are detailed in Appendix 7. 
Table 6:

Change in means for male $(\mathrm{N}=6)$ and female groups $(\mathrm{N}=22)$ range of motion variables. Repeated measures ANOVA significance values for the range of motion variables due to time, gender and the interaction between time and gender.

\begin{tabular}{|c|c|c|c|c|c|c|}
\hline \multirow[t]{2}{*}{ Variables } & \multicolumn{2}{|c|}{ Change in Mean } & \multirow{2}{*}{$\begin{array}{l}\text { Time } \\
\text { (p) }\end{array}$} & \multirow{2}{*}{$\begin{array}{c}\text { Gender } \\
\text { (p) }\end{array}$} & \multirow{2}{*}{$\begin{array}{l}\text { Time } x \\
\text { Gender } \\
\text { (p) }\end{array}$} & \multirow{2}{*}{$\begin{array}{l}\text { Reliable } \\
\text { (घ) }\end{array}$} \\
\hline & Males & Females & & & & \\
\hline R/Hip Flex & -6.36 & -2.44 & 0.115 & 0.344 & 0.656 & \\
\hline R/Hip Ext & 1.51 & -4.58 & 0.542 & 0.811 & 0.293 & \\
\hline R/Hip Abd & 1.42 & 0.99 & 0.295 & 0.053 & 0.446 & \\
\hline R/Hip Add & -1.18 & -1.06 & 0.994 & 0.363 & 0.264 & 凶 \\
\hline R/Hip Int Rot & -1.49 & -5.03 & 0.301 & 0.001 & 0.242 & 区 \\
\hline R/Hip Ext Rot & 1.27 & -4.15 & 0.739 & 0.015 & 0.104 & \\
\hline R/Knee Ext & 2.47 & 0.63 & 0.247 & 0.031 & 0.014 & 凶 \\
\hline R/Knee Flex & 0.8 & -2.13 & 0.132 & 0.356 & 0.276 & 凶 \\
\hline R/Ankle DF & 0.88 & 3.12 & 0.438 & 0.666 & 0.438 & \\
\hline R/Ankle PF & -6.85 & -3.01 & 0.030 & 0.001 & 0.270 & 凶 \\
\hline $\mathrm{R} / \mathrm{RCSP}$ & 0.62 & 0.6 & 0.917 & 0.569 & 0.917 & \\
\hline R/ First MPJ DF & 6.14 & 6.62 & 0.077 & 0.677 & 0.104 & 凶 \\
\hline L/Hip Flex & -4.47 & -1.21 & 0.576 & 0.577 & 0.777 & \\
\hline L/Hip Ext & -3.74 & 1.77 & 0.353 & 0.877 & 0.207 & \\
\hline L/Hip Abd & 4.88 & -0.28 & 0.358 & 0.912 & 0.225 & \\
\hline L/Hip Add & -1.74 & -1.98 & 0.425 & 0.907 & 0.577 & \\
\hline L/Hip Int Rot & -2.99 & -9.09 & 0.082 & 0.000 & 0.106 & 凶 \\
\hline L/Hip Ext Rot & 9.79 & -4.92 & 0.038 & 0.029 & 0.000 & 区 \\
\hline L/Knee Ext & 1.72 & -0.63 & 0.382 & 0.139 & 0.055 & \\
\hline L/Knee Flex & 1.41 & -5.21 & 0.976 & 0.540 & 0.391 & 凶 \\
\hline L/Ankle DF & 10.76 & -1.09 & 0.089 & 0.006 & 0.069 & 凶 \\
\hline L/Ankle PF & 1.55 & -6.49 & 0.396 & 0.031 & 0.177 & 凶 \\
\hline $\mathrm{L} / \mathrm{RCSP}$ & -0.29 & -0.32 & 0.440 & 0.483 & 0.791 & \\
\hline L/First MPJ DF & 6.58 & 2.42 & 0.464 & 0.934 & 0.785 & 区 \\
\hline
\end{tabular}

(Note: $\mathrm{R}=$ Right, $\mathrm{L}=$ Left, Flex $=$ Flexion, Ext $=$ Extension, Add $=$ Adduction, $\mathrm{Abd}=$ Abduction, Int Rot $=$ Internal Rotation, Ext Rot $=$ External Rotation, DF $=$ Dorsi flexion, $\mathrm{PF}=$ Plantar flexion, $\mathrm{RCSP}=$ Resting Clacaneal Stance Position, MPJ = Metatarsophalangeal Joint)

From Table 6 it can be seen that changes in range of motion were significantly different between genders for right hip internal rotation (males $=-1.49$; females $=-5.03$; $\mathrm{p}=0.001$ ), right ankle plantar flexion (males $=-6.85$; females $=-3.01 ; p=0.001$ ) and left internal hip rotation $($ males $=-2.99$; females $=-9.09 ; \mathrm{p}=0.000$ ). For left and right hip internal rotation and right ankle plantar flexion the changes in mean range of motion was not significant over time. Changes in range of motion variable means between males and 
females from baseline to retest were not significantly different for left hip external rotation, however an interaction between time and gender was demonstrated $(\mathrm{p}=0.000)$. A plot of the interaction between time and gender for left hip external rotation is represented in Figure 13. From the reliability testing using ICC, left hip external rotation $(\mathrm{p}=0.62)$ was seen to be a reliable measure.

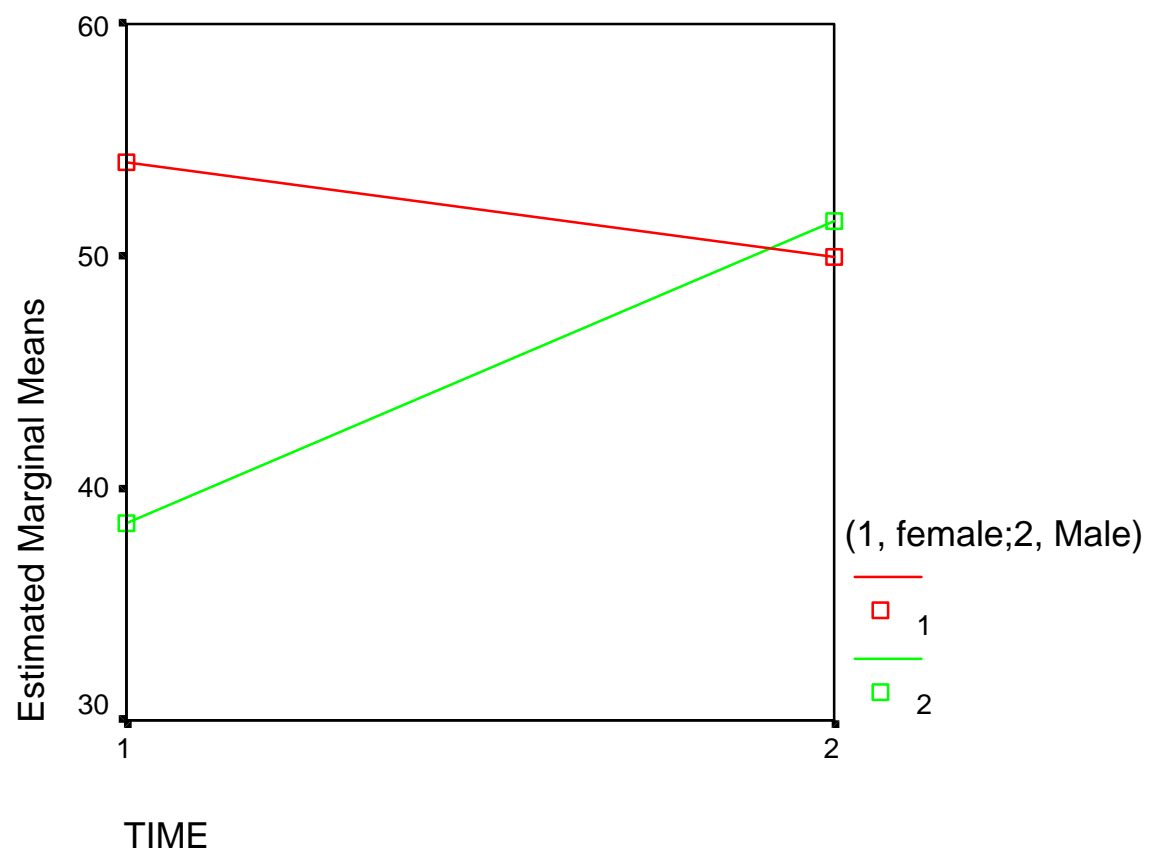

Figure 13. SPSS plot of the interaction between time and gender for left hip external rotation.

The plot in Figure 13 shows that the male and female groups had a different baseline mean left hip external range of motion. The mean left hip external rotation significantly changed by increasing in the females and decreasing in the males from baseline to retest. At retest the difference between mean left hip external rotation of the two groups was minimal. The results relating to the main effect of gender should be treated with caution in relation to left external hip rotation due to the interaction between time and gender.

Due to the small number of males who developed MTSS ( $\mathrm{N}=1)$, only the female subjects ( $\mathrm{N}=22$, of whom 13 developed MTSS) data was utilized in the following 
statistical analyses. A repeated measures ANOVA was performed to determine the relationship of left hip external rotation, left and right hip internal rotation and right ankle plantar flexion to injury, in the female subjects from baseline to retest as shown in Table 7. The means and standard deviations for the injured and non-injured female groups of left hip external rotation, right and left hip internal rotation and right ankle plantar flexion at baseline and retest are shown in Appendix 8.

\section{Table 7:}

Repeated measures ANOVA of the influence of left hip external rotation, left and right hip internal rotation, and right ankle plantar flexion on the incidence of MTSS from baseline (bl) to retest (rt) in the female subjects $(\mathrm{N}=22)$

\begin{tabular}{|c|c|c|c|c|c|}
\hline \multirow[t]{2}{*}{ Variable } & \multicolumn{2}{|c|}{ Change in Mean } & \multirow[t]{2}{*}{ Time (p) } & \multirow{2}{*}{$\begin{array}{l}\text { Injury } \\
\text { (p) }\end{array}$} & \multirow{2}{*}{$\begin{array}{c}\text { Time } x \\
\text { Injury }(p)\end{array}$} \\
\hline & Injured & Non-injured & & & \\
\hline L/Hip Ext Rot & -4.74 & -3.11 & 0.029 & 0.161 & 0.638 \\
\hline L/ Hip Int Rot & -9.92 & -6.55 & 0.001 & 0.340 & 0.450 \\
\hline R/Hip Int Rot & -6.31 & -3.89 & 0.038 & 0.245 & 0.604 \\
\hline $\mathrm{R} /$ ankle PF & -3.62 & -0.33 & 0.115 & 0.376 & 0.185 \\
\hline
\end{tabular}

(Note: R= Right; L= Left; Ext Rot = External Rotation; Int Rot = Internal Rotation; $\mathrm{PF}=$ Plantar flexion)

Table 7 indicates that in the 22 females, left hip external rotation did not change significantly from baseline to retest, and that any change did not influence the onset of MTSS. It can also be seen from Table 7 that for both the injured group and the noninjured group, the mean left hip external rotation decreases. The amount of decrease injured group $=-4.7$; non-injured $=-3.1$ ) was not significantly different between the two groups.

In this study, right hip internal rotation and right ankle plantar flexion did not change significantly from baseline to retest. However, left hip internal rotation did change significantly from baseline to retest, though this change did not influence the onset of MTSS. Table 7 shows that for both the injured and non-injured groups, the mean left hip internal rotation decreased. The amount of decrease (injured group $=-9.92$; noninjured group $=-6.55$ ) was not significantly different between the two groups. 
Gender differences are well documented in the literature to be a precipitating cause of overuse injury, more commonly in relation to stress fractures of the lower limb (Bennell et al., 1996). Bennell et al. (1996) demonstrated that gender and its interaction with hip external rotation has no relationship with the onset of stress fractures. Similarly, in this study the decreases in left hip external rotation in the female subjects did not influence the onset of MTSS.

\subsection{The occurrence of MTSS and its relationship to duration and intensity of physical activity}

Physical activity has been postulated in the literature as a contributing factor in the pathogenesis of several overuse syndromes of the lower limb. This particular part of the study aimed to investigate the relationship of physical activity levels to the incidence of MTSS.

\subsubsection{The relationship between duration of physical activity, injury, and injury side of MTSS}

A repeated measures ANOVA was used to determine whether the average weekly level of physical activity significantly influenced the onset of MTSS during the course of the study. Twelve of the injured subjects and nine non-injured subjects were included for this analysis as these were the only subjects to fully complete the physical activity survey prior to and during the present study. The mean weekly time spent for injured and noninjured groups at baseline (based on the six months prior to the present study) and retest (based on the mean over the 13 weeks of the present study) and the significance values for physical activity in relation to time, injury as the main effects and interaction between time and injury are detailed in Table 8. 
Table 8:

Mean weekly time in minutes (mins) spent completing physical activity at baseline (bl) and retest (rt) for injured $(\mathrm{N}=12)$ and non-injured groups $(\mathrm{N}=9)$. Repeated measures ANOVA significance values for physical activity in relation to time, injury and the interaction between time and injury

\begin{tabular}{|c|c|c|c|c|c|c|c|}
\hline \multirow[t]{3}{*}{ Variable } & \multicolumn{4}{|c|}{ Mean Weekly Time Spent (mins) } & \multirow[t]{3}{*}{ Time $(p)$} & \multirow[t]{3}{*}{ Injury } & \multirow{3}{*}{$\begin{array}{l}\text { Time } x \\
\text { Injury } \\
\text { (p) }\end{array}$} \\
\hline & & & Non & red & & & \\
\hline & bl & $\mathrm{Rt}$ & bl & Rt & & & \\
\hline \multirow{2}{*}{$\begin{array}{c}\text { Physical Activity } \\
\text { Change }\end{array}$} & 695 & 434 & 460 & 324 & 0.003 & 0.057 & 0.299 \\
\hline & \multicolumn{2}{|c|}{-261} & \multicolumn{2}{|c|}{-136} & & & \\
\hline
\end{tabular}

Table 8 indicates that at baseline the injured group exercised for greater time than the non-injured group. Both groups decreased their average weekly physical activity during the 13 week period. Such a decrease may be due to the intensity of physical activity participated in by the subjects. Whilst the subjects decreased their physical activity duration, the intensity of physical activity from baseline to retest may have been higher than prior to baseline. In the injured group the decrease in physical activity from baseline to retest was greater than the non-injured group (261 mins vs 136 mins). This difference was significant over time, however this change was not related to the onset of MTSS.

The 14 subjects who developed MTSS, experienced injuries on different sides with three left sided, two right sided and nine bilateral injuries. A repeated measures ANOVA was used to determine whether average weekly duration of physical activity significantly related to the injury side of MTSS. The mean weekly time spent in physical activity at baseline and retest for bilateral, left and right sided injured groups and the significance values in relation to time, injury side as the main effect and the interaction between time and injury are detailed in Table 9. 
Table 9:

Mean weekly time spent in minutes (mins) completing physical activity at baseline (bl) and retest ( $\mathrm{rt}$ ) for bilateral $(\mathrm{N}=9)$, left $(\mathrm{N}=2)$, right sided $(\mathrm{N}=1)$ MTSS groups and noninjured ( $\mathrm{N}=9$ )group. Repeated Measures ANOVA significance for time, injury side and the interaction between time and side of injury .

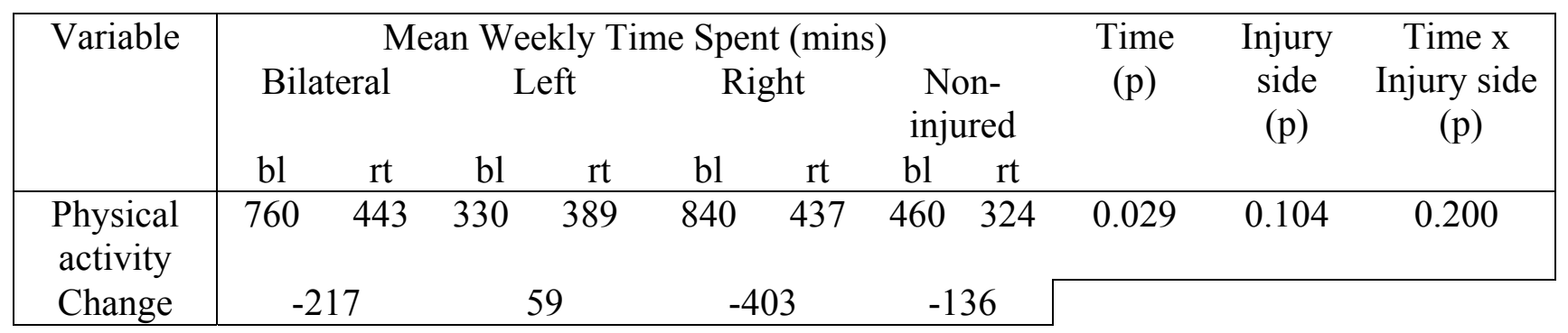

The results in Table 9 indicate that changes in the average weekly duration of physical activity was significantly different from baseline to retest. However, the changes in physical activity did not differ significantly between injury side groups. Therefore, physical activity was not demonstrated to be related to the side of onset of MTSS. Extraneous variables not controlled for such as bone mineral density, footwear or terrain trained upon may have influenced the results

In the present study, the side of injury may have also been determined by the level of bone mineral density of the tibial bone in that region. A study by Magnusson et al. (2001) of 18 athletes with long standing MTSS, found that those who had symptoms of MTSS unilaterally, had significantly lower bone mineral density on the unaffected side relative to the same region in control subjects. Further, symptomatic individuals did not exhibit a significant difference in bone mineral density between affected and unaffected sides. The symptoms of MTSS in the study by Magnusson et al. (2001) were not isolated to one side as was the case in the present study in nine of the injured subjects.

Other studies previously completed (Jordaan \& Schwellnus, 1994; Ross, 1993) have kept the level of physical activity constant across the sample in an attempt to identify other risk factors. These studies involved military or naval recruits because their basic training regime requires the subjects to complete the same type and level of physical activity. Whilst the level of physical activity did not contribute to the incidence 
of MTSS in the present study, other factors such as footwear worn and training terrain may have influenced the onset of MTSS.

Footwear, if inappropriate relative to the type and duration of activity, may increase the risk of injury. Many of the studies into overuse injuries involve military recruits all of whom wear military boots during their military duties. It is these military boots that have been implicated as a risk factor for stress fractures due to their lack of built-in shock absorbancy (Milgrom et al., 1985). However, the extent to which abnormal motion and associated compensations within the lower limb and foot occur is dependent on the type of terrain trained upon.

Terrain type has been implicated in the study completed by Milgrom et al. (1988) which investigated the foot/ground interface. It was concluded that hard irregular surfaces can predispose to overuse injury. This concurs with Beck (1998), who implicated irregular surfaces such as sand, as likely to increase the incidence of overuse injury. Richie et al. (1993) concluded that harder surfaces place a greater strain on the lower leg musculature and thus can increase the risk of the development of overuse injury. The type of surface trained upon was not controlled for in the present study.

Interestingly, both the bilateral group and the right sided group both exhibited decreases in the average total and weekly time spent on physical activity. Most of the literature (Orava et al., 1978; Messier \& Pitalla, 1988; Jordaan \& Schwellnus, 1994; Ross, 1993) identifies sudden increases in the intensity and duration of activities as a factor in the pathogenesis of MTSS. However, in the present study, the only group which exhibited a slight increase in physical activity time was the left sided group.

However, differences between the groups and therefore variations in physical activity time did not significantly influence the side of injury in MTSS. However such results must be treated with caution due to the low numbers of subjects in each of the injury groups and overall small sample size. 


\subsubsection{The relationship between the intensity of physical activity and the onset of MTSS}

A repeated measures ANOVA was used to determine whether intensity of physical activity significantly influenced the onset of MTSS during the course of the study. The total time spent completing walking, vigorous, and moderate physical activity in the six months prior to, and during the 13 week period of the study was compared for injured and non-injured groups. The significance values for physical activity in relation to time, injury as the main effects and interaction between time and injury are detailed in Table 10. In this part of the study, only 9 non-injured and 12 injured subjects completed the physical activity survey prior to and during the course of the study.

Table 10:

Mean weekly time spent completing in minutes (mins) walking (W), vigorous (V), and moderate $(\mathrm{M})$ physical activity in the six months before and during the study for noninjured $(\mathrm{N}=9)$ and injured $(\mathrm{N}=12)$. Repeated measures ANOVA significance values for physical activity intensity in relation to time, injury and the interaction between time and injury.

\begin{tabular}{|c|c|c|c|c|c|c|c|}
\hline \multirow[t]{3}{*}{ Variable } & \multicolumn{4}{|c|}{ Mean Weekly Time Spent (mins) } & \multirow[t]{3}{*}{ Time $(p)$} & \multirow[t]{3}{*}{ Injury (p) } & \multirow{3}{*}{$\begin{array}{c}\text { Time } \mathrm{x} \\
\text { Injury }(\mathrm{p})\end{array}$} \\
\hline & \multicolumn{4}{|c|}{ Injured Non-injured } & & & \\
\hline & Before & During & Before & During & & & \\
\hline W & 335 & 92 & 207 & 74 & 0.000 & 0.029 & 0.024 \\
\hline M & 105 & 99 & 67 & 55 & 0.572 & 0.128 & 0.866 \\
\hline $\mathrm{V}$ & 255 & 214 & 193 & 183 & 0.437 & 0.263 & 0.641 \\
\hline
\end{tabular}

Table 10 indicates that in the six months leading up to the commencement of the present study, the injured group on average exercised for greater time than the noninjured group in the three measured intensities: walking, vigorous and moderate activities. Both groups decreased their mean weekly time spent completing the three intensities of physical activity during the 13 week period. Such a decrease may have coincided with the subjects' change in lifestyle, university commitments whilst the discrepancy between the injured and non-injured groups may be in relation to the type and intensity of activity undertaken. 
In both the injured and non-injured groups, the activity with the largest decrease in mean weekly time spent was walking. These decreases were shown to be significant changes from baseline to retest. The injured group demonstrated a greater decrease in mean weekly time spent walking than the non-injured group from baseline to retest (233mins vs 133 mins). The decreases of mean weekly time spent walking between the injured and non-injured groups was significantly different over time $(p=0.000)$. Decreases in mean weekly time spent walking influenced the main effect of injury and hence the onset of MTSS $(p=0.029)$. A plot of the interaction between time and injury ( $p$ $=0.024$ ) for mean weekly time spent walking is represented in Figure 14 .

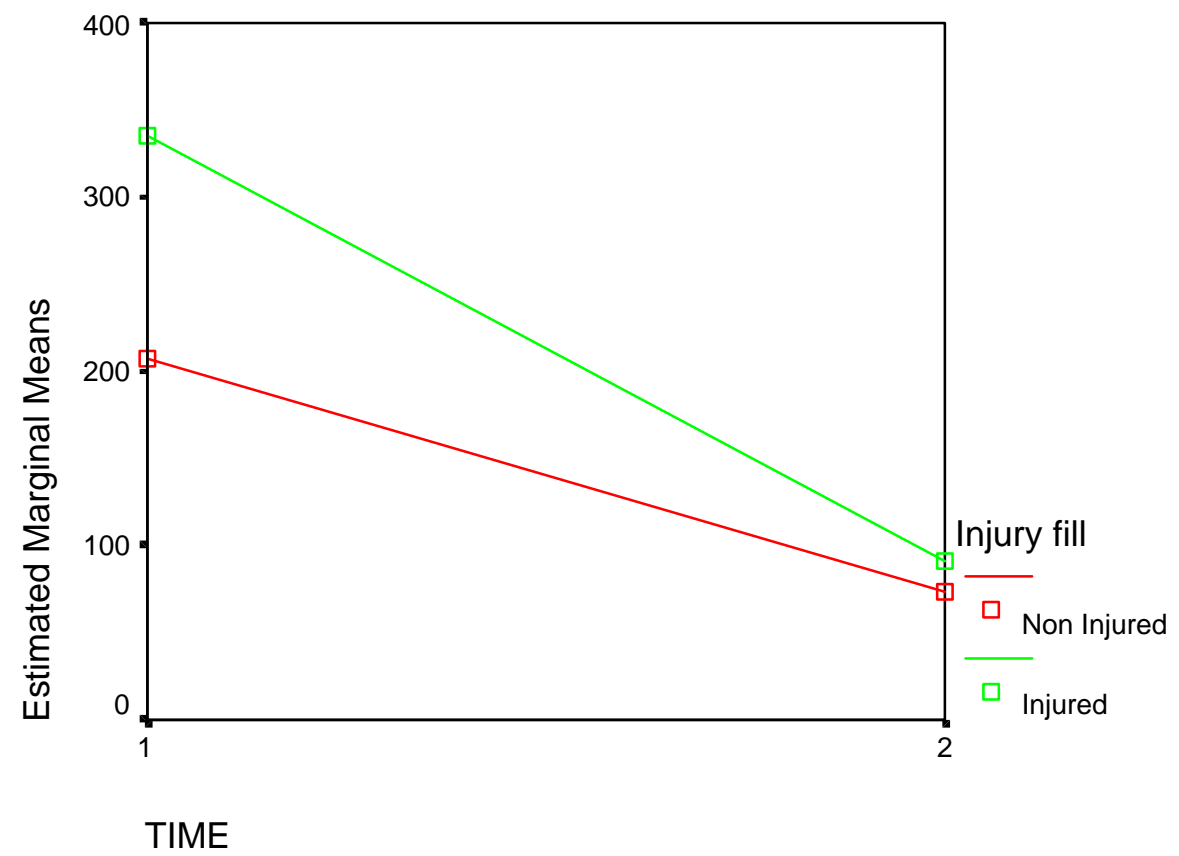

\section{Figure 14. SPSS plot of the interaction between time and injury for mean weekly time spent walking}

Figure 14 shows that at baseline the injured group on average was walking for much longer per week than the non-injured group. However, during the present study, it appears that both groups on average did a similar amount of walking per week on average (injured $=74$ mins; non-injured $=92$ mins). With such a low level of low intensity activity such as the walking, the injured group, in decreasing their average weekly time spent walking by a greater margin, may have been unduly limiting themselves to high 
intensity activity. Higher intensity activity could have placed a greater physical exertion on the medial musculature of the lower limb, such as soleus, and may have predisposed the subjects to the onset of MTSS. The main effect of injury must be treated with caution due to the interaction between time and injury.

A repeated measures ANOVA was used to determine whether intensity of physical activity significantly influenced the side of onset of MTSS during the course of the study. The total time spent completing walking, vigorous, and moderate physical activity in the six months prior to, and during the 13 week period of the study was compared for bilateral, right sided and left-sided groups. The significance values for physical activity in relation to time, injury as the main effects and interaction between time and injury are detailed in Table 11.

Table 11:

Mean weekly time spent completing in minutes (mins) walking (W), vigorous (V), and moderate (M) physical activity in the six months before and during the study for bilateral $(\mathrm{N}=9)$, right sided $(\mathrm{N}=1)$, left sided $(\mathrm{N}=2)$ injured and non-injured (9). Repeated measures ANOVA significance values for physical activity intensity in relation to time, injury and the interaction between time and injury.

\begin{tabular}{|c|c|c|c|c|c|c|c|c|c|c|c|}
\hline \multirow[t]{3}{*}{ Variable } & \multicolumn{8}{|c|}{ Mean Weekly Time Spent (mins) } & \multirow{3}{*}{$\begin{array}{l}\text { Time } \\
\text { (p) }\end{array}$} & \multirow{3}{*}{$\begin{array}{l}\text { Injury } \\
\text { (p) }\end{array}$} & Time \\
\hline & \multicolumn{2}{|c|}{ Bilateral } & \multicolumn{2}{|c|}{ Left } & \multicolumn{2}{|c|}{ Right } & \multicolumn{2}{|c|}{ Non-injured } & & & $\mathrm{x}$ \\
\hline & Before & During & Before & During & Before & During & Before & During & & & $\begin{array}{l}\text { Injury } \\
\text { (p) }\end{array}$ \\
\hline $\mathrm{W}$ & 380 & 101 & 150 & 71 & 300 & 46 & 207 & 74 & 0.000 & 0.011 & 0.008 \\
\hline M & 113 & 87 & 60 & 134 & 120 & 138 & 67 & 55 & 0.531 & 0.492 & 0.278 \\
\hline $\mathrm{V}$ & 267 & 222 & 120 & 174 & 420 & 219 & 193 & 183 & 0.309 & 0.264 & 0.531 \\
\hline
\end{tabular}

Table 11 indicates that in the six months leading up to the commencement of the present study, all groups on average exercised for greater time in relation to the three measured intensities: walking, vigorous and moderate activities. However, in the left and right-sided injury groups, mean weekly level of moderate activity intensity was seen to increase. The changes for all groups for the three measure intensities may have coincided with the subjects' change in lifestyle, and university commitments .Whilst the mean weekly time spent changed in all groups for moderate and vigorous activity intensity, no significant differences were noted between the groups, and these changes was not related to the onset of MTSS. 
In all groups, the activity intensity with the largest change in mean weekly time spent was walking. All groups demonstrated a decrease in mean weekly time spent walking from baseline to retest. These decreases were shown to be significant changes ( $p$ $=0.000)$. The bilateral injury group demonstrated the greatest decrease in mean weekly time spent walking compared to the other groups from baseline to retest The decreases of mean weekly time spent walking between the injured and non-injured groups was significantly different $(\mathrm{p}=0.011)$.. A plot of the significant interaction $(\mathrm{p}=0.008)$ between time and injury site for mean weekly time spent walking is represented in Figure 15.

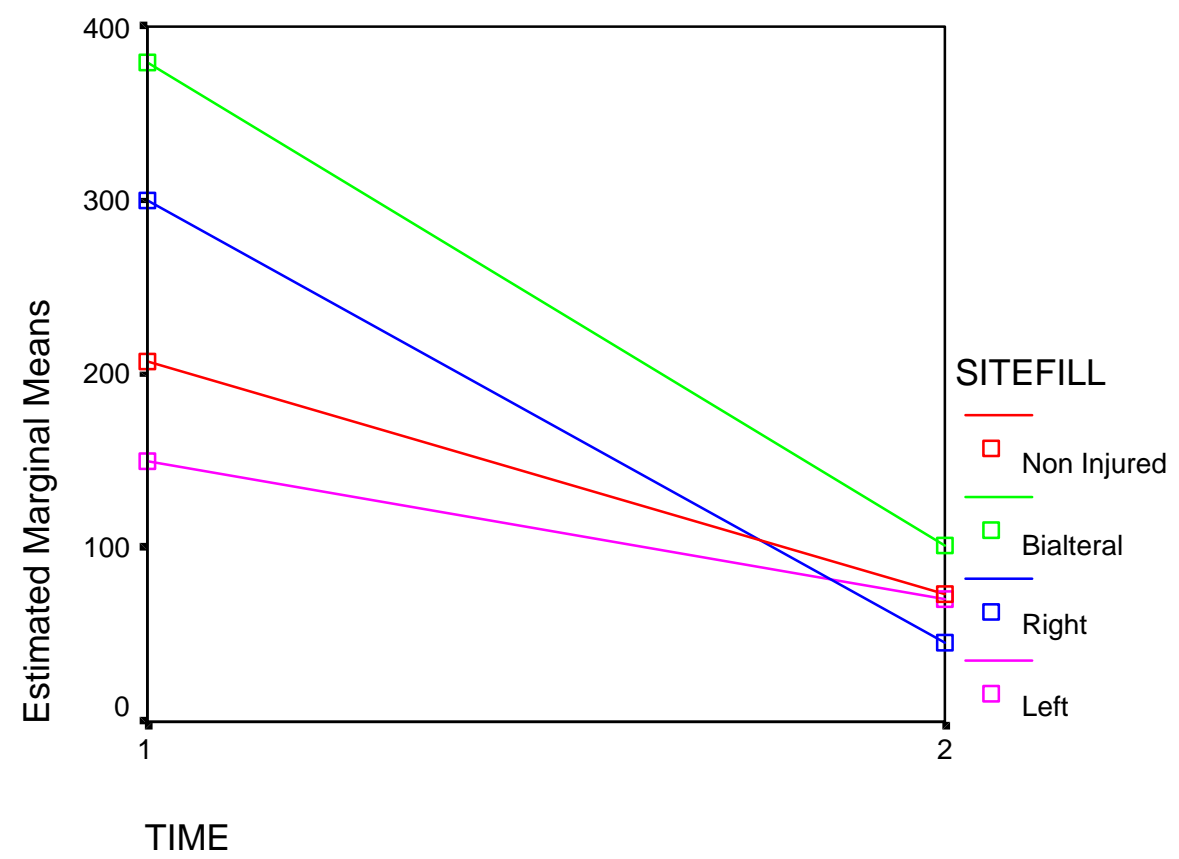

\section{Figure 15. SPSS plot for the interaction between time and injury site in relation to mean weekly time spent walking}

Figure 15 shows that at baseline the bilateral group on average was walking for the greatest length of time per week. It is the difference in the amount of change between the groups that influenced the side of onset of MTSS in the injured subjects. A StudentNewman-Keuls post hoc analysis was utilized to determine which of the four groups influenced the interaction between the main effect of injury side and time. From the analysis, the greatest difference existed between the bilateral group and the other three 
groups $(\mathrm{p}<0.05)$. However, these results must be treated with caution due to the low numbers of subjects in each group and the interaction between the main effect of injury side and time.

Some studies (for example, Orava et al., 1978; Messier \& Pitalla, 1988; Jordaan \& Schwellnus, 1994; Ross, 1993), have found a relationship between stress fractures of the lower limb, and training intensity and duration.. In the study by Orava, et al. (1978) it was reported that a change in training intensity levels from low to high was responsible for the onset of stress fractures of the tibia, a common end-stage condition of MTSS. However in the present study, intensity of activity was not seen to influence the onset of MTSS.

Messier and Pitalla (1988) also demonstrated a link between shin splints and a recent sudden increase in activity. Messier and Pitalla (1988), through their comparison of those with shin splints and those without injury, found that those with no injury had been running for the most years training at a moderate intensity. Conversely those with shin splints had been running the least number of years. However in the present study, those who had experienced the greatest drop in physical activity time were the subjects to develop MTSS bilaterally.

\subsection{Physical activity levels and variables in joint range of motion as predictors of MTSS onset}

A logistic stepwise regression was undertaken to investigate whether any of the range of motion test variables and other variables such as gender, height, weight and body mass index, could be intrinsic predictors of MTSS injury. Physical activity was investigated as an extrinsic predictor of MTSS injury.

According to the reliability statistical analyses completed as part of this study, only reliable variables as determined by the ICC were utilized in the logistic stepwise regression. The significant predictor of MTSS in this group of 28 subjects is shown in Table 12. 
Table 12:

Change in mean degrees of knee extension for the non-injured $(\mathrm{N}=14)$ and injured $(\mathrm{N}=14)$ MTSS groups. Significance value for this change and odds ratio for knee extension as a predictor of MTSS

\begin{tabular}{|c|cccccc|}
\hline Variable & \multicolumn{2}{|c|}{ Mean (degrees) } & Significance (p) & Odds Ratio & \multicolumn{2}{c|}{ 95\% CI for Odds Ratio } \\
& Injured & $\begin{array}{c}\text { Non- } \\
\text { Injured }\end{array}$ & & & Lower & Upper \\
\hline R/ Knee Ext & 3.43 & 0.07 & 0.028 & 1.514 & 1.045 & 2.192 \\
\hline
\end{tabular}

(Note: R/Knee Ext = Right Knee Extension)

The results of the logistic stepwise regression indicated that right knee extension was the only significant predictor of MTSS injury in the group of 28 subjects followed from baseline through to retest. From Table 12, it can be seen that subjects were 1.5 times more likely to develop MTSS if they exhibited an increase in right knee extension (that is, hyperextension). This can be seen in the three degrees difference in the mean baseline values for right knee extension between the injured and non-injured groups.

Knee hyperextension has been postulated as a possible risk factor for lower limb injuries in general by Neely (1998). However, military studies such as Giladi et al., (1987), Montgomery et al. (1989), Cowan et al. (1996) have not isolated knee hyperextension as a factor in the pathology of overuse injury and more specifically tibial stress fractures. However, military studies generally investigate males and knee hyperextension is generally a female phenomenon. In the present study, knee hyperextension was found to be a predictor of injury. This may be in part due to the higher numbers of female subjects in the present studies than military studies. Knee hyperextension may increase stride length during running which can result in a compensatory rapid contact phase pronation of the rear foot, thus causing overuse of the antagonistic musculature like the soleus muscle (Michael \& Holder, 1985; Detmer, 1986; Beck \& Osternig, 1994).

The literature tends to suffer from a lack of predictive correlational studies which utilize logistical regression analyses to identify previously hypothesized intrinsic and extrinsic predictors of MTSS. This makes it difficult to directly compare this part of the study to previously completed research. 
Hip extension and knee flexion were not predictors in the incidence of MTSS in the present study. The hamstrings have a role in extending the thigh at the hip joint whilst flexing and medially rotating the leg at the knee joint (Snell, 1995). Messier and Pittala (1988) in their investigation of 64 recreational and competitive runners did not find a relationship between flexibility (predominately of the hamstrings) and the incidence of overuse injuries (17 in the shin splints group) with the minimal differences of the hamstrings in the injured and non-injured groups not demonstrating any significance. The decrease in the mean of both the injured and non-injured groups also did not differ significantly in the present study. The present study and that by Messier and Pitalla (1988) both have subjects both from non-military populations who developed similar overuse injuries.

In the present study, height was not a significant predictor of MTSS. It has been hypothesized that increased height, and thus higher centre of gravity may predispose a person to overuse injury (Tameila et al., 1990). Further, Tameila et al. implicated greater limb length as requiring greater leverage resulting in more stress on limbs and injury. Studies by Finestone et al. (1991) and Ross and Woodward (1994) did not find a correlation between heights and overuse injury. Alternatively, Jones, Bovee et al. (1993), in 310 military recruits (124 male and 186 female), found in their prospective study over eight weeks that the shortest $25 \%$ of female recruits were 1.7 higher risk of developing an overuse injury than the $75 \%$ taller recruits. The contradiction between the present study and that by Jones, Bovee et al., (1993) may be due to differing sample sizes, whereby the latter study with the larger sample size would have an increased likelihood of demonstrating relationship between heights and overuse injury. Also, the range of height of subjects in the study by Jones, Bovee et al. (1993) may have been larger and more reflective of the general population than in the present study which investigated university students. In the present study, height did not significantly differ between the injured and non-injured groups and thus was not a factor in the development of MTSS.

Along with height, body weight has not been shown to significantly influence the onset of overuse injury. Military studies (Finestone et al., 1991; Ross \& Woodward, 1994), have failed to find a link between increased or decreased (abnormal) bodyweight. 
The majority of studies investigating a link between bodyweight and overuse injury involve military subjects. The rationale behind further investigation into bodyweight was to see if a link could be demonstrated in non-military populations in relation to MTSS. The current study did not detect a relationship between the incidence of MTSS and bodyweight. This means that the bodyweight between the injured and non-injured groups did not differ significantly from baseline to retest and thus were not a factor in the development of MTSS.

DeLacerda (1980) discussed the importance of body mass indices (BMI) in overuse injury. As the speed of ambulation or running increases, supportive and propulsive stress on the lower limbs increase, which is in part due to body weight. In a study by Ross and Woodward. (1994), Australian Air Force recruits with a BMI greater than 27 had a seven times greater chance of developing an overuse injury than those with a BMI under 20. Jones, Bovee et al. (1993) found in their study that high BMI (not specified) did increase the risk of lower limb overuse injury in men. However, in a study by Jones, Cowan et al. (1993), BMI was not found to be significant in the pathogenesis of overuse injury. The present study is supports the findings with the studies by Delacereda (1980) and Jones, Cowan et al. (1993) in that BMI was not shown to affect the onset of MTSS. In the present study, average BMI for both injured and non-injured groups were within normal ranges. 


\section{CHAPTER FIVE - SUMMARY AND CONCLUSIONS}

\subsection{Introduction}

This research is the first to simultaneously investigate range of motion at the hip, knee, ankle, first metatarsophalangeal joints (MPJ) and RCSP in relation to MTSS within a single study. Furthermore, a direct relationship between a biomechanical anomaly in the kinetic chain of the lower extremity and MTSS has never been established.

The purpose of this study was to prospectively determine whether:

1. Variations in joint range of motion in the lower limb increase the incidence of MTSS.

2. The amount and intensity of physical activity influences the onset of MTSS.

3. Joint ranges of motion and the amount and intensity of physical activity enable the prediction of those predisposed to developing MTSS.

The above mentioned objectives were utilized to develop three research questions for this study and they were whether:

1. Differences in hip, knee, ankle, RCSP, and first MPJ range of motion increase the incidence of MTSS.

2. Differences in physical activity levels increase the incidence of MTSS.

3. Differences in hip, knee, ankle, RCSP, and first MPJ range of motion and physical activity can be used as predictors for the development of MTSS

\subsection{Procedure}

The data collection phase of this study took place over a 13 week period. The subjects were first year students from the School of Human Movement and Sport Sciences at the University of Ballarat who volunteered for the study. Fifty six subjects presented for baseline testing. The baseline testing involved passive goniometric measurements of the hip, knee, ankle, RCSP, and first MPJ. Over the course of thirteen weeks the subjects were enrolled in the Fundamentals of Fitness unit in semester one at 
the University of Ballarat. This is so the subjects could be followed over the course of this unit which consisted of a training component. It was acknowledged by the researchers that despite undertaking the same training program whilst at University, that some subjects were involved in external training programs. For this reason, each subject was invited to complete a survey of their physical activity levels for each of the thirteen weeks between baseline testing and retesting.

Only twenty eight (28) subjects returned for the retest and 14 (50\%) had developed MTSS. Of these fourteen subjects who developed MTSS, nine had symptoms bilaterally, three on the left, and two on the right. Eight subjects returned for a third test to determine the reliability of the measurements being taken.

Only twelve of the tested variables were found to be reliable when analysed with ICC statistical tests. Through repeated measures ANOVA statistical tests, range of motion at the hip, knee, ankle, RCSP, and first MPJ Dorsi flexion were not seen to have a significant effect on the development of MTSS in the 28 subjects followed from baseline to retest. However, right first MPJ Dorsi flexion was seen to significantly change over time $(p=0.002)$, though this increase did not influence the incidence of MTSS.

Of the 28 subjects followed from baseline through to retest, 22 were female and six were male. The change in the range of motion measures from baseline to retest in the male and female groups was shown to be significantly different for right hip internal rotation $(p=0.001)$, right ankle plantar flexion $(p=0.001)$, left hip internal rotation $(p=0.000)$ with an interaction between time and gender for left hip external rotation $(\mathrm{p}=0.000)$. However, right and left hip internal rotation, right ankle plantar flexion and left hip external rotation did not to influence the onset of MTSS in either gender.

Through repeated measures AVOVA, level of physical activity failed to demonstrate a significant effect on the incidence of MTSS. However, a difference existed between the injured and non-injured groups over time $(p=0.003)$, whereby the injured group had the greatest decrease in mean weekly time spent completing physical activity. 
Physical activity levels was not shown to be significant in its effect on the injury side of those who developed MTSS. There was a relationship found between the intensity of activity and the side of injury. Changes in mean weekly time spent walking did change significantly over time $(p=0.000)$, with the greater decrease of the injured group influencing the onset of injury of MTSS $(\mathrm{p}=0.029)$. Similarly, decreases in mean weekly time spent walking were significantly different between injury side groups $(\mathrm{p}=$ 0.011 ) with the greatest decrease existing between the bilateral group, and the other three groups $(\mathrm{p}<0.05)$.

Physical activity was not shown to be a predictor of the incidence of MTSS using logistic stepwise regression analysis Right knee extension was demonstrated to be a significant predictor of the development of MTSS in the sample of 28 subjects in this study using a logistic stepwise regression analysis. Those subjects with increased right knee hyperextension were 1.5 times more likely to develop MTSS. All other range of motion variables, age, gender, height, weight, and BMI were not found to be predictors of the incidence of MTSS.

\subsection{Conclusions}

The following conclusions were drawn from this study of the 28 subjects followed from baseline to retest in the thirteen week period of the study.

- All range of motion measures taken were not shown to significantly influence the incidence of MTSS.

- Physical activity levels did not significantly influence the onset of MTSS.

- Increased right knee extension was seen to be a predictor of the onset of MTSS.

- Mean weekly time spent walking did influence the site of injury.

- In the 12 subjects surveyed, those who developed MTSS bilaterally demonstrated the greatest decrease in average weekly time spent walking. 
Conclusions pertaining to range of motion measures must be treated with caution due to low reliability of some variables and low number of subjects studied.

\subsection{Recommendations for Further Study}

Many of the factors implicated and their mechanism in the pathogenesis of many overuse injuries still remain unclear. Recommendations, based on the results of this study, are made for possible future research.

1. A more reliable form of measurement needs be considered in relation to the range of motion investigated in this study,

2. Future studies could investigate the relationship between the type of footwear and terrain trained upon and the onset of MTSS.

3. Future studies could investigate different styles of orthotic interventions and their effectiveness in reducing the onset of MTSS.

4. Prospective studies could investigate whether restricting excessive knee extension reduces the risk of the development of MTSS.

5. Prospective studies could investigate the dosages and intensity of activity, for example, the relationship between a decreased dosage of activity and the onset of MTSS.

Prospective studies could investigate the effect of differences in Bone Mineral density between subjects and the effect of this on the onset of MTSS. 


\section{REFERENCES}

Armstrong, T., Bauman, A., \& Davies, J. (2000). Physical activity patterns of Australian adults: Results of the 1999 National Physical Activity Survey. Canberra: Australian Institute of Health and Welfare.

Australian Sports Commission (ASC). (1998). Active Australia National Physical Activity Survey 1997. Canberra: ASC.

Bagget, B.D., \& Young. G. (1993) Ankle Joint Dorsi flexion. Establishment of a Normal Range. Journal of the American Podiatric Medical Association, 83(5), 251-254.

Batt, M.E. (1995). Shin Splints: A Review of the terminology. Clinical Journal of Sports Medicine, 5(1), 53-57.

Batt, M.E., Ugalde, V., Anderson, M.W., \& Shelton, D.K. (1998). A prospective controlled study of diagnostic imaging for acute shin splints. Medicine \& Science Sports \& Exercise, 30(11), 1564-1571.

Bauman, A., Owen, N., \& Leslie, E. (2000). Physical activity and health outcomes: Epidemiological evidence, national guidelines and public health initiatives. Australian Journal of Nutrition \& Dietetics, 57(4), 224-229.

Bauman, A., Wright, C., \& Brown, W. (2000). Physical activity recommendations for Australians: A position paper prepared by The Heart Foundation Physical Activity Program Committee. Canberra: National Heart Foundation.

Beck, B.R. (1998). Tibial stress injuries. An aetiological review for the purposes of guiding management. Sports Medicine, 26(4), 265-279.

Beck, B.R., \& Osternig, L.R. (1994). Medial Tibial Stress Syndrome: The location of muscles in the leg in relation to symptoms. The Journal of Bone and Joint Surgery, 76A(4), 1057-1061. 
Beck, T.J., Ruff, C.B., Shaffer, R.A., Betsinger, K., Trone, D.W., \& Brodine, S.K. (2000). Stress Fractures in Military Recruits: Gender Differences in Muscle and Bone Susceptibility Factors. Bone, 27(3), 437-444.

Bennell, K., Malcolm, S.A., Thomas, S.A., Reid, S.J., Bruckner, P.D., Ebeling, P.R., \& Wark, J.D. (1996). Risk factors for stress fractures in track and field Athletes: A twelve month prospective Study, The American Journal of Sports Medicine, 24(6), 810-818.

Bennett, J.E., Reinking, M.F., Pluener, B., Pentel, A., Seaton, M., \& Killian, C. (2001). Factors contributing to the development of medial tibial stress syndrome in high school runners. Orthopaedic and Sports Physical Therapy, 31(9), 504-510.

Bierma-Zeinstra, S.M.A., Bohnen, A.M., Ramlal, R., Ridderkhoff, J., Verhaar, J.A.N., \& Prins, A. (1998). Comparison between two devices for measuring hip joint motions. Clinical Rehabilitation, 12, 497-505.

Boone, D.C., \& Azen, S.P. (1979). Normal range of motion of joints in male subjects. The Journal of Bone and Joint Surgery, 61A(5), 756-759.

Brunet, M.E., Cook, S.D., Brinker, M.R., \& Dickinson, J.A. (1990). A survey of running injuries in 1505 competitive and recreational runners. The Journal of Sports Medicine and Physical Fitness,30(3), 307-315.

Bull, F.C. (2000). The reliability and validity of recall of moderate-intensity physical activity. Perth: Department of Public Health, University of Western Australia.

Chao, E.Y.S., Neluheni, E.V.D., Hsu, R.W.W., Paley, D. (1994). Biomechanics of malalignment. Orthopedic Clinics of North America,25(3), 379-386.

Cibulka, M.T., Sinacore, A.D.R., \& Mueller, M.J. (1994). Shin splints and forefoot contact running: a case report. Journal of Orthopedic Sports and Physical Therapy,20(2), 98-102. 
Clapper, M.P., \& Wolf, S.L. (1988). Comparison of the reliability of the orthoranger and the standard goniometer for assessing active lower extremity range of motion. Physical Therapy, 68(2), 214-218.

Close, J.R., Inman,V.T., Poor, P.M., \& Todd, F.N. (1967). The function of the subtalar joint. Clinical Orthopedics and Related Research, 50, 159-179.

Cook, A., Gorman, I., \& Morris, J. (1988). Evaluation of the neutral position of the subtalar joint. Journal of the American Podiatry Association, 78(9), 449-451.

Cowan, D.N., Jones, B.H., Frykman, P.N., Polly, D.W., Harman, E.A, Rosenstein, R.M., \& Rosenstein, M.T. (1996). Lower limb morphology and risk of overuse injury in male infantry trainees. Medicine and Science in Sports and Exercise, 28(8), 945952.

Cowan, D.N., Jones, B.H., \& Robinson, J.R. (1993). Foot morphologic characteristics and risk of Exercise-Related Injury. Archives of Family Medicine, 2, 773-777.

DeLacerda, F.G. (1980). A Study of anatomical factors involved in shin splints. The Journal of Orthopedic and Sports Physical Therapy, 2(2), 55-59.

Department of Health and Ageing (DHA). (1999). National physical activity guidelines for Australians. Canberra: DHA.

Detmer, D.E. (1986). Chronic shin splints: Classification and management of medial tibial stress syndrome. Sports Medicine, 3, 436-446.

Ekstrand, J., Wiktorsson, M., Oberg, B., Gillquist, J. (1982). Lower extremity goniometric measurements: A study to determine their reliability. Archives of Physical and Medical Rehabilitation, 63,171-175.

Elveru, R.A., Rothstein, J.M., \& Lamb, R.L. (1988). Goniometric reliability in the clinical setting: Subtalar and ankle joint measurements. Physical Therapy, 68(5), $672-677$. 
Eliasziw, M., Young, S.L., Woodbury, M.G., \& Field, K.F. (1994). Statistical methodology for the concurrent assessment of interrater and intrarater reliability: using goniometric measurements as an example. Physical Therapy ,74(8), 777-788

Eriksen, E.F., Melsen, F., \& Mosekilde, L. (1984). Reconstruction of the resorptive site in iliac trabecular bone: a kinetic model for bone resorption in 20 normal individuals. Metab. Bone Dis \& Rel. Res,5, 235-242.

Fallon, K.E. (1996). Musculoskeletal injuries in the ultra marathon: The 1990 Westfield Sydney to Melbourne run. British Journal of Sports Medicine,30, 319-323.

Finestone, A., Shlamkovitch, N., Eldad, A., \& Wosk, J. (1991). Risk Factors for Stress Fractures among Israeli Infantry Recruits. Military Medicine, 156(10), 528-530.

Fredericson, M., Bergman, A.G., Hoffman, K.L., \& Dillingham, M.S. (1995). Tibial stress reaction in runners. Correlation of clinical symptoms and scinitgraphy with a new MRI grading system. The American Journal of Sports Medicine, 23(4), 472481.

Freeman, A.C. (1990). A study of inter-observer and intra-observer reliability in the measurement of resting calcaneal stance position, and neutral calcaneal stance position. Australian Podiatrist,10-13.

Frey, J.H. (1983). Survey research by telephone. Newbury Park, CA: Sage Publications

Friberg, O. (1982). Leg length symmetry in stress fractures: A clinical and radiological study. Journal of Sports Medicine, 22, 485-488.

Gehlsen, G.M., \& Seger, A. (1980). Selected measures of angular displacement, strength, and flexibility in subjects with and without shin splints. Research Quarterly for Exercise and Sport, 51(3), 478-485.

Giladi, M., Milgrom, C., Stein, M., Kashtan, H., Margulies, J., Chisin, R., Steinberg, R., Kedem, R., Aharonson, Z., \& Simkin, A. (1987). External rotation of the hip: A 
predictor of risk for stress fractures. Clinical Orthopaedics and Related Research, 216, 131-134.

Hartig, D.E., \& Henderson, J.M. (1999). Increasing hamstring flexibility decreases lower extremity overuse injuries in basic trainees. The American Journal of Sports Medicine, 27(2), 173-176.

Hoffman, J.R., Chapnik, L., Shamis, A., Givon, U., \& Davidson, B. (1999). The effect of leg strength on the incidence of lower extremity overuse injuries during military training. Military Medicine, 164(2), 153-156.

Holder, L.E., \& Michael, R.H. (1984). The specific scintigraphic pattern of shin splints in the lower leg": Concise communication. Journal of Nuclear Medicine,25(8) 865869.

Hopkins, W.G. (2000). Measures of reliability in sports medicine and science. Sports Medicine, 30(1), 1-15.

Johnell, O., Rausing, A., Wedeberg, B., \& Westlin, N. (1982). Morphologic bone changes in shin splints. Clinical Orthopedics and Related Research, 167, 180-184.

Jones, B.H., Bovee, M.W., Harris, J.McA., \& Cowan, D.N. (1993). Intrinsic risk factors for exercise-related injuries among male and female army athletes. The American Journal of Sports Medicine, 21(5), 705-710.

Jones, B.H., Cowan, D.N., Tomlinson, J.P., Robinson, J.R., Polly, D.W., \& Frykman, P.N. (1993). Epidemiology of injuries associated with physical training among young men in the army. Medicine and Science in Sports and Exercise, 25(2),197203.

Jordaan, G., \& Schwellnus, P.M. (1994). The incidence of overuse injuries in military recruits during basic military training. Military Medicine, 159(6), 421-426. 
Kaufman, K.R., Brodine, S.K., Shaffer, R.A., Johnson, C.W., \& Cullison, T.R. (1999). The effect of foot structure and range of motion on musculoskeletal overuse injuries. The American Journal of Sports Medicine, 27(5), 585-593.

Korpelainen, R., Orava, S., Karpakka, J., Slira, P., \& Hulkko, A. (2001). Risk factors for recurrent stress fractures in athletes. The American Journal of Sports Medicine, 29(3), 304-310.

Kortebein, P.M., Kaufman, K.R., Basford, J.R., \& Stuart, M.J. (2000). Medial tibial stress syndrome. Medicine \& Science in Sports and Exercise, 32(3 Suppl), 27-33.

Krivickas, L.S. (1997). Anatomical factors associated with overuse sports injuries. Sports Medicine, 24(2), 132-146.

Macleod, M.A., Houston, A.S., \& Saunders, I. (1999). Incidence of trauma related stress fractures and shin splints in male and female army recruits; retrospective case study. British Medical Journal,318(7175), 29.

Magnusson, H.I., Westlin, N.F., Nvqvist, F., Gardsell, P., Seeman, F., \& Karlsson, M.K. (2001). Abnormally decreased regional bone density in athletes with medial tibial stress syndrome. American Journal of Sports Medicine 29(6), 712-715.

Menz, H.B, (1995) Clinical Hindfoot Measurement; A critical review of the Literature. The Foot, 5, 57-64.

Menz, H.B, \& Keenan, A. (1997) Reliability of Two Instruments in the Measurement of Closed-Chain Subtalar Joint Positions. The Foot: International Journal of Clinical Foot Science 7(4), 194-201.

Messier, S.P., \& Pittala, K.A. (1988).Etiologic factors associated with selected running injuries. Medicine and Science in Sports and Exercise, 20(5), 501-505.

Michael, R.H., \& Holder, L.E. (1985). The soleus syndrome: A cause of medial tibial stress (shin splints). The American Journal of Sports Medicine, 13(2), 87-94. 
Milgrom, C. (1989). The Israeli elite infantry recruit: a model for understanding the biomechanics of stress fractures. J R Coll Surg Edinb, 34(6 Suppl), 18-22.

Milgrom, C., Finestone, A., Shlamkovitch, N., Rand, N., Lev, B., Simkin, A., Wiener, M. (1994). Youth as a risk factor for stress fracture: A study of 783 infantry recruits. The Journal of Bone and Joint Surgery, 76, 20-2.

Milgrom, C., Giladi, M., Kashtan, H., Simkin, A., Chisin, R., Margulies, J., Steinberg, R., Aharonson, Z., Stein, M. (1985). A prospective study of the effect of a shockabsorbing orthotic device on the incidence of stress fractures in military recruits. Foot \& Ankle, 6(2), 101-104.

Milgrom, C., Giladi, M., Simkin, A., Rand, N., Kedem, R., Kashtan, H., \& Stein, M. (1988). An analysis of the biomechanical mechanism of tibial stress fractures among Israeli infantry recruits. A prospective study. Clinical Orthopedics, 231, 216-221.

Milgrom, C., Giladi, M., Stein, M., Kashtan, H., Margulies, J.Y., Chisin, R., Steinberg, R., \& Abaronson, Z. (1985). Stress fractures in military recruits. A prospective study showing an unusually high incidence. The Journal of Bone and Joint Surgery, 67(5), 732-735.

Montgomery, L.C., Nelson, F.R.T., Norton, J.P., \& Deuster, P.A. (1989). Orthopedic history and examination in the etiology of overuse injuries. Medicine and Science in Sports and Exercise, 21(3), 237-243.

Mubarak, S.J., Gould, R.N., Lee, Y.F., Schmidt, D.A., \& Hargens, A.R. (1982). The medial tibial stress syndrome. A cause of shin splints. American Journal of Sports Medicine, 10(4), 201-205.

Neely, F.G. (1998). Intrinsic risk factors for exercise related lower limb injuries. Sports Medicine, 26(4), 253-263.

Norkin, C.C., \& White, D.J. (1995). Measurement of joint motion: A guide to goniometry $\left(2^{\text {nd }}\right.$ Ed.). Philadelphia: F.A. Davis Company. 
Orava, S., Puranen, J., \& Ala-Ketola, L. (1978). Stress fractures caused by physical exercise. Acta Orthop Scand, 49, 19-27.

Pavol, M.J., \& Grabiner, M.D. (2000). Knee strength variability between individuals across ranges of motion and hip angles. Medicine and Science in Sports and Exercise, 32(5), 985-992.

Payne, C.B., \& Danaberg, H.J. (1997). Sagittal plane facilitation model of the foot. Australasian Journal of Podiatric Medicine, 31 (1), 7-11.

Puranen, J. (1974). Medial tibial stress syndrome: Exercise ischaemia in the medial fascial compartment of the leg. The Journal of Bone and Joint Surgery, 56B(4), $712-715$.

Redmond, A., Burns, J., \& Crosbie, J. (2001). A rating system for the quantification of foot posture: The foot posture index. Gait \& Posture.

Reynolds, K.L., White, J.S., Knapik, J.J., Witt, C.E., \& Amoroso, P.J. (1999). Injuries and risk factors in a 100 mile $(161 \mathrm{~km})$ infantry road march. Preventative Medicine, $28,167-173$.

Richie, D.H., DeVries, H.A., \& Endo, C.K. (1993). Shin muscle activity and sports surfaces: An electromyographic study. Journal of the American Podiatry Association. 83(4), 181-190.

Roach, K.E., \& Miles, T.P. (1991). Normal hip and knee active range of motion: The relationship to age. Physical Therapy, 71(9), 656-665.

Roass, A., \& Andersson, G.B.J. (1982). Normal range of motion of the hip, knee, and ankle joints in male subjects, 30-40 years of age. Acta Orthop Scand, 53, 205-208.

Rome, K., \& Cowleson, F. (1996). A reliability study of the universal goniometer, fluid goniometer, and electrogoniometer for the measurement of ankle Dorsi flexion. Foot \& Ankle, 17(1), 28-32. 
Root, M.L., Orien, W.P., \& Weed, J.H. (1977). Normal and abnormal function of the foot. Clinical Biomechanics (vol II). Clinical Biomechanical Corporation: Los Angeles.

Ross, J. (1993). A review of lower limb overuse injuries during basic military training. Part 1:Types of overuse injuries. Military Medicine, 158(6), 410-415.

Ross, J. (1993). A review of lower limb overuse injuries during basic military training, Part 2: Prevention of overuse injuries. Military Medicine,158(6), 415-420.

Ross, J., \& Woodward, A. (1994). Risk factors for injury during basic military training. Is there a social element to injury pathogenesis? JOM, 36(10), 1120-1126.

Rudzki, S.J. (1997). Injuries in Australian army recruits. Part II: Location and cause of injuries seen in recruits. Military Medicine, 162(7), 477-481.

Saxena, A., O'Brien, T., \& Bunce, D. (1990). Anatomic dissection of the tibialis posterior muscle and its correlation to medial tibial stress syndrome. The Journal of Foot Surgery, 29(2), 105-108.

Sommer, H.L., \& Vallentyne, S.W. (1995). Effect of foot posture on the incidence of medial tibial stress syndrome. Medicine and Science in Sports and Exercise, 27(6), 800-804.

Tax, H. (1985). Podopaediatrics ( $2^{\text {nd }}$ Ed.). Baltimore: Williams \& Williams.

Taimela, S., Kujala, U.M., \& Ostermen, K. (1990). Intrinsic risk factors and athletic injuries. Sports Medicine, 9(4), 205-215.

Taunton, J.E., McKenzie, D.C., \& Clement, D.B. (1988). The role of biomechanics in the epidemiology of injuries. Sports Medicine, 6, 107-120.

Touliopolous, S., \& Hershman, E.B. (1999). Lower leg pain: Diagnosis and treatment of compartment syndromes and other pain syndromes of the leg. Sports Medicine, 27(3), 193-204. 
Twellar, M., Verstappen, T.J., Husan, A., \& van Mechelen, W. (1997). Physical characteristics as risk factors for sports injuries: A four year prospective study. International Journal of Sports Medicine, 18(1), 66-71.

Yates, B., \& White, S. (2004). The incidence and risk factors in the development of medial tibial stress syndrome among naval recruits. The American Journal of Sports Medicine, 32(3), 772-780. 


\section{APPENDICES}

\section{$\underline{\text { Appendix } 1}$}

Have you ever had any injuries or defects diagnosed in your legs?

\begin{tabular}{|c|c|}
\hline 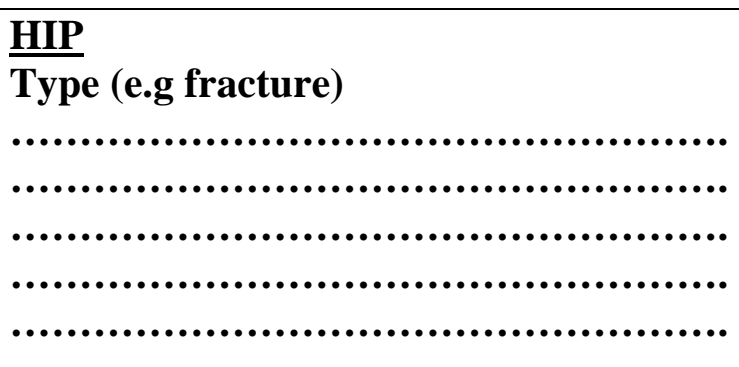 & 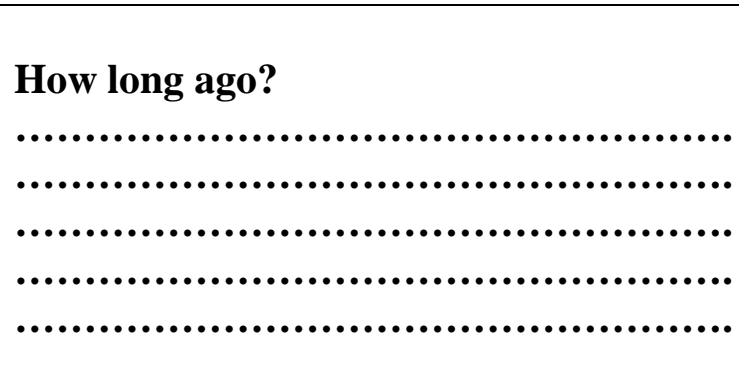 \\
\hline 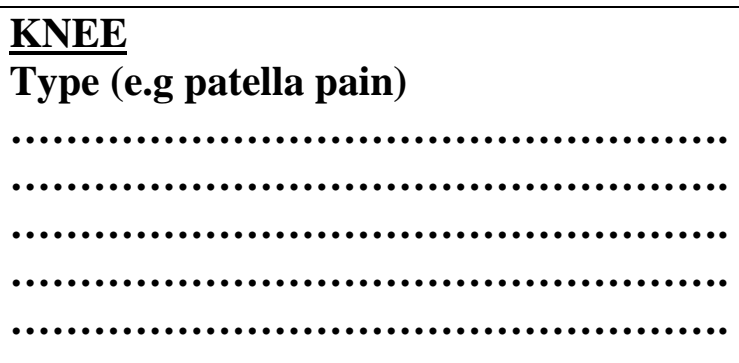 & 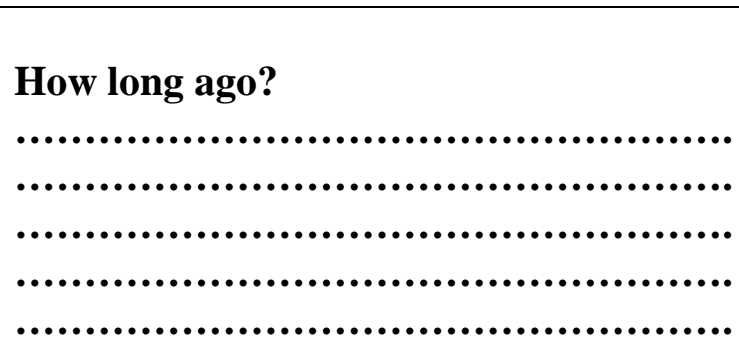 \\
\hline 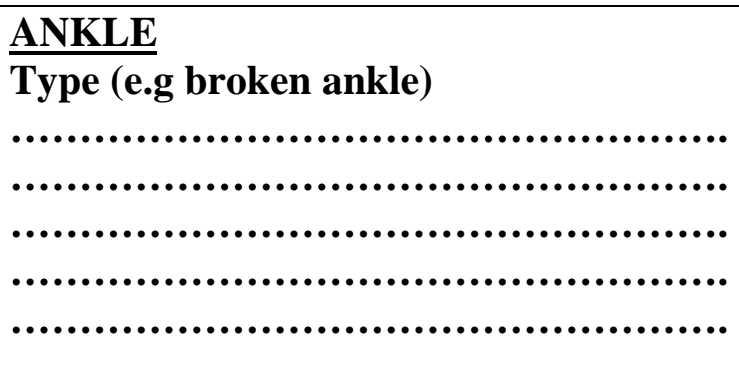 & 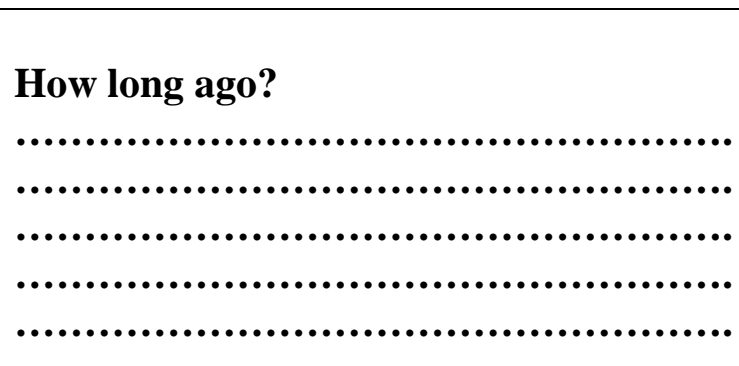 \\
\hline 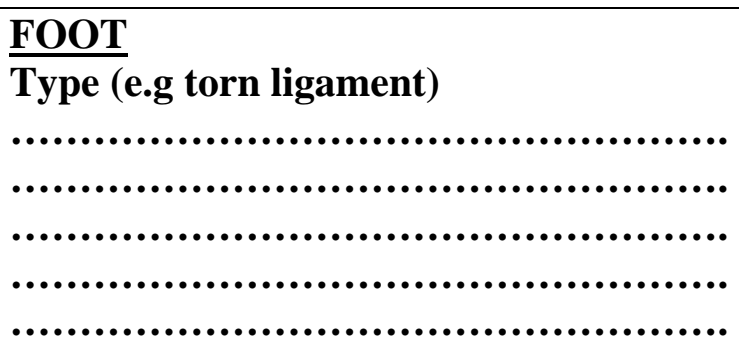 & 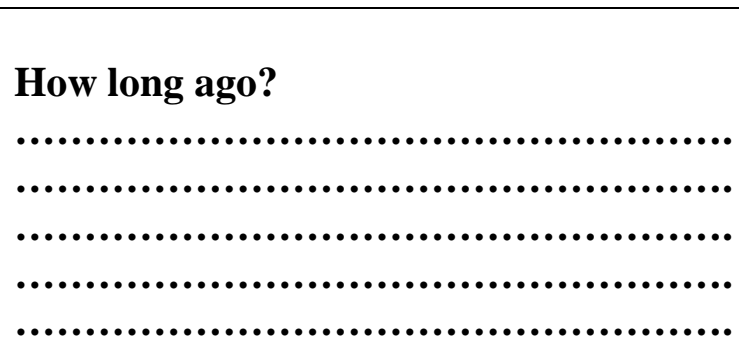 \\
\hline
\end{tabular}

Have you ever had persistent shin pain or been diagnosed with shin splints? 


\section{Appendix 2}

\section{DATA COLLECTION}

Subject Code:

Date of Birth:

Height:

Weight:

BMI:

\begin{tabular}{|c|c|c|c|}
\hline \multicolumn{4}{|c|}{ ROM Testing } \\
\hline Joint & Test & Right Leg & Left Leg \\
\hline \multirow[t]{6}{*}{ Hip } & Flexion & & \\
\hline & Extension & & \\
\hline & Abduction & & \\
\hline & Adduction & & \\
\hline & Int. Rotation & & \\
\hline & Ext. Rotation & & \\
\hline \multirow[t]{2}{*}{ Knee } & Flexion & & \\
\hline & Extension & & \\
\hline \multirow[t]{2}{*}{ Ankle } & Dorsi flexion & & \\
\hline & Plantar flexion & & \\
\hline RCSP & (I=Inverted;E=Everted) & & \\
\hline First MPJ & Dorsi flexion & & \\
\hline
\end{tabular}




\section{$\underline{\text { Appendix } 3 \text { (a) }}$}

AVERAGE WEEKLY LEVEL OF ACTIVITY IN THE LAST SIX (6) MONTHS

Name: ID number:

In the last six(6) months how much time did you spend each week: (circle appropriate answer for average number of hours per week for the last six months)

a) walking for recreation/exercise or to get to and from places?
None
1 hour
2 hours
3 hours
5 hours
7 hours or more

b) vigorous physical activity, which made you breathe harder or puff and pant? (excluding household chores, occupational activity or gardening). Eg. Tennis, footy, netball, keep fit exercises.
None
1 hour
2 hours
3 hours
5 hours
7 hours or more

c) doing any other more moderate physical activity that you haven't already mentioned? Eg. Golf, recreational swimming.
None
1 hour
2 hours
3 hours
5 hours
7 hours or more 


\section{Appendix 3 (b)}

\section{PARTICIPATION IN ACTIVITIES DURING THE PAST WEEK}

Name:

ID number:

\section{In the last week how many times have you: (circle appropriate answer)}

a) walked continuously, for at least 10 mins, for recreation exercise or to get to and from places?(W)

$\begin{array}{lllllllll}\text { None } & \text { Once } & 2 & 3 & 4 & 5 & 6 & 7 & 7+\end{array}$

b) done vigorous household chores (including gardening) which made you breathe harder or puff and pant? (h)

$\begin{array}{lllllllll}\text { None } & \text { Once } & 2 & 3 & 4 & 5 & 6 & 7 & 7+\end{array}$

c) done any vigorous physical activity which made you breathe harder or puff and pant? (excluding home chores or occupational activities). EG tennis, footy, keep fit exercises.

(v)

$\begin{array}{lllllllll}\text { None } & \text { Once } & 2 & 3 & 4 & 5 & 6 & 7 & 7+\end{array}$

d) done any moderate physical activity you have not already mentioned? (excluding home chores or occupational activities). Eg. Golf, recreational swimming. (m)

$\begin{array}{lllllllll}\text { None } & \text { Once } & 2 & 3 & 4 & 5 & 6 & 7 & 7+\end{array}$

In the last week how long would you estimate that you spent:

(Please place the letter which represents each of following, in the corresponding table below).

Walking continuously (w)

doing vigorous home chores $(\mathrm{h})$

doing vigorous physical activity (v)

doing moderate physical activity $(\mathrm{m})$

(remember the totals for each of the above for each day and to start working backwards for seven days from yesterday)

\begin{tabular}{|l|l|l|l|l|l|l|l|}
\hline & Mon & Tue & Wed & Thurs & Fri & Sat & Sun \\
\hline None & & & & & & & \\
\hline $1-10 \mathrm{~min}$ & & & & & & & \\
\hline $11-20 \mathrm{~min}$ & & & & & & & \\
\hline $21-30 \mathrm{~min}$ & & & & & & & \\
\hline $31-40 \mathrm{~min}$ & & & & & & & \\
\hline $41-50 \mathrm{~min}$ & & & & & & & \\
\hline $51-60 \mathrm{~min}$ & & & & & & & \\
\hline $60+\min$ & & & & & & & \\
\hline
\end{tabular}


Appendix 4

OVER THE PAST THIRTEEN (13) WEEKS HAVE YOU EXPERIENCED ANY LOWER LEG SHIN AND/OR CALF PAIN?

Yes

No

(please circle) 


\section{Appendix 5}

Means and standard deviations (sd) for the injured $(\mathrm{N}=14)$ and non-injured $(\mathrm{N}=14)$ groups for all lower limb range of motion measures at baseline (bl) and retest (rt).

\begin{tabular}{|c|c|c|c|c|c|c|c|c|}
\hline \multirow[t]{3}{*}{ Variable } & \multicolumn{4}{|c|}{ Injured } & \multicolumn{4}{|c|}{ Non-Injured } \\
\hline & \multicolumn{2}{|c|}{ bl } & \multicolumn{2}{|c|}{$\mathrm{rt}$} & \multicolumn{2}{|c|}{ bl } & \multicolumn{2}{|c|}{$\mathrm{rt}$} \\
\hline & Mean & $\mathrm{sd}$ & Mean & sd & Mean & sd & Mean & $\mathrm{sd}$ \\
\hline R/Hip Flex & 139.07 & 7.49 & 136.71 & 7.61 & 132.93 & 10.92 & 128.35 & 9.08 \\
\hline R/Hip Ext & 46.64 & 8.90 & 43.04 & 6.03 & 44.93 & 9.83 & 42.21 & 5.00 \\
\hline R/Hip Abd & 30.71 & 6.78 & 31.29 & 4.20 & 25.86 & 5.76 & 27.21 & 4.87 \\
\hline R/Hip Add & 15.71 & 3.95 & 15.36 & 3.25 & 14.07 & 3.52 & 13.07 & 5.06 \\
\hline R/Hip Int Rot & 58.50 & 7.82 & 52.79 & 9.01 & 49.71 & 11.73 & 47.21 & 9.50 \\
\hline R/Hip Ext Rot & 58.86 & 5.65 & 52,57 & 5.40 & 48.71 & 12.77 & 49.21 & 6.83 \\
\hline R/Knee Ext & 3.43 & 3.76 & 2.14 & 1.96 & 0.07 & 2.79 & 0.93 & 1.73 \\
\hline R/Knee Flex & 154.57 & 3.94 & 152.14 & 3.23 & $152 . .71$ & 6.47 & 151.86 & 6.48 \\
\hline R/Ankle DF & 10.64 & 3.88 & 17.29 & 15.99 & 11.57 & 5.76 & 12.14 & 6.06 \\
\hline R/Ankle PF & 65.42 & 8.14 & 61.93 & 6.75 & 59.14 & 7.4 & 56.21 & 13.81 \\
\hline R/RCSP & -2.71 & 3.67 & -2.64 & 1.98 & -1.21 & 3.42 & -1.57 & 3.16 \\
\hline R/First MPJ DF & 60.71 & 6.38 & 69.57 & 9.14 & 62.93 & 10.48 & 65.79 & 10.81 \\
\hline L/Hip Flex & 139.64 & 10.65 & 135.39 & 13.06 & 133.21 & 10.97 & 133.14 & 9.92 \\
\hline L/Hip Ext & 45.71 & 8.31 & 45.79 & 7.52 & 43.54 & 10.57 & 42.36 & 5.11 \\
\hline L/Hip Abd & 30.00 & 7.82 & 29.29 & 6.13 & 28.36 & 5.26 & 29.93 & 5.90 \\
\hline L/Hip Add & 15.79 & 3.62 & 13.71 & 4.56 & 14.86 & 3.8 & 13.86 & 3.78 \\
\hline L/Hip Int Rot & 60.36 & 6.59 & 50.64 & 5.12 & 51.00 & 12.75 & 47.14 & 9.17 \\
\hline L/Hip Ext Rot & 54.86 & 8.06 & 52.29 & 6.74 & 46.57 & 12.77 & 48.36 & 4.81 \\
\hline L/Knee Ext & 2.86 & 3.39 & 2.29 & 2.76 & 1.14 & 3.74 & 1.36 & 1.91 \\
\hline L/Knee Flex & 150.29 & 11.48 & 145.93 & 24.31 & 148.86 & 7.32 & 149.07 & 9.21 \\
\hline L/Ankle DF & 15.64 & 4.21 & 15.00 & 5.67 & 13.43 & 5.54 & 16.93 & 12.95 \\
\hline L/Ankle PF & 65 & 8,26 & 57.00 & 16.50 & 58.21 & 8.31 & 56.79 & 6.67 \\
\hline L/RCSP & -2.57 & 3.44 & -3.29 & 1.68 & -1.5 & 3.96 & -1.79 & 3.29 \\
\hline L/First MPJ DF & 60.86 & 10.74 & 69.00 & 8.16 & 60.79 & 12.78 & 59.71 & 19.91 \\
\hline
\end{tabular}

(Note: $\mathrm{R}=$ Right, $\mathrm{L}=$ Left, Flex $=$ Flexion, Ext $=$ Extension, Add = Adduction, $\mathrm{Abd}=$ Abduction, Int Rot $=$ Internal Rotation, Ext Rot $=$ External Rotation, DF $=$ Dorsi flexion, $\mathrm{PF}=$ Plantar flexion, RCSP $=$ Resting Clacaneal Stance Position, MPJ = Metatarsophalangeal Joint) 


\section{Appendix 6 (a)}

Means and standard deviations for the right $(\mathrm{N}=2)$, right $(\mathrm{N}=3)$ and bilateral $(\mathrm{N}=9)$ injured groups for all right lower limb range of motion measures at baseline (bl) and retest (rt).

\begin{tabular}{|c|c|c|c|c|c|c|}
\hline \multirow[t]{2}{*}{ Variables } & \multicolumn{2}{|c|}{ Right } & \multicolumn{2}{|c|}{ Left } & \multicolumn{2}{|c|}{ Bilateral } \\
\hline & $\mathrm{bl}$ & $\mathrm{rt}$ & bl & $\mathrm{rt}$ & bl & $\mathrm{rt}$ \\
\hline R/Hip Flex & 142.00 & 140.00 & 138.00 & 135.83 & 138.78 & 136.28 \\
\hline sd & 14.14 & 14.14 & 9.54 & 1.76 & 6.38 & 8.07 \\
\hline R/Hip Ext & 50.00 & 37.50 & 45.00 & 44.00 & 46.44 & 43.94 \\
\hline sd & 2.83 & 3.54 & 9.00 & 4.36 & 10.17 & 6.62 \\
\hline R/Hip Abd & 31.00 & 29.50 & 28.67 & 28.33 & 31.33 & 32.67 \\
\hline $\mathrm{sd}$ & 1.41 & 0.71 & 7.09 & 3.06 & 7.73 & 4.47 \\
\hline R/Hip Add & 16.50 & 14.50 & 18.33 & 17.67 & 14.67 & 14.78 \\
\hline sd & 0.71 & 0.71 & 5.51 & 2.52 & 3.71 & 3.60 \\
\hline R/Hip Int Rot & 56.00 & 50.00 & 61.00 & 52.33 & 58.22 & 53.56 \\
\hline $\mathrm{sd}$ & 12.73 & 1.41 & 7.81 & 13.87 & 7.74 & 9.00 \\
\hline R/Hip Ext Rot & 58.50 & 51.50 & 63.67 & 55.00 & 57.33 & 52.00 \\
\hline $\mathrm{sd}$ & 6.36 & 4.95 & 4.04 & 7.81 & 5.61 & 5.05 \\
\hline R/Knee Ext & 4.00 & 2.50 & 3.33 & 2.67 & 3.33 & 1.89 \\
\hline $\mathrm{sd}$ & 1.41 & 0.71 & 3.51 & 2.52 & 4.42 & 2.09 \\
\hline R/Knee Flex & 154.50 & 152.00 & 155.33 & 152.33 & 154.33 & 152.11 \\
\hline $\mathrm{sd}$ & 4.95 & 2.83 & 3.78 & 2.08 & 4.27 & 3.86 \\
\hline R/Ankle DF & 7.00 & 6.00 & 10.00 & 13.00 & 11.67 & 21.22 \\
\hline $\mathrm{sd}$ & 0.00 & 2.83 & 1.73 & 2.65 & 4.36 & 18.88 \\
\hline R/Ankle PF & 71.00 & 69.00 & 65.67 & 66.33 & 64.11 & 58.89 \\
\hline $\mathrm{sd}$ & 4.24 & 1.41 & 8.62 & 7.23 & 8.78 & 5.53 \\
\hline $\mathrm{R} / \mathrm{RCSP}$ & -0.50 & -1.50 & -3.67 & -1.67 & -2.89 & -3.22 \\
\hline sd & 7.78 & 0.71 & 1.53 & 2.08 & 3.48 & 2.05 \\
\hline R/First MPJ DF & 62.50 & 70.00 & 62.33 & 71.67 & 59.78 & 68.78 \\
\hline $\mathrm{sd}$ & 3.54 & 14.14 & 5.51 & 10.41 & 7.36 & 9.01 \\
\hline
\end{tabular}

(Note: $\mathrm{R}=$ Right, Flex $=$ Flexion, Ext $=$ Extension, $\mathrm{Add}=$ Adduction, $\mathrm{Abd}=$ Abduction, Int Rot $=$ Internal Rotation, Ext Rot $=$ External Rotation, $\mathrm{DF}=$ Dorsi flexion, $\mathrm{PF}=$ Plantar flexion, RCSP $=$ Resting Clacaneal Stance Position, MPJ = Metatarsophalangeal Joint) 


\section{Appendix 6 (b)}

Mean and standard deviations ( $(\mathrm{sd})$ for the right $(\mathrm{N}=2)$, left $(\mathrm{N}=3)$ and bilateral $(\mathrm{N}=9)$ injured groups for all left lower limb range of motion measures at baseline (bl) and retest $(\mathrm{rt})$.

\begin{tabular}{|c|c|c|c|c|c|c|}
\hline \multirow[t]{2}{*}{ Variables } & \multicolumn{2}{|c|}{ Right } & \multicolumn{2}{|c|}{ Left } & \multicolumn{2}{|c|}{ Bilateral } \\
\hline & bl & $\mathrm{rt}$ & bl & bl & $\mathrm{rt}$ & bl \\
\hline L/Hip Flex & 150.50 & 131.50 & 129.33 & 138.00 & 140.67 & 135.39 \\
\hline sd & 7.78 & 27.58 & 14.98 & 11.79 & 7.09 & 11.87 \\
\hline L/Hip Ext & 47.50 & 39.00 & 43.67 & 49.33 & 46.00 & 46.11 \\
\hline sd & 14.85 & 5.66 & 13.50 & 9.02 & 6.04 & 7.15 \\
\hline L/Hip Abd & 33.00 & 30.50 & 29.00 & 27.67 & 29.67 & 29.56 \\
\hline sd & 5.66 & 2.12 & 5.29 & 8.02 & 9.24 & 6.56 \\
\hline L/Hip Add & 16.50 & 14.50 & 15.33 & 9.00 & 15.78 & 15.11 \\
\hline sd & 3.54 & 2.12 & 4.16 & 1.00 & 3.90 & 4.73 \\
\hline L/Hip Int Rot & 60.50 & 50.50 & 60.00 & 49.33 & 60.44 & 51.11 \\
\hline sd & 3.54 & 2.12 & 5.00 & 5.51 & 7.92 & 5.80 \\
\hline L/Hip Ext Rot & 57.00 & 48.50 & 63.67 & 55.33 & 51.44 & 52.11 \\
\hline $\mathrm{sd}$ & 5.66 & 7.78 & 2.89 & 9.29 & 7.49 & 6.13 \\
\hline L/Knee Ext & 4.50 & 3.50 & 1.67 & 2.67 & 2.89 & 1.89 \\
\hline sd & 4.95 & 2.12 & 1.53 & 3.79 & 3.72 & 2.57 \\
\hline L/Knee Flex & 153.00 & 154.50 & 154.00 & 152.00 & 148.44 & 142.00 \\
\hline $\mathrm{sd}$ & 4.24 & 3.54 & 4.36 & 3.00 & 14.01 & 30.13 \\
\hline L/Ankle DF & 12.50 & 16.50 & 15.00 & 14.67 & 16.56 & 14.78 \\
\hline $\mathrm{sd}$ & 6.36 & 12.02 & 1.00 & 5.03 & 4.48 & 5.21 \\
\hline L/Ankle PF & 70.00 & 67.00 & 70.00 & 68.67 & 62.22 & 50.89 \\
\hline $\mathrm{sd}$ & 2.83 & 1.41 & 9.17 & 6.11 & 8.04 & 17.74 \\
\hline $\mathrm{L} / \mathrm{RCSP}$ & 1.00 & -2.50 & -4.67 & -3.33 & -2.67 & -3.44 \\
\hline $\mathrm{sd}$ & 5.66 & 0.71 & 1.15 & 1.53 & 3.16 & 1.94 \\
\hline L/First MPJ DF & 64.50 & 75.50 & 58.33 & 70.33 & 60.89 & 67.11 \\
\hline $\mathrm{sd}$ & 0.71 & 13.44 & 12.58 & 8.96 & 11.91 & 7.10 \\
\hline
\end{tabular}

(Note: $\mathrm{L}=$ Left, Flex $=$ Flexion, Ext $=$ Extension, $\mathrm{Add}=$ Adduction, $\mathrm{Abd}=$ Abduction, Int Rot $=$ Internal Rotation, Ext Rot $=$ External Rotation, $D F=$ Dorsi flexion, $P F=$ Plantar flexion, RCSP $=$ Resting Clacaneal Stance Position, MPJ = Metatarsophalangeal Joint) 


\section{$\underline{\text { Appendix } 7}$}

Means and standard deviations ( $(\mathrm{sd})$ for the male $(\mathrm{N}=6)$ and female $(\mathrm{N}=22)$ groups for all lower limb range of motion measures at baseline (bl) and retest (rt).

\begin{tabular}{|c|c|c|c|c|c|c|c|c|}
\hline \multirow[t]{3}{*}{ Variable } & \multicolumn{4}{|c|}{ Males } & \multicolumn{4}{|c|}{ Females } \\
\hline & \multicolumn{2}{|c|}{ bl } & \multicolumn{2}{|c|}{$\mathrm{rt}$} & \multicolumn{2}{|c|}{$\mathrm{bl}$} & \multicolumn{2}{|c|}{$\mathrm{rt}$} \\
\hline & Mean & sd & Mean & sd & Mean & $\mathrm{sd}$ & Mean & sd \\
\hline R/Hip Flex & 132.33 & 13.98 & 130.17 & 11.81 & 137.00 & 8.34 & 133.18 & 8.66 \\
\hline R/Hip Ext & 43.17 & 13.20 & 44.33 & 3.14 & 46.50 & 8.12 & 42.16 & 5.89 \\
\hline R/Hip Abd & 24.00 & 5.90 & 26.83 & 5.04 & 29.45 & 6.47 & 29.91 & 4.80 \\
\hline R/Hip Add & 12.83 & 2.93 & 14.00 & 6.54 & 15.45 & 3.83 & 14.27 & 3.73 \\
\hline R/Hip Int Rot & 42.00 & 6.13 & 42.33 & 5.47 & 15.41 & 9.30 & 52.09 & 9.39 \\
\hline R/Hip Ext Rot & 44.50 & 14.04 & 47.50 & 9.38 & 56.32 & 8.76 & 51.82 & 5.03 \\
\hline R/Knee Ext & -1.50 & 1.87 & 1.00 & 1.26 & 2.64 & 3.55 & 1.68 & 2.06 \\
\hline R/Knee Flex & 154.67 & 9.42 & 154.33 & 9.05 & 153.36 & 3.90 & 151.36 & 3.32 \\
\hline R/Ankle DF & 14.00 & 7.24 & 14.00 & 8.60 & 10.32 & 3.82 & 14.91 & 13.11 \\
\hline R/Ankle PF & 54.00 & 3.85 & 47.33 & 15.79 & 64.55 & 7.72 & 62.27 & 6.91 \\
\hline R/RCSP & -1.50 & 3.51 & -1.50 & 3.27 & -2.09 & 3.65 & -2.27 & 2.51 \\
\hline R/First MPJ DF & 63.33 & 12.09 & 63.67 & 10.54 & 61.41 & 7.69 & 68.77 & 9.82 \\
\hline L/Hip Flex & 133.83 & 14.46 & 133.00 & 8.99 & 137.14 & 10.31 & 134.61 & 12.18 \\
\hline L/Hip Ext & 47.67 & 13.94 & 41.67 & 5.61 & 43.80 & 7.99 & 44.73 & 6.74 \\
\hline L/Hip Abd & 27.50 & 5.89 & 31.67 & 6.38 & 29.64 & 6.82 & 29.05 & 5.81 \\
\hline L/Hip Add & 14.83 & 2.04 & 14.50 & 5.09 & 15.45 & 4.03 & 13.59 & 3.92 \\
\hline L/Hip Int Rot & 43.50 & 11.40 & 43.17 & 4.54 & 59.00 & 8.48 & 50.45 & 7.46 \\
\hline L/Hip Ext Rot & 38.50 & 10.25 & 51.50 & 6.95 & 54.05 & 9.21 & 50.00 & 5.97 \\
\hline L/Knee Ext & -0.50 & 1.87 & 1.50 & 1.38 & 2.68 & 3.70 & 1.91 & 2.60 \\
\hline L/Knee Flex & 149.00 & 9.53 & 153.00 & 8.49 & 149.73 & 9.68 & 146.00 & 19.84 \\
\hline L/Ankle DF & 17.33 & 6.12 & 25.00 & 16.82 & 13.77 & 4.46 & 13.50 & 5.28 \\
\hline L/Ankle PF & 51.83 & 4.17 & 53.33 & 2.16 & 64.27 & 7.84 & 57.86 & 13.80 \\
\hline L/RCSP & -1.17 & 3.06 & -2.00 & 2.10 & -2.27 & 3.79 & -2.68 & 2.83 \\
\hline L/First MPJ DF & 61.33 & 13.44 & 63.17 & 15.39 & 60.68 & 11.40 & 64.68 & 16.08 \\
\hline
\end{tabular}

(Note: $\mathrm{R}=$ Right, $\mathrm{L}=$ Left, Flex $=$ Flexion, $\mathrm{Ext}=$ Extension, $\mathrm{Add}=$ Adduction, $\mathrm{Abd}=$ Abduction, Int Rot $=$ Internal Rotation, Ext Rot $=$ External Rotation, $\mathrm{DF}=$ Dorsi flexion, $\mathrm{PF}=$ Plantar flexion, $\mathrm{RCSP}=$ Resting Clacaneal Stance Position, $\mathrm{MPJ}=$ Metatarsophalangeal Joint) 


\section{Appendix 8}

Means and standard deviations (sd) for the injured $(\mathrm{N}=13)$ and non-injured $(\mathrm{N}=9)$ female groups for left hip external rotation, left and right hip internal rotation and right ankle plantar flexion at baseline (bl) and retest (rt).

Variable

Injured

Non-Injured

\begin{tabular}{lcccccccc} 
& \multicolumn{2}{c}{ bl } & \multicolumn{2}{c}{ rt } & \multicolumn{2}{c}{ bl } & \multicolumn{2}{c}{ rt } \\
& Mean & sd & Mean & sd & Mean & sd & Mean & sd \\
& & & & & & & & \\
\hline L/Hip Ext Rot & 56.08 & 6.91 & 51.34 & 6.08 & 51.11 & 11.60 & 48.00 & 5.52 \\
L/ Hip Int Rot & 60.77 & 6.67 & 50.85 & 5.27 & 56.44 & 10.47 & 49.89 & 10.18 \\
R/Hip Int Rot & 59.54 & 7.07 & 53.23 & 9.22 & 54.33 & 11.59 & 50.44 & 9.93 \\
R/ankle PF & 66.31 & 7.75 & 62.69 & 6.37 & 62.00 & 7.35 & 61.67 & 7.98
\end{tabular}

(Note: $\mathrm{R}=$ Right; L= Left; Ext Rot = External Rotation; Int Rot = Internal Rotation; $\mathrm{PF}=$ Plantar flexion) 